\title{
Molecular Biology of Cancer
}

\author{
Jesse D. Martinez \\ Michele Taylor Parker \\ Kimberly E. Fultz \\ Natalia A. Ignatenko \\ Eugene W. Gerner \\ Departments of Radiation Oncology/Cancer Biology Section \\ Molecular and Cellular Biology \\ Biochemistry and Molecular Biophysics \\ Cancer Biology Graduate Program \\ The University of Arizona \\ Tuscon, Arizona
}

Burger's Medicinal Chemistry and Drug Discovery Sixth Edition, Volume 5: Chemotherapeutic Agents Edited by Donald J. Abraham ISBN 0-471-37031-2 ㄷ) 2003 John Wiley \& Sons, Inc.

\section{Contents}

1 Introduction, 2

2 Tumorigenesis, 2

2.1 Normal-Precancer-Cancer Sequence, 2

2.2 Carcinogenesis, 3

2.3 Genetic Variability and Other Modifiers of Tumorigenesis, 5

2.3.1 Genetic Variability Affecting Cancer, 5

2.3.2 Genetic Variability in

c-myc-Dependent Expression of

Ornithine Decarboxylase, 7

2.4 Epigenetic Changes, 7

3 Molecular Basis of Cancer Phenotypes, 10

3.1 Immortality, 10

3.2 Decreased Dependence on Growth Factors to Support Proliferation, 11

3.3 Loss of Anchorage-Dependent Growth and Altered Cell Adhesion, 12

3.4 Cell Cycle and Loss of Cell Cycle Control, 14

3.5 Apoptosis and Reduced Sensitivity to Apoptosis, 16

3.6 Increased Genetic Instability, 19

3.7 Angiogenesis, 20

4 Cancer-Related Genes, 21

4.1 Oncogenes, 21

4.1.1 Growth Factors and Growth Factor Receptors, 21

4.1.2 G Proteins, 23

4.1.3 Serine/Threonine Kinases, 24

4.1.4 Nonreceptor Tyrosine Kinases, 24

4.1.5 Transcription Factors as Oncogenes, 25

4.1.6 Cytoplasmic Proteins, 26 
4.2 Tumor Suppressor Genes, 26

4.2.1 Retinoblastoma, 27

$4.2 .2 \mathrm{p} 53,27$

4.2.3 Adenomatous Polyposis Coli, 29

4.2.4 Phosphatase and Tensin Homologue, 30

4.2.5 Transforming Growth Factor- $\beta, 30$

4.2.6 Heritable Cancer Syndromes, 32

5 Interventions, 32

5.1 Prevention Strategies, 32

5.2 Targets, 33

5.2.1 Biochemical Targets, 33

5.2.2 Cyclooxygenase-2 and Cancer, 33

5.2.3 Other Targets, 35

5.3 Therapy, 35

5.3.1 Importance of Studying Gene Expression, 35

5.3.2 cDNA Microarray Technology, 35

5.3.3 Discoveries from cDNA Microarray Data, 37

\section{INTRODUCTION}

Cancer is a major human health problem worldwide and is the second leading cause of death in the United States (1). Over the past 30 years, significant progress has been achieved in understanding the molecular basis of cancer. The accumulation of this basic knowledge has established that cancer is a variety of distinct diseases and that defective genes cause these diseases. Further, gene defects are diverse in nature and can involve either loss or gain of gene functions. A number of inherited syndromes associated with increased risk of cancer have been identified.

This chapter will review our current understanding of the mechanisms of cancer development, or carcinogenesis, and the genetic basis of cancer. The roles of gene defects in both germline and somatic cells will be discussed as they relate to genetic and sporadic forms of cancer. Specific examples of oncogenes, or cancer-causing genes, and tumor suppressor genes will be presented, along with descriptions of the relevant pathways that signal normal and cancer phenotypes.

While cancer is clearly associated with an increase in cell number, alterations in mechanisms regulating new cell birth, or cell proliferation, are only one facet of the mechanisms of cancer. Decreased rates of cell death, or ap-
5.3.4 Limitations of Microarray

Technologies, 37

5.4 Modifying Cell Adhesion, 37

5.4.1 MMP Inhibitors, 37

5.4.2 Anticoagulants, 38

5.4.3 Inhibitors of Angiogenesis, 38

5.5 Prospects for Gene Therapy of Cancer, 39

5.5.1 Gene Delivery Systems, 39

5.5.1.1 Viral Vectors, 40

5.5.1.2 Non-Viral Gene Delivery

Systems, 42

5.6 Gene Therapy Approaches, 43

5.6.1 Immunomodulation, 43

5.6.2 Suicidal Gene Approach, 44

5.6.3 Targeting Loss of Tumor Suppressor

Function and Oncogene

Overexpression, 44

5.6.4 Angiogenesis Control, 45

5.6.5 Matrix Metalloproteinase, 45

6 Acknowledgments, 46

optosis, are now known to contribute to certain types of cancer. Cancer is distinctive from other tumor-forming processes because of its ability to invade surrounding tissues. This chapter will address mechanisms regulating the important cancer phenotypes of altered cell proliferation, apoptosis, and invasiveness.

Recently, it has become possible to exploit this basic information to develop mechanismbased strategies for cancer prevention and treatment. The success of both public and private efforts to sequence genomes, including human and other organisms, has contributed to this effort. Several examples of mechanismbased anti-cancer strategies will be discussed. Finally, potential strategies for gene therapy of cancer will also be addressed.

\section{TUMORIGENESIS}

\subsection{Normal-Precancer-Cancer Sequence}

Insight into tumor development first came from epidemiological studies that examined the relationship between age and cancer incidence that showed that cancer incidence increases with roughly the fifth power of elapsed age (2). Hence, it was predicted that at least five rate-limiting steps must be overcome before a clinically observable tumor could arise. It is now known that these rate-limiting steps 
are genetic mutations that dysregulate the activities of genes that control cell growth, regulate sensitivity to programmed cell death, and maintain genetic stability. Hence, tumorigenesis is a multistep process.

Although the processes that occur during tumorigenesis are only incompletely understood, it is clear that the successive accumulation of mutations in key genes is the force that drives tumorigenesis. Each successive mutation is thought to provide the developing tumor cell with important growth advantages that allow cell clones to outgrow their more normal neighboring cells. Hence, tumor development can be thought of as Darwinian evolution on a microscopic scale with each successive generation of tumor cell more adapted to overcoming the social rules that regulate the growth of normal cells. This is called clonal evolution (3).

Given that tumorigenesis is the result of mutations in a select set of genes, much effort by cancer biologists has been focused on identifying these genes and understanding how they function to alter cell growth. Early efforts in this area were lead by virologists studying retrovirus-induced tumors in animal models. These studies led to cloning of the first oncogenes and the realization that oncogenes, indeed all cancer-related genes, are aberrant forms of genes that have important functions in regulating normal cell growth (4). In subsequent studies, these newly identified oncogenes were introduced into normal cells in an effort to reproduce tumorigenesis in vitro. Importantly, it was found that no single oncogene could confer all of the physiological traits of a transformed cell to a normal cell. Rather this required that at least two oncogenes acting cooperatively to give rise to cells with the fully transformed phenotype (5). This observation provides important insights into tumorigenesis. First, the multistep nature of tumorigenesis can be rationalized as mutations in different genes with each event providing a selective growth advantage. Second, oncogene cooperativity is likely to be cause by the requirement for dysregulation of cell growth at multiple levels.

Fearon and Vogelstein (6) have proposed a linear progression model (Fig. 1.1) to describe tumorigenesis using colon carcinogenesis in humans as the paradigm. They suggest that malignant colorectal tumors (carcinomas) evolve from preexisting benign tumors (adenomas) in a stepwise fashion with benign, less aggressive lesions giving rise to more lethal neoplasms. In their model, both genetic [e.g., adenomatous polyposis coli (APC) mutations] and epigenetic changes (e.g., DNA methylation affecting gene expression) accumulate over time, and it is the progressive accumulation of these changes that occur in a preferred, but not invariable, order that are associated with the evolution of colonic neoplasms. Other important features of this model are that at least four to five mutations are required for the formation of a malignant tumor, in agreement with the epidemiological data, with fewer changes giving rise to intermediate benign lesions, that tumors arise through the mutational activation of oncogenes and inactivation of tumor suppressor genes, and that it is the sum total of the effect of these mutations on tumor cell physiology that is important rather than the order in which they occur.

An important implication of the multistep model of tumorigenesis is that lethal neoplasms are preceded by less aggressive intermediate steps with predictable genetic alterations. This suggests that if the genetic defects which occur early in the process can be identified, a strategy that interferes with their function might prevent development of more advanced tumors. Moreover, preventive screening methods that can detect cells with the early genetic mutations may help to identify these lesions in their earliest and most curable stages. Consequently, identification of the genes that are mutated in cancers and elucidation of their mechanism of action is important not only to explain the characteristic phenotypes exhibited by tumor cells, but also to provide targets for development of therapeutic agents.

\subsection{Carcinogenesis}

Carcinogenesis is the process that leads to genetic mutations induced by physical or chemical agents. Conceptually, this process can be divided into three distinct stages: initiation, promotion, and progression (7). Initiation involves an irreversible genetic change, usually a mutation in a single gene. Promotion is gen- 


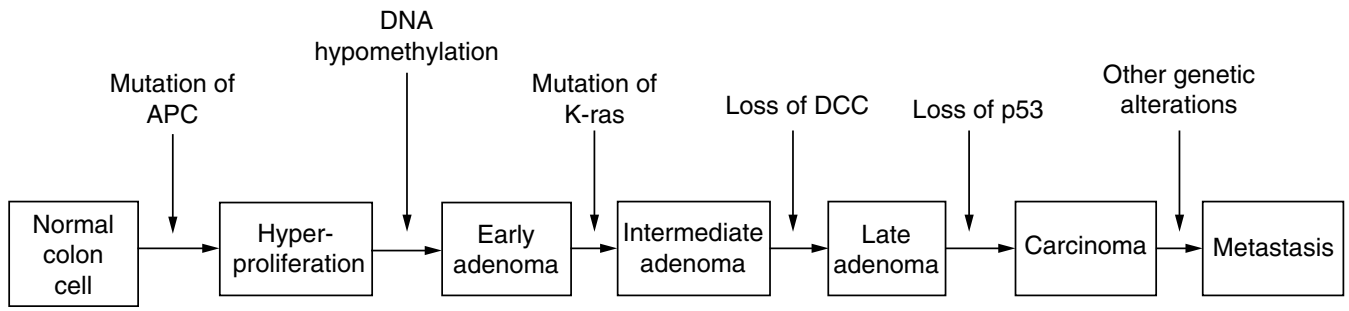

Figure 1.1. Adenoma-carcinoma sequence. Fearon and Vogelstein (6) proposed this classic model for the multistage progression of colorectal cancer. A mutation in the APC tumor suppressor gene is generally considered to be the initiation event. This is followed by the sequential accumulation of other epigenetic and genetic changes that eventually result in the progression from a normal cell to a metastatic tumor.

erally associated with increased proliferation of initiated cells, which increases the population of initiated cells. Progression is the accumulation of more genetic mutations that lead to the acquisition of the malignant or invasive phenotype.

In the best-characterized model of chemical carcinogenesis, the mouse skin model, initiation is an irreversible event that occurs when a genotoxic chemical, or its reactive metabolite, causes a DNA mutation in a critical growth controlling gene such as Ha-ras (8). Outwardly, initiated cells seem normal. However, they remain susceptible to promotion and further neoplastic development indefinitely. DNA mutations that occur in initiated cells can confer growth advantages, which allow them to evolve and/or grow faster bypassing normal cellular growth controls. The different types of mutations that can occur include point mutations, deletions, insertions, chromosomal translocations, and amplifications. Three important steps involved in initiation are carcinogen metabolism, DNA repair, and cell proliferation. Many chemical agents must be metabolically activated before they become carcinogenic. Most carcinogens, or their active metabolites, are strong electrophiles and bind to DNA to form adducts that must be removed by DNA repair mechanisms (9). Hence, DNA repair is essential to reverse adduct formation and to prevent DNA damage. Failure to repair chemical adducts, followed by cell proliferation, results in permanent alterations or mutation(s) in the genome that can lead to oncogene activation or inactivation of tumor suppressor genes.
Promotion is a reversible process in which chemical agents stimulate proliferation of initiated cells. Typically, promoting agents are nongenotoxic, that is they are unable to form DNA adducts or cause DNA damage but are able to stimulate cell proliferation. Hence, exposure to tumor promoting agents results in rapid growth of the initiated cells and the eventual formation of non-invasive tumors. In the mouse skin tumorigenesis model, application of a single dose of an initiating agent does not usually result in tumor formation. However, when the initiation step is followed by repeated applications of a tumor promoting agent, such as 12-O-tetradecanoyl-phorbol13-acetate (TPA), numerous skin tumors arise and eventually result in invasive carcinomas. Consequently, tumor promoters are thought to function by fostering clonal selection of cells with a more malignant phenotype. Importantly, tumor formation is dependent on repeated exposure to the tumor promoter. Halting application of the tumor promoter prevents or reduces the frequency with which tumors form. The sequence of exposure is important because tumors do not develop in the absence of an initiating agent even if the tumor promoting agent is applied repeatedly. Therefore, the genetic mutation caused by the initiating agent is essential for further neoplastic development under the influence of the promoting agent.

Progression refers to the process of acquiring additional mutations that lead to malignancy and metastasis. Many initiating agents can also lead to tumor progression, strong support for the notion that further mutations are 


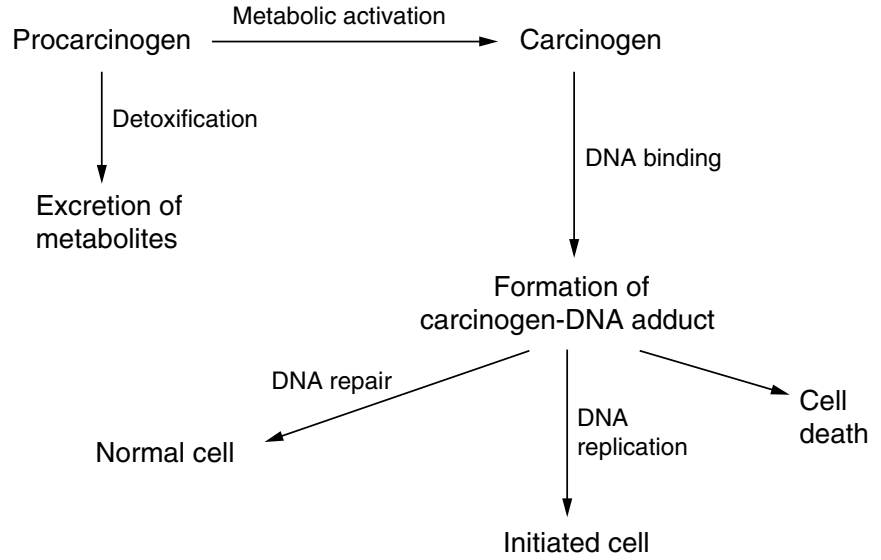

Figure 1.2. Possible outcomes of carcinogen metabolic activation. Once a carcinogen is metabolically activated it can bind to DNA and form carcinogen-DNA adducts. These adducts will ultimately lead to mutations if they are not repaired. If DNA repair does not occur, the cell will either undergo apoptosis or the DNA will be replicated, resulting in an initiated cell. needed for cells to acquire the phenotypic characteristics of malignant tumor cells. Some of these agents include benzo(a)pyrene, $\beta$-napthylamine, 2 -acetylaminofluorene, aflatoxin $\mathrm{B}_{1}$, dimethylnitrosamine, 2-amino-3methylimidazo(4,5-f)quinoline (IQ), benzidine, vinyl chloride, and 4-(methylnitrosamino)-1-(3-pyridyl)-1-butanone (NNK) (10). These chemicals are converted into positively charged metabolites that bind to negatively charged groups on molecules like proteins and nucleic acids. This results in the formation of DNA adducts which, if not repaired, lead to mutations (9) (Fig. 1.2). The result of these mutations enables the tumors to grow, invade surrounding tissue, and metastasize.

Damage to DNA and the genetic mutations that can result from them are a central theme in carcinogenesis. Hence, the environmental factors that cause DNA damage are of great interest. Environmental agents that can cause DNA damage include ionizing radiation, ultraviolet (UV) light, and chemical agents (11). Some of the DNA lesions that can result include single-strand breaks, double-strand breaks, base alterations, cross-links, insertion of incorrect bases, and addition/deletion of DNA sequences. Cells have evolved several different repair mechanisms that can reverse the lesions caused by these agents, which has been extensively reviewed elsewhere (12).

The metabolic processing of environmental carcinogens is also of key importance because this can determine the extent and duration to which an organism is exposed to a carcinogen. Phase I and phase II metabolizing enzymes play important roles in the metabolic activation and detoxification of carcinogenic agents. The phase I enzymes include monooxygenases, dehydrogenases, esterases, reductases, and oxidases. These enzymes introduce functional groups on the substrate. The most important superfamily of the phase I enzymes are the cytochrome P450 monooxygenases, which metabolize polyaromatic hydrocarbons, aromatic amines, heterocyclic amines, and nitrosamines. Phase II metabolizing enzymes are important for the detoxification and excretion of carcinogens. Some examples include epoxide hydrase, glutathione- $S$-transferase, and uridine 5 '-diphosphate (UDP) glucuronide transferase. There are also some direct acting carcinogens that do not require metabolic activation. These include nitrogen mustard, dimethylcarbamyl chloride, and $\beta$-propiolactone.

\subsection{Genetic Variability and Other Modifiers of Tumorigenesis}

2.3.1 Genetic Variability Affecting Cancer. Different types of cancers, as well as their severity, seem to correlate with the type of mutation acquired by a specific gene. Mutation "hot spots" are regions of genes that are frequently mutated compared with other regions within that gene. For example, observations that the majority of colon adenomas are associated with alterations in the adenomatous polyposis coli (APC) have been based on immunohistochemical analysis of $\beta$-catenin localization and formation of less than full 


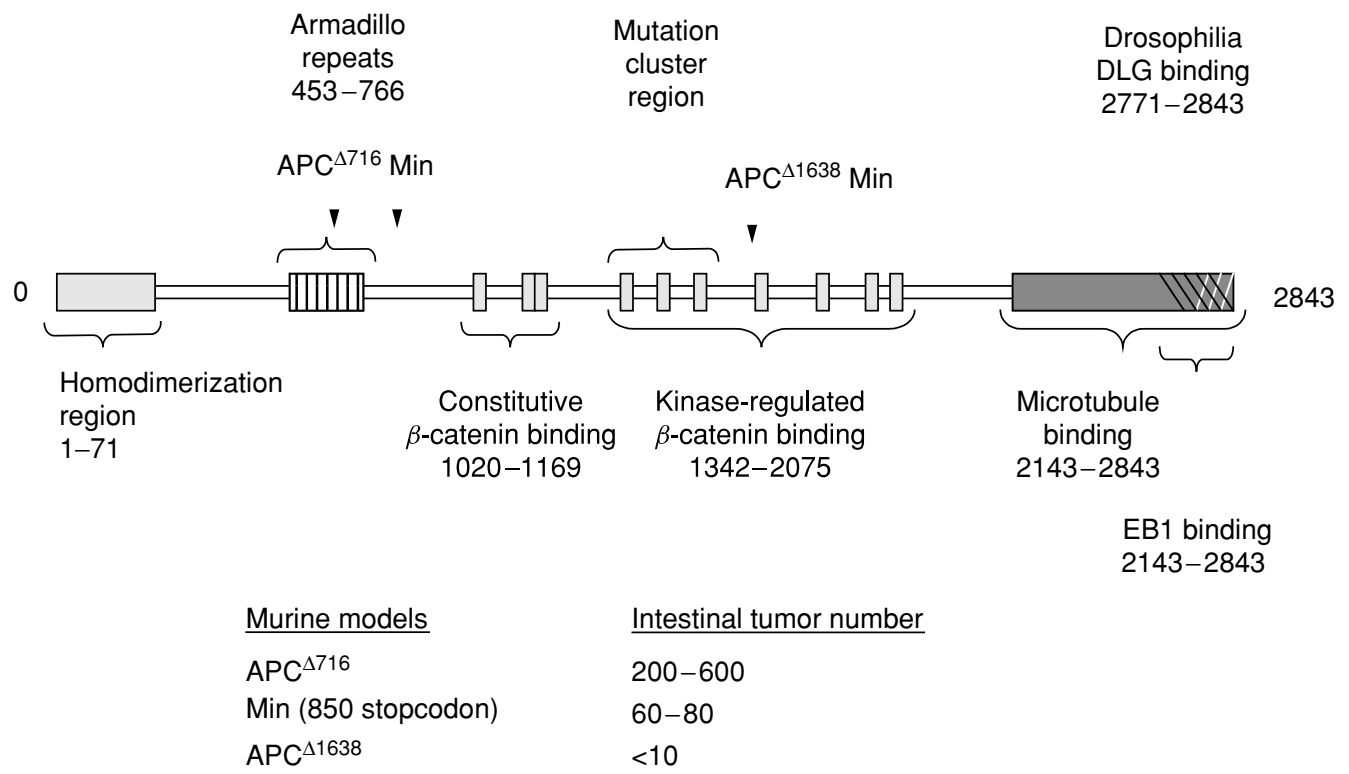

Figure 1.3. Diagram of APC protein regions, relating risk of intestinal carcinogenesis to length of APC peptide translated. APC contains 2833 amino acids. Mutation hot spot regions are found in areas between amino acids 1500-2000. Three genetically altered mouse models of APC-dependent intestinal carcinogenesis have been developed. Min mice have a stop codon mutation in codon 850 of the murine APC homolog. Two transgenic mice, $\mathrm{APC}^{\Delta 716}$ and $\mathrm{APC}^{\Delta 1635}$, also have been developed. Intestinal tumor number in these models is inversely related to size of the APC peptide translated.

length APC protein production after in vitro translation of colonic mucosal tissue RNA. These studies have not documented specific gene mutations in APC. This is important, because it is known from animal studies that the location of APC mutations can have a dramatic effect on the degree of intestinal carcinogenesis. Thus, it is possible that colon adenoma size, and subsequent risk of colon cancer could be dictated by location of specific mutations in APC (Fig. 1.3).

As suggested by the model depicted in Fig. 1.3, high risk might be associated with mutations causing stop codons in the amino terminal end of the protein. Low risk might be associated with mutations resulting in peptides of greater length. Current research is testing the hypothesis that specific genetic alterations in APC alone may be sufficient as a prognostic factor for risk of adenoma recurrence and subsequently, colon cancer development.

One type of genetic alteration that is gaining increasing attention is the single nucleotide polymorphism (SNP). This polymorphism results from a single base mutation that leads to the substitution of one base for another. SNPs occur quite frequently (about every 0.3$1 \mathrm{~kb}$ within the genome) and can be identified by several different techniques. A common method for the analysis of SNPs is based on the knowledge that single-base changes have the capability of destroying or creating a restriction enzyme site within a specific region of DNA. Digestion of a piece of DNA, containing the site in question, with the appropriate enzyme can distinguish between variants based on the resulting fragment sizes. This type of analysis is commonly referred to as restriction fragment length polymorphism (RFLP).

The importance of analyzing SNPs rests on the premise that individuals with a nucleotide at a specific position may display a normal phenotype, whereas individuals with a different nucleotide at this same position may exhibit increased predisposition for a certain disease or phenotype. Therefore, many studies are being conducted to determine the fre- 


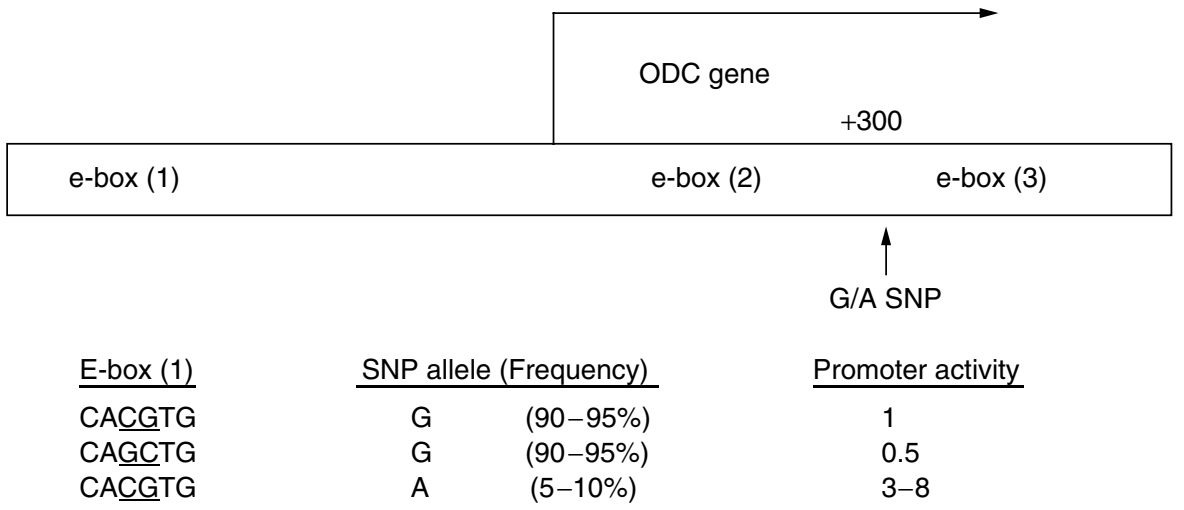

Figure 1.4. Influence of specific genetic changes on ODC promoter activity. These data were derived from transient transfection experiments in human colon tumor-derived HT29 cells. The arrow in this figure 1.4 shows the SNP. The SNP occurs between two E-boxes that are located 3' of the transcription start site. The effects of this genetic change are taken from Guo et al. (56). It is important to point out that the constructs used to assess the promoter activity of the polymorphic region containing the SNP and E-boxes 2 and 3 contained some of the $5^{\prime}$ promoter region, but not E-box 1 (56). The constructs used to assess the role of E-box 1 in HT-29 contained the major, c-myc unresponsive allele between E-boxes 2 and 3 .

quency of specific SNPs in the general population and to use these findings to explain phenotypic variation.

For example, a recent study found an association between a polymorphism leading to an amino acid substitution (aspartate to valine) in codon 1822 of the APC gene and a reduced risk for cancer in people eating a low-fat diet (13). The variant valine had an allele frequency of $22.8 \%$ in a primarily Caucasian control population. This non-truncating mutation has not yet been shown to have functional significance. If functional, such a polymorphism could cooperate with single allele truncating mutations that occur with high frequency in sporadic colon adenomas (14), to increase colon cancer risk. This polymorphism is especially interesting, because dietary factors, specifically fat consumption, may contribute to risk in only specific genetic subsets.

2.3.2 Genetic Variability in c-myc-Dependent Expression of Ornithine Decarboxylase. The proliferation-associated polyamines are essential for cell growth but may contribute to carcinogenesis when in excess. Various studies have shown that inhibition of polyamine synthesis impedes carcinogenesis. Ornithine decarboxylase (ODC), the first enzyme in poly- amine synthesis, may play a key role in tumor development. Therefore, elucidation of the mechanisms by which ODC is regulated is essential. The literature indicates that ODC is a downstream mediator of APC and suggests that ODC may be an APC modifier gene. Thus, polymorphisms in the ODC promoter affecting c-myc-dependent ODC transcription could be a mechanism of genetic variability of APC-dependent carcinogenesis.

O'Brien and colleagues (15) have measured the incidence in several human subgroups of a SNP in a region of the ODC promoter, $3^{\prime}$ of the transcription start site, that is flanked by two E-boxes (CACGTG) (Fig. 1.4). The E-box is a DNA sequence where specific transcription factors bind. The two resulting alleles are identified by a polymorphic PstI RFLP. The minor allele (A at position +317 ) is homozygous in $6-10 \%$ of individuals, whereas the major allele $(\mathrm{G}$ at position +317$)$ is homozygous or heterozygous in $90-94 \%$ of these groups. They have also measured functionality of the polymorphisms. When ODC promoter-reporter constructs are expressed in rodent cells, the minor allele confers 3-8 times the promoter activity compared with the major allele. Further, expression of the minor allele is 
enhanced by c-myc expression to a greater extent than the major allele.

\subsection{Epigenetic Changes}

Gene function can be disrupted either through genetic alterations, which directly mutate or delete genes, or epigenetic alterations, which alter the state of gene expression. Epigenetic mechanisms regulating gene expression include signal transduction pathways, DNA methylation, and chromatin remodeling. Methylation of DNA is a biochemical addition of a methyl group at position 5 of the pyrimidine ring of cytosine in the sequence CG. This modification occurs in two ways: (1) from a preexisting pattern on the coding strand or (2) by de novo addition of a methyl group to fully unmethylated DNA. Cleavage of DNA with the restriction endonuclease HpaII, which cannot cut the central $\mathrm{C}$ in the sequence CCGG if it is methylated, allows detection of methylated sites in DNA. Small regions of DNA with methylated cytosine, called " $\mathrm{CpG}$ islands," have been found in the 5 '-promoter region of about one-half of all human genes (including most housekeeping genes).

There are three DNA methyltransferases (Dnmt), Dnmt1, Dnmt3a, and Dnmt3b, that have been identified in mammalian cells (16). The most abundant and ubiquitous enzyme, Dnmt1, shows high affinity for hemimethylated DNA, suggesting a role of Dnmt1 in the inheritance of preexisting patterns of DNA methylation after each round of DNA replication. The other two enzymes, Dnmt3a and Dnmt3b, are tissue specific and have been shown to be involved in de novo methylation. De novo CpG island methylation, however, is not a feature of proliferating cells, and can be considered a pathologic event in neoplasia.

Over the years, a number of different methyl-CpG binding proteins, such as methylCpG-binding domain-containing proteins (MBD1-4) were identified (17) that compete with transcription factors and prevent them from binding to promoter sequences. These methyl-CpG binding factors can also recruit histone deacetylases (HDACs), resulting in condensation of local chromatin structure (Fig. 1.5). This makes the methylated DNA less accessible to transcription factors and results in gene silencing.
Gene expression is inhibited by DNA methylation. DNA methylation patterns dramatically change at different stages of cell development and differentiation and correlate with changes in gene expression (18). Demethylation releases gene expression in the first days of embryogenesis. Later, de novo methylation establishes adult patterns of gene methylation. In differentiated cells, methylation status is retained by the activity of the Dnmt1 enzyme. In normal tissues, DNA methylation is associated with gene silencing, chromosome $\mathrm{X}$ inactivation (19), and imprinting (20). Because the most normal methylation takes place within highly repeated transposable elements, it has been proposed that such methylation plays a role in genome defense by suppressing potentially harmful effects of expression at these sites.

Neoplastic cells are characterized by simultaneous global DNA hypomethylation, localized hypermethylation that involves $\mathrm{CpG}$ islands and increased HDAC activity (21). Hypomethylation has been linked to chromosomal instability in vitro and it seems to have the same effect in carcinogenesis (22). 5-Methylcytosine is a relatively unstable base because its spontaneous deamination leads to the formation of uracil. Such changes can also contribute to the appearance of germline mutations in inherited disease and somatic mutations in neoplasia. Aberrant $\mathrm{CpG}$ island hypermethylation in normally unmethylated regions around gene transcription start sites, which results in transcriptional silencing of genes, suggests that it plays an important role as an alternate mechanism by which tumor suppressor genes are inactivated in cancer (21). Hypermethylated genes identified in human cancers include the tumor suppressor genes that cause familial forms of human cancer when mutated in the germline, as well as genes that are not fully documented tumor suppressors (Table 1.1). Some of these genes, such as APC, the breast cancer gene BRCA-1, E-cadherin, mismatch repair gene hMLH1, and the Von Hippel-Lindau gene can exhibit this change in non-familial cancers.

Recent studies indicate that promoter hypermethylation is often an early event in tumor progression. It has been shown in the colon that genes that have increased hyper- 


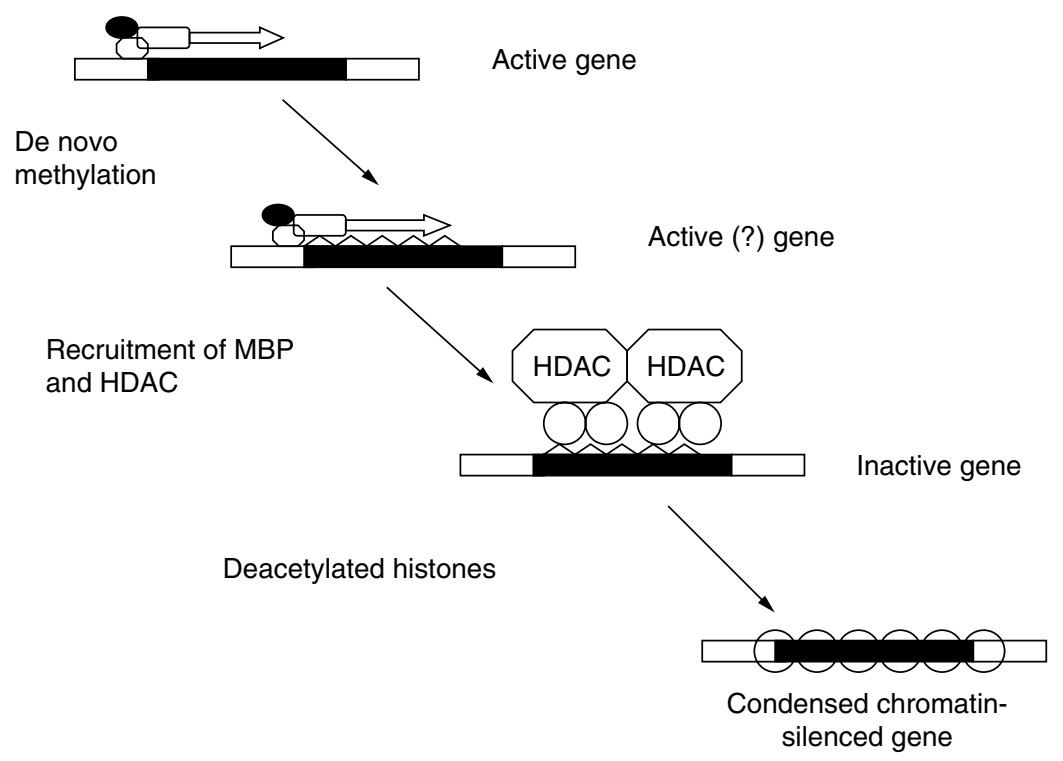

Figure 1.5. Effect of methylation and histone deacetylation on gene expression. When a gene is active, the promoter region is occupied by transcription factors that direct production of messenger RNA. De novo methylation has minimal effects on gene expression. However, methylated DNA attracts methyl-binding proteins (MBP). These methyl-binding proteins in turn attract a protein complex that contains histone deacetylase (HDAC). This results in inhibition of messenger RNA synthesis, and no functional protein can be made from the gene. Through the action of MBP and HDAC, the DNA structure changes to a compact, "condensed chromatin" configuration, which results in permanent inhibition of messenger RNA and protein synthesis (silencing).

methylation in the promoter region in normal tissue as a function of aging are the same as genes with the highest rate of promoter hypermethylation in tumors (9). Interestingly, this group of genes does not include classic tumor suppressor genes. Some genes, such as the estrogen receptor where age-related hypermethylation in the colon was first discovered, may be important for the modulation of cell growth and differentiation in the colonic mucosa.

Promoter hypermethylation of genes, which are normally unmethylated at all ages, has also been found early in tumorigenesis. These epigenetic alterations can produce the early loss of cell cycle control, altered regulation of gene transcription factors, disruption of cell-cell interactions, and multiple types of genetic instability, which are all characteristic of neoplasia. For example, hypermethylation of the APC gene has recently been reported for a subset of colon cancers (23). Hypermethylation of hMLH1, which is associated with microsatellite instability in colon, endometrial, and gastric neoplasia, has been seen in early stages of cancer progression (24). Finally, hypermethylation of the E-cadherin promoter frequently occurs in early stages of breast cancer and can trigger invasion (25).

Loss of gene function through epigenetic changes differs from genetic changes in terms of its consequences for tumor biology. First, gene function loss caused by aberrant promoter methylation may manifest in a more subtle, selective advantage than gene mutations during tumor progression. Second, although promoter hypermethylation causing gene silencing is usually stable in cancer cells, this change, unlike mutation, is potentially reversible. It has become evident that not only the mutagens, but various factors influencing cell metabolism, particularly methylation, lie at the origin of carcinogenesis.

Silencing of gene expression by methylation may be modulated by biochemical or biological manipulation. It has been shown that pharmacological inhibition of methyltrans- 
Table 1.1 Hypermethylated Genes in Cancer

\begin{tabular}{lll}
\hline Gene & \multicolumn{1}{c}{ Function } & \multicolumn{1}{c}{ Type of Tumor } \\
\hline Familial Cancers & & \\
APC & Signal transduction & Colon cancer \\
BRCA1 & DNA repair & Breast cancer \\
E-cadherin & Adhesion and metastasis & Multiple cancers \\
hMLH1 & DNA mismatch repair & Colon, gastric, and endometrial \\
& & cancer \\
p16/CDKN2A & Cell cycle regulation & Multiple cancers \\
RB1 & Cell cycle regulation & Retinoblastoma \\
VHL & Cytoskeletal organization, angiogenesis & Renal-cell cancer \\
& inhibition & \\
Other Cancers & & \\
Androgen receptor & Growth and differentiation & Prostate cancer \\
c-ABL & Tyrosine kinase & Chronic myelogenous leukemia \\
Endothelin receptor B & Growth and differentiation & Prostate cancer \\
Estrogen receptor $\alpha$ & Transcription & Multiple cancers \\
FHIT & Detoxification & Esophageal cancer \\
GST- $\pi$ & Drug transport & Prostate cancer \\
MDR1 & Drug transport & Acute leukemias \\
O6-MGMT & DNA repair & Multiple cancers \\
p14/ARF & Cell cycle regulation & Colon cancer \\
p15/CDKN2B & Cell cycle regulation & Malignant hematologic disease \\
Progesterone receptor & Growth and differentiation & Breast cancer \\
Retinoic acid receptor $\beta$ & Growth and differentiation & Colon and breast cancer \\
THBS1 & Angiogenesis inhibition & Colon cancer, glioblastoma \\
TIMP3 & Metastasis & multiforme \\
\hline
\end{tabular}

ferases resulted in reactivation of gene expression in vitro (26) and prevented tumor growth in animal models (27). These studies generated interest in the clinical uses of hypomethylating agents in humans.

\section{MOLECULAR BASIS OF CANCER PHENOTYPES}

Cancer is a multistep process that requires the accumulation of multiple genetic mutations in a single cell that bestow features characteristic of a neoplastic cell. Typically, tumor cells differ from normal cells in that they exhibit uncontrolled growth. Because features that distinguish tumor from normal cells may be key to understanding neoplastic cell behavior and may ultimately lead to therapies that can target tumor cells, considerable effort has been directed at identifying the phenotypic characteristics of in vitro-transformed cells and of tumor cells derived from natural sources. This work has resulted in a list of properties that are characteristic of tumor cells and that are now known to be the basis for the behaviors exhibited by neoplastic cells. Some of the features that will be discussed in detail include immortality, decreased dependence on growth factors to support proliferation, loss of anchorage-dependent growth, loss of cell cycle control, reduced sensitivity to apoptotic cell death, and increased genetic instability. Other morphological and biochemical characteristics used to identify the transformed phenotype are cytological changes, altered enzyme production, and the ability to produce tumors in experimental animals (28).

\subsection{Immortality}

Normal diploid fibroblasts have a limited capacity to grow and divide both in vivo and in vitro. Even if provided with optimal growth conditions, in vitro normal cells will cease dividing after $50-60$ population doublings and then senesce and die. In contrast, malignant cells that have become established in culture 
proliferate indefinitely and are said to be immortalized. The barrier that restricts the life span of normal cells is known as the Hayflick limit and was first described in experiments that attempted immortalization of rodent cells (29). Normal embryo-derived rodent cells, when cultured in vitro, initially divide rapidly. Eventually, however, these cultures undergo a crisis phase during which many of the cells senesce and die. After extended maintenance, however, proliferation in the cultures increases and cells that can divide indefinitely emerge. The molecular changes that take place during crisis have revealed at least two important restrictions that must be overcome for cells to become immortalized and both of these changes occur in natural tumor cells.

One barrier to cellular immortalization is the inability of the DNA replication machinery to efficiently replicate the linear ends of DNA at the $5^{\prime}$ ends, which leads to the shortening of the chromosome. In bacteria, the endreplication problem is solved with a circular chromosome. In human cells, the ends of chromosomes are capped with $5-15 \mathrm{~kb}$ of repetitive DNA sequences known as telomeres. Telomeres serve as a safety cap of noncoding DNA that is lost during normal cell division without consequence to normal function of the cell. However, because telomere length is shortened with each round of cell division, indefinite proliferation is impossible because eventually the inability to replicate chromosomal ends nibbles into DNA containing vital genes.

Telomeres seem to be lengthened during gametogenesis as a consequence of the activity of an enzyme called telomerase. Telomerase activity has been detected in normal ovarian epithelial tissue. More importantly, telomerase activity is elevated in the tumor tissue but not the normal tissue from the same patient. This implies that one mechanism by which tumor cells overcome the shortening telomere problem and acquire the capacity to proliferate indefinitely is through abnormal up-regulation of telomerase activity. The finding that telomerase activity is found almost exclusively in tumor cells is significant because it suggests that this enzyme may be a useful therapeutic target (30). Therapies aimed at suppressing telomerase would eliminate a feature essential for tumor cell survival and would be selective.
A second feature of immortalization is loss of growth control by elimination of tumor suppressor activity. Recent evidence suggests that inactivating mutations in both the $\mathrm{Rb}$ and p53 tumor suppressor genes occurs during crisis. Both of these genes are discussed in more detail later in this chapter and both function to inhibit cell proliferation by regulating cell cycle progression. Consequently, loss of tumor suppressor function also appears to be a critical event in immortalization.

\subsection{Decreased Dependence on Growth Factors to Support Proliferation}

Cells grown in culture require media supplemented with various growth factors to continue proliferating. In normal human tissues, growth factors are generally produced extracellularly at distant sites and then are either carried through the bloodstream or diffuse to their nearby target cells. The former mode of growth factor stimulation is termed endocrine stimulation, and the latter mode, paracrine stimulation. However, tumor cells often produce their own growth factors that bind to and stimulate the activity of receptors that are also present on the same tumor cells that are producing the growth factor. This results in a continuous self-generated proliferative signal known as autocrine stimulation that drives proliferation of the tumor cell continuously even in the absence of any exogenous proliferative signal. Autocrine stimulation is manifested as a reduced requirement for serum because serum is the source of many of the growth factors in the media used to propagate cells in vitro.

Because of the prominent role that growth factors and their cognate receptors play in tumor cell proliferation, they have also become favorite therapeutic targets. For example, the epidermal growth factor receptor (EGFR) is known to play a major role in the progression of most human epithelial tumors, and its overexpression is associated with poor prognosis. As a consequence, different approaches have been developed to block EGFR activation function in cancer cells, including anti-EGFR blocking monoclonal antibodies (MAb), epidermal growth factor (EGF) fused to toxins, and small molecules that inhibit the receptor's tyrosine kinase activity (RTK). Of these, an 
orally active anilinoquinazoline, ZD1839 ("Iressa") shows the most promise as an antitumor agent by potentiating the antitumor activity of conventional chemotherapy (31).

\subsection{Loss of Anchorage-Dependent Growth and Altered Cell Adhesion}

Most normal mammalian cells do not grow, but instead undergo cell death if they become detached from a solid substrate. Tumor cells, however, frequently can grow in suspension or in a semisolid agar gel. The significance of the loss of this anchorage-dependent growth of cancer cells relates to the ability of the parent tumor cells to leave the primary tumor site and become established elsewhere in the body. The ability of cancer cells to invade and metastasize foreign tissues represents the final and most difficult-to-treat stage of tumor development, and it is this change that accompanies the conversion of a benign tumor to a lifethreatening cancer.

Metastasis is a complex process that requires the acquisition of several new characteristics for tumor cells to successfully colonize distant sites in the body. Epithelial cells normally grow attached to a basement membrane that forms a boundary between the epithelial cell layers and the underlying supporting stroma separating the two tissues. This basement membrane consists of a complex array of extracellular matrix proteins including type IV collagen, proteoglycans, laminin, and fibronectin, which normally acts as a barrier to epithelial cells. A common feature of tumor cells with metastatic potential is the capacity to penetrate the basement membrane by proteolysis, to survive in the absence of attachment to this substrate, and to colonize and grow in a tissue that may be foreign relative to the original tissue of origin.

Consequently, metastasis is a multistep process that begins with detachment of tumor cells from the primary tumor and penetration through the basement membrane by degradation of the extracellular matrix (ECM) proteins. This capacity to proteolytically degrade basement membrane proteins is driven, in part, by the expression of matrix metalloproteinases. Matrix metalloproteinases, or MMPs, are a family of enzymes that are either secreted (MMPs 1-13, 18-20) or anchored in the cell membrane (MMPs 14-17) (Table 1.2). Regulation of MMPs occurs at several levels: transcription, proteolytic activation of the zymogen, and inhibition of the active enzyme (32). MMPs are typically absent in normal adult cells, but a variety of stimuli, such as cytokines, growth factors, and alterations in cell-cell and cell-ECM interactions, can induce their expression. The expression of MMPs in tumors is frequently localized to stromal cells surrounding malignant tumor cells. Most of the MMPs are secreted in their inactive (zymogen) form and require proteolytic cleavage to be activated. In some cases, MMPs have been shown to undergo mutual and/or autoactivation in vitro (33).

Several lines of evidence implicate MMPs in tumor progression and metastasis. First, MMPs are overexpressed in tumors from a variety of tissues and the expression of one, matrilysin, is clearly elevated in invasive prostate cancer epithelium (34-36). Second, reduction of tissue inhibitor of matrix metalloproteinases-1 (TIMP-1) expression in mouse fibroblasts (Swiss 3T3), using antisense RNA technology, increased the incidence of metastatic tumors in immunocompromised mice. Similarly, overexpression of the various MMPs has provided direct evidence for their role in metastasis. Importantly, synthetic MMP inhibitors have also been produced and they lead to a reduction in metastasis in several experimental models of melanoma, colorectal carcinoma, and mammary carcinoma, suggesting a mechanism by which the invasive potential of tumors may be reduced (37).

Once tumor cells escape through the basement membrane, they can metastasize through two major routes, the blood and lymphatic vessels. Tumors originating in different parts of the body have characteristic patterns of invasion. Some tumors, such as those of the head and neck, spread initially to regional lymph nodes. Others, such as breast tumors, have the ability to spread to distant sites relatively early. The site of the primary tumor generally dictates whether the invasion will occur through the lymphatic or blood vessel system. The cells that escape into the vasculature must evade host immune defense mechanisms to be successfully transported to regional or distal locations. Tumor cells then 
Table 1.2 MMPs

\begin{tabular}{|c|c|c|c|}
\hline MMP & Common Name & Substrates & Cell Surface \\
\hline 1 & $\begin{array}{l}\text { collagenase- } 1 \text {, interstitial } \\
\text { collagenase }\end{array}$ & collagen I, II, III, VII, X, IGFBP & yes \\
\hline 2 & gelatinase $\mathrm{A}$ & $\begin{array}{l}\text { gelatin, collagen I, IV, V, X, laminin, IGFBP, } \\
\text { latent TGF- } \beta\end{array}$ & yes \\
\hline 3 & stromelysin-1 & $\begin{array}{l}\text { collagen III, IV, V, IX, X, gelatin, } \\
\text { E-cadherin, IGFBP, fibronectin, } \\
\text { elastin, laminin proteoglycans, perlecan, } \\
\text { HB-EGF, proMMP-13 }\end{array}$ & unknown \\
\hline 7 & matrilysin & $\begin{array}{l}\text { laminin, fibronectin, gelatin, collagen IV, } \\
\text { proteoglycans FasL, proMMP-1, HB-EGF }\end{array}$ & yes \\
\hline 8 & $\begin{array}{l}\text { collagenase- } 2 \text {, neutrophil } \\
\text { collagenase }\end{array}$ & collagen I, II, III, VII, X & unknown \\
\hline 9 & gelatinase $\mathrm{B}$ & $\begin{array}{l}\text { collagen I, IV, V, X, gelatin, IGFBP, latent } \\
\text { TGF-b }\end{array}$ & yes \\
\hline 10 & stromelysin-2 & $\begin{array}{l}\text { collagen III, IV, IX, X, gelatin, laminin, } \\
\text { proteoglycans, proMMP-1, proMMP-13 }\end{array}$ & unknown \\
\hline 11 & stromelysin-3 & IGFBP, a-1-antiprotease & unknown \\
\hline 12 & metalloelastase & elastin, proMMP-13 & unknown \\
\hline 13 & collagenase-3 & $\begin{array}{l}\text { collagen I, II, III, IV, VII, X, XIV, } \\
\text { fibronectin, proMMP-9, tenascin, aggrecan }\end{array}$ & unknown \\
\hline 14 & MT1-MMP & $\begin{array}{l}\text { gelatin, collagen I, fibrin, proteoglycans, } \\
\text { laminin, fibronectin, proMMP-2 }\end{array}$ & yes \\
\hline 15 & MT2-MMP & $\begin{array}{l}\text { laminin, fibronectin, proMMP-2, proMMP- } \\
\text { 13, tenascin }\end{array}$ & yes \\
\hline 16 & MT3-MMP & gelatin, collagen III, fibronectin, proMMP-2 & yes \\
\hline 17 & MT4-MMP & unknown & yes \\
\hline $18 / 19$ & RASI-1 & unknown & unknown \\
\hline 20 & Enamelysin & amelogenin & unknown \\
\hline
\end{tabular}

exit blood vessels and escape into the host tissue by again compromising a basement membrane, this time the basement membrane of the blood vessel endothelium. Projections called invadopodia, which contain various proteases and adhesive molecules, adhere to the basement membrane, and this involves membrane components such as laminin, fibronectin, type IV collagen, and proteoglycans. The tumor cells then produce various proteolytic enzymes, including MMPs, which degrade the basement membrane and allow invasion of the host tissue. This process is referred to as extravasation.

The interaction between cells and extracellular matrix proteins occurs through cell-surface receptors, the best characterized of which is the fibronectin receptor that binds fibronectin. Other receptors bind collagen and laminin. Collectively these receptors are called integrins, and their interaction with matrix components conveys regulatory signals to the cell (38). They are heterodimeric molecules consisting of one of several alpha and beta subunits that may combine in any number of permutations to generate a receptor with distinct substrate preferences. Changes in the expression of integrin subunits is associated with invasive and metastatic cells facilitating invasion by shifting the cadre of integrins to integrins that preferentially bind the degraded subunits of extracellular matrix proteins produced by MMPs. Hence, integrin expression has served as a marker for the invasive phenotype and may be a logical target for novel therapies that interfere with the progress of advanced tumors.

In addition to their role in invasion, the evidence also indicates that MMPs may play a role in tumor initiation and in tumorigenicity. Expression of MMP-3 in normal mammary epithelial cells led to the formation of invasive tumors (39). A proposed mechanism for this initiation involves the ability of MMP-3 to 
cleave E-cadherin. E-cadherin is a protein involved in cell-cell adhesion together with other proteins such as $\beta$-catenin and $\alpha$-catinin. Loss of E-cadherin function is known to lead to tumorigenicity and invasiveness as a result of loss of cellular adhesion. Interestingly, inhibition of MMP-7 and MMP-11, using antisense approaches, did not affect invasiveness or metastatic potential in vitro. However, tumorigenicity was altered (40). Matrilysin, MMP-7 messenger RNA (mRNA), are present in benign tumors and malignant tumor cells of the colon. The relative level of matrilysin expression correlates with the stage of tumor progression.

\subsection{Cell Cycle and Loss of Cell Cycle Control}

Proliferation is a complex process consisting of multiple subroutines that collectively bring about cell division. At the heart of proliferation is the cell cycle, which consists of many processes that must be completed in a timely and sequence specific manner. Accordingly, regulation of cell cycle events is a multifaceted affair and consists of a series of checks and balances that monitor nutritional status, cell size, presence or absence of growth factors, and integrity of the genome. These cell cycle regulatory pathways and the signal transduction pathways that communicate with them are populated with oncogenes and tumor suppressor genes.

Cell division is divided into four phases: G1, $\mathrm{S}, \mathrm{G} 2$, and $\mathrm{M}$ (Fig. 1.6). The entire process is punctuated by two spectacular events, the replication of DNA during S phase and chromosome segregation during mitosis or $\mathrm{M}$ phase. Of the four cell cycle phases, three can be assigned to replicating cells and only the G1 phase, and a related quiesent phase, G0, are nonreplicative in nature. Normal cycling cells that cease to proliferate enter the resting phase, or G1, and their exit into the replicative phases is strongly dependent on the presence of growth factors and nutrients. However, once the cells enter the replicative phase of the cell cycle, they become irrevocably committed to completing cell division. Hence, the conditions that lead to exit from G1 and entry into S are tightly regulated and are frequently misregulated in neoplastic cells that exhibit un- controlled proliferation. Studies first conducted by Arthur Pardee revealed the existence of a point in G1 that restricted the passage of cells into $\mathrm{S}$ phase, and this was postulated to be controlled by a labile protein factor (41). Passage across this restriction point, or $\mathrm{R}$ point, is now known to be sensitive to growth factor stimulation.

Movement through the cell cycle is controlled by two classes of cell cycle proteins, cyclins and cyclin dependent kinases (CDKs), which physically associate to form a protein kinase that drives the cell cycle forward (42). At least 8 cyclins and 12 CDKs have been identified in mammalian cells. The name "cyclin" derives from the characteristic rise and fall in abundance of cyclin B as cells progress through the cell cycle. The accumulation of cyclin proteins occurs through cell cycle-dependent induction of gene transcription, but elimination of cyclins occurs by carefully regulated degradation that is enabled through protein sequence tags known as destruction boxes and PEST sequences. Although not all of the cyclin types exhibit this oscillation in protein quantity, those cyclins that play key roles in progression through the cell cycle (cyclins $\mathrm{E}, \mathrm{A}$, and B) are most abundant during discrete phases of the cell cycle. Cyclin D1 is synthesized during G1 just before the restriction point and plays an important role in regulation of the $R$ point. Cyclin $\mathrm{E}$ is most abundant during late G1 and early $\mathrm{S}$ and is essential for exit from $\mathrm{G} 1$ and progression into $\mathrm{S}$ phase. Elevated levels of these two G1 cyclins can result in uncontrolled proliferation. Indeed, both cyclin D1 and cyclin E are overexpressed in some tumor types, suggesting that the cyclins and other components of the cell cycle may be useful therapeutic targets (43).

The second component of the enzyme complex is CDK that, as the name implies, requires an associated cyclin to become active. At least 12 of the protein kinases have been isolated from humans, Xenopus, and Drosoph$i l a$, and are numbered according to a standardized nomenclature beginning with CDK1, which for historical reasons, is most frequently referred to as cell division cycle 2 (cdc2). Unlike the cyclins, abundance of the CDK proteins remains relatively constant 


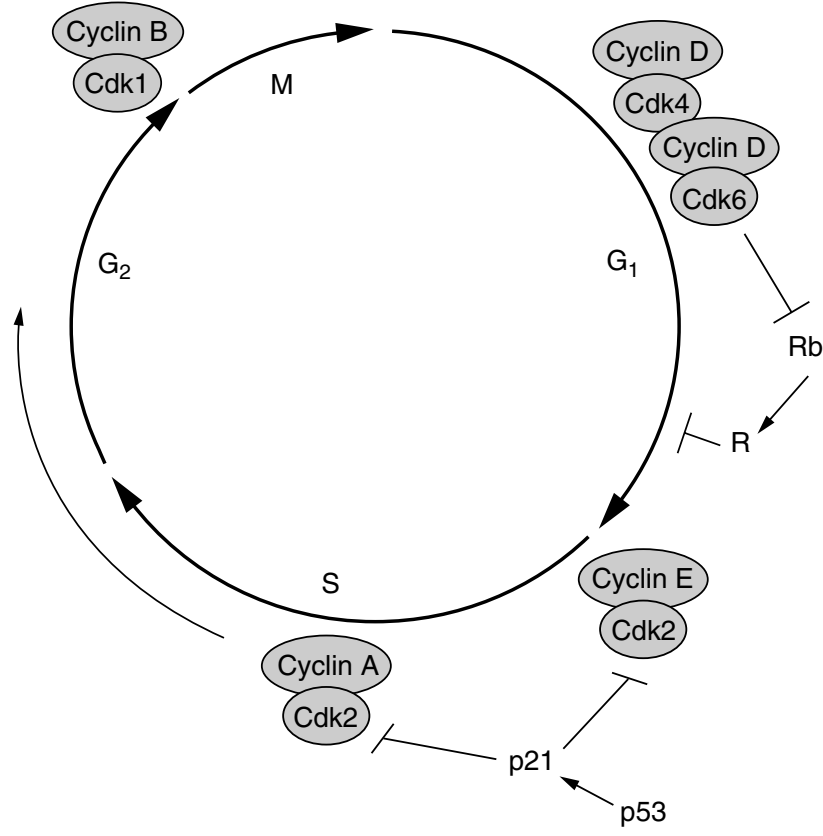

Figure 1.6. Model of the cell cycle and the cyclin/cdk complexes that are required at each cell cycle phase. CyclinD/ cdk4-6 complexes suppress $\mathrm{Rb}$ function by phosphorylating the protein allowing transition across the restriction R-point. P53 suppresses cell cycle progression by stimulating the expression of the cyclin dependent kinase inhibitor p21, which binds with and inactivates a variety of cyclin/cdk complexes. throughout the cell cycle. Instead, their activity changes during different phases of the cell cycle in accordance with whether or not an activating cyclin is present and whether or not the kinase itself is appropriately phosphorylated. Both cyclins and CDKs are highly conserved from yeast to man and function similarly, suggesting that the cell cycle is controlled by a universal cell cycle engine that operates through the action of evolutionarily conserved proteins. Hence, drug discovery studies aimed at identifying agents that regulate the cell cycle may be performed in model organisms, such as yeast, C. elegans, and Drosophila with some assurance that the targeted mechanisms will also be relevant to humans.

It is now clear that specific cyclin/cdk complexes are required during specific stages of the cell cycle. Cyclin D1/cdk4,6 activity is essential for crossing the restriction point and pushing cells into replication. A major substrate of the cyclin $\mathrm{D} 1 / \mathrm{cdk} 4,6$ complex is the retinoblastoma $(\mathrm{Rb})$ tumor suppressor protein, which when phosphorylated by this kinase complex, is inactivated. This frees the cell from the restrictions on cell proliferation imposed by the Rb protein. It is this event that is believed to be decisive in the stimulation of resting cells to undergo proliferation. Cyclin
$\mathrm{E} / \mathrm{cdk} 2$ plays a role later in the cell cycle for proliferating cells by pushing them from G1 into $\mathrm{S}$ phase. Cyclin $\mathrm{E}$ is overexpressed in some breast cancers where it may enhance the proliferative capacity of tumor cells. Cyclin $\mathrm{A} / \mathrm{cdk} 2$ sustains DNA replication and is therefore required during $\mathrm{S}$ phase. Cyclin $\mathrm{B} / \mathrm{cdc} 2$ is required by cells entering mitosis up through metaphase. At the end of metaphase, cyclin B is degraded, and cdc2 becomes inactivated, allowing mitotic cells to progress into anaphase and to complete mitosis. Sustaining the activity of cyclin $\mathrm{B} / \mathrm{cdc} 2$ causes cells to arrest in metaphase. Hence, it is the collective result brought about by the activation and deactivation of cyclin/cdk complexes that pushes proliferating cells through the cell cycle.

Superimposed on the functions of the cell cycle engine is a complex network of both positive and negative regulatory pathways. Important negative regulators are the cyclin dependent kinase inhibitors or CKIs. There are two families of CKIs, the Cip/Kip family and the INK4 family (44). The Cip/Kip family consists of three members, p21/Cip1/waf1/Sdi1, p21/Kip1, and p57/Kip2. All of the proteins in this family have broad specificity and can bind to and inactivate most of the cyclin/cdk complexes that are essential for progression 
through the cell cycle. $\mathrm{p} 21^{\text {waf1 }}$, the first discovered and best characterized member of the Cip/Kip family, is stimulated by the p53 tumor suppressor protein in response to DNA damage and halts cell cycle progression to allow for DNA repair (45). The INK4 family of CKIs contains four member proteins, p16/INK4a, p15/INK4b, p18/INK4c, and p19/INK4d. Unlike the Cip/Kip family, the INK4 proteins have restricted binding and associate exclusively with cdk4/6. Consequently, their principal function is to regulate cyclin D1/cdk4/6 activity, and therefore, the phosphorylation status of the Rb tumor suppressor. p16/INK4a is itself a tumor suppressor that is frequently mutated in melanoma (46). Indeed, at least one component of the $\mathrm{p} 16 /$ cyclin $\mathrm{D} 1 / \mathrm{Rb}$ pathways is either mutated or deregulated in some fashion in over $90 \%$ of lung cancers, emphasizing the importance of this pathway in regulating tumor cell proliferation.

Transit through the cell cycle is regulated by two types of controls. In the first type, the cumulative exposure to specific signals, such as growth factors, is assessed and if the sum of these signals satisfies the conditions required by the $\mathrm{R}$ point, proliferation ensues. In the second, feedback controls or checkpoints monitor whether the genome is intact and whether previous cell cycle steps have been completed. At least five cell cycle checkpoints have been identified, two that monitor integrity of the DNA and halt cell cycle progression in either G1 or G2, one that ensures DNA synthesis has been completed before mitosis begins, one that monitors completion of mitosis before allowing another round of DNA synthesis, and one that monitors chromosome alignment on the equatorial plate before initiation of anaphase. Of these, the two checkpoints that monitor integrity of DNA have been the most extensively studied, and as might be expected, these checkpoints and the genes that enforce them are critically important for the response that cells mount to genotoxic stresses. Abrogation of checkpoints leads to genomic instability and an increased mutation frequency (47).

Progress in elucidating the mechanisms of checkpoint function reveals that a number of checkpoint genes are frequently mutated in human cancers. For example, the p53 tumor suppressor functions as a cell cycle checkpoint that halts cell cycle progression in G1 by inducing the expression of the p $21^{\text {waf }}$ gene in the presence of damaged DNA (45). The p53 gene is frequently mutated in human cancers and consequently, most tumor cells lack the DNA damage-induced p53-dependent G1 checkpoint, increasing the likelihood that mutations will be propagated in these cells. Because p53 also promotes apoptosis, the lack of p53 in these cells also makes them more resistant to the DNA damage-induced apoptosis. Because most chemotherapeutic agents kill cells through DNA damage-induced apoptosis, tumor cells with mutant p53 are also more resistant to conventional therapies (48).

\subsection{Apoptosis and Reduced Sensitivity to Apoptosis}

Apoptosis is a genetically controlled form of cell death that is essential for tissue remodeling during embryogenesis and for maintenance of the homeostatic balance of cell numbers later in adult life. The importance of apoptosis to human disease comes from the realization that disruption of the apoptotic process is thought to play a role in diverse human diseases ranging from malignancy to neurodegenerative disorders. Because apoptosis is a genetically controlled process, much effort has been spent on identifying these genetic components to better understand the apoptotic process as well as to identify potential therapeutic targets that might be manipulated in disease conditions where disruption of apoptosis occurs.

Although multiple forms of cell death have been described, apoptosis is characterized by morphological changes including cell shrinkage, membrane blebbing, chromatin condensation and nuclear fragmentation, loss of microvilli, and extensive degradation of chromosomal DNA. In general, the apoptotic program can be subdivided into three phases: the initiation phase, the decision/effector phase, and the degradation/execution phase (Fig. 1.7). In the initiation phase, signal transduction pathways that are responsive to external stimuli, such as death receptor ligands, or to internal conditions, such as that produced by DNA damage, are activated. During the ensuing decision/effector phase, changes in the mitochondrial membrane occur that result in 


\begin{tabular}{|c|c|c|}
\hline $\begin{array}{c}\text { Premitochondrial } \\
\text { phase }\end{array}$ & $\begin{array}{l}\text { Mitochondrial } \\
\text { phase }\end{array}$ & $\begin{array}{l}\text { Postmitochondrial } \\
\text { phase }\end{array}$ \\
\hline $\begin{array}{c}\text { Signal } \\
\text { transduction }\end{array}$ & $\begin{array}{c}\text { Membrane } \\
\text { permeabilization }\end{array}$ & $\rightarrow \begin{array}{c}\text { Mitochondrial } \\
\text { proteins } \\
\text { released }\end{array}$ \\
\hline $\begin{array}{l}\text { Initiation } \\
\text { phase }\end{array}$ & $\begin{array}{c}\text { Decision/effector } \\
\text { phase }\end{array}$ & $\begin{array}{c}\text { Degradation/execution } \\
\text { phase }\end{array}$ \\
\hline
\end{tabular}

Figure 1.7. Mitochondria-mediated apoptosis. Mitochondria-mediated apoptosis is divided into three phases. Mitochondrial stress stimulates signal transduction and constitutes the initiation phase. During the second phase, changes in the structure of the mitochondrial membrane make it permeable to large proteins, allowing the release of cytochrome $\mathrm{c}$ and induction of the third and final phase, during which degradation of cellular proteins occurs.

disruption of the mitochondrial membrane potential and ultimately loss of mitochondrial membrane integrity. A key event in the decision/effector phase is the release of cytochrome $\mathrm{c}$ into the cytoplasm and activation of proteases and nucleases that signal the onset of the final degradation/execution phase. An important concept in understanding apoptosis is that the mitochrondrion is a key target of apoptotic stimuli and disruption of mitochondrial function is central to subsequent events that lead to degradation of vital cellular components.

Of the signal transduction pathways that initiate apoptosis, the best understood at the molecular level involves the death receptors including Fas/cluster of differentiation 95 (CD95), tumor necrosis factor receptor 1 (TNFR1), and death receptors 3,4 , and 5 (DR $3,4,5$ ) (Fig. 1.8). All death receptors share an amino acid sequence known as the death domain (DD) that functions as a binding site for a specific set of death signaling proteins. Stimulation of these transmembrane receptors can be induced by interaction with its cognate ligand or by binding to an agonistic antibody, which results in receptor trimerization and recruitment of intracellular death molecules and stimulation of downstream signaling events. Here death receptors are classified as either CD95-like (Fas/CD95, DR4, and DR5) or TNFR1-like (TNF-R1, DR3, and DR6) based on the downstream signaling events that are induced as a consequence of receptor activation.

Activation of Fas/CD95 leads to clustering and recruitment of Fas-associated death do- main (FADD; sometimes called Mort1) to the Fas/CD95 intracellular DD (49). FADD contains a C-terminal DD that enables it to interact with trimerized Fas receptor as well as an $N$-terminal death effector domain (DED), which can associate with the prodomain of the serine protease, caspase- 8 . This complex is referred to as the death-inducing signaling complex (DISC). As more procaspase-8 is recruited to this complex, caspase- 8 undergoes transcatalytic cleavage to generate active protease. Activation of TNFR1-like death receptors results in similar events except that the first protein to be recruited to the activated receptor is the TNFR-associated death domain (TRADD) adaptor protein that subsequently recruits FADD and procaspase-8. Signaling through the TNFR1-like receptors is more complex and includes recruitment of other factors that do not interact with Fas/CD95. For example, TRADD also couples with the receptor interacting protein (RIP), which links stimulation of TNFR1 to signal transduction mechanisms, leading to activation of nuclear factor-kappa $B$ $(\mathrm{NF}-\kappa \mathrm{B})$. Because RIP does not interact with Fas/CD95, this class of receptors does not activate NF-kappa B.

The critical downstream effectors of death receptor activation are the caspases, and these are considered the engine of apoptotic cell death (50). Caspases are a family of cysteine proteases with at least 14 members. They are synthesized in the cells as inactive enzymes that must be processed by proteolytic cleavage at aspartic acid residues. These cleavage sites are between the $\mathrm{N}$-terminal prodomain, the 


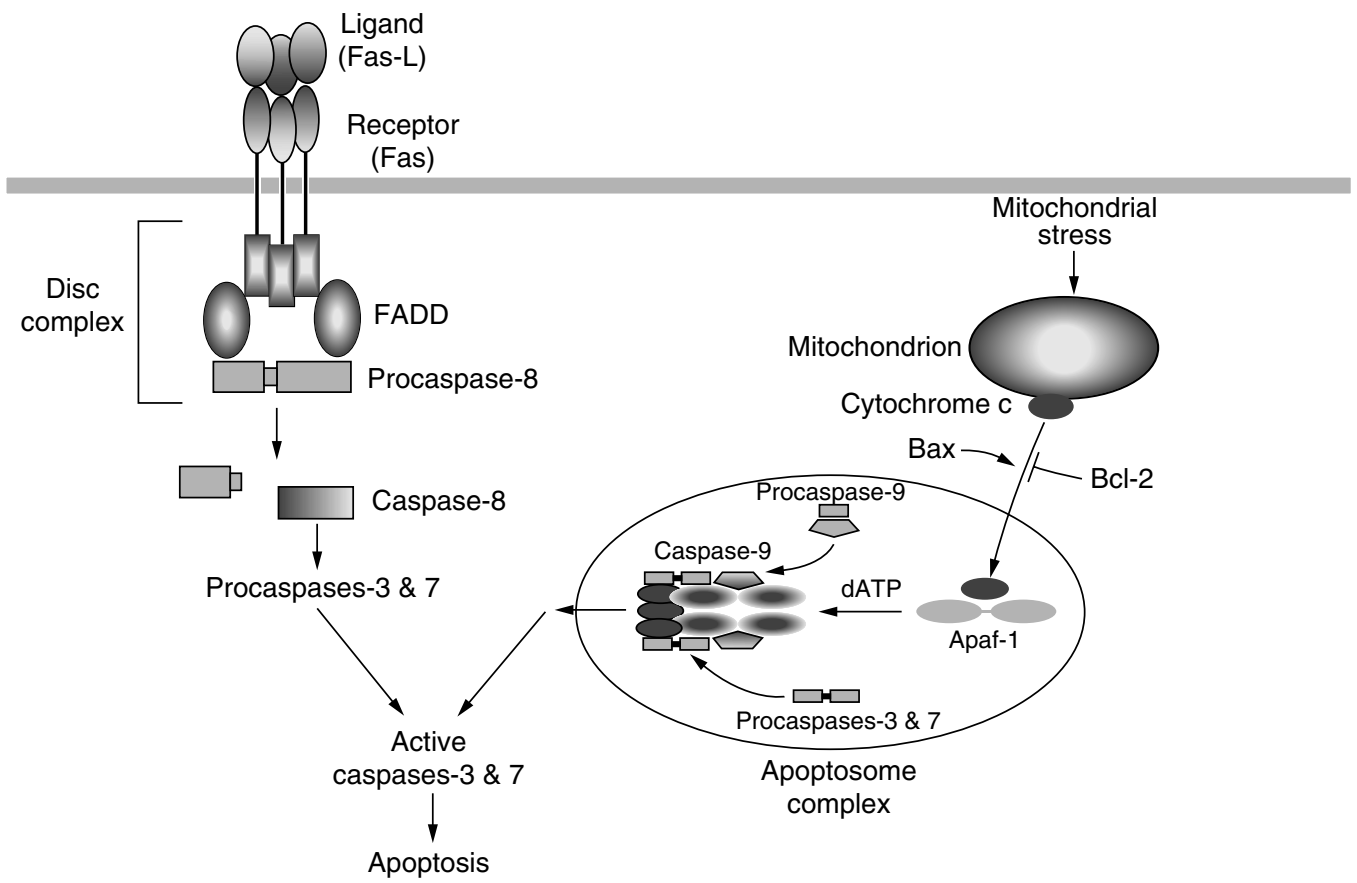

Figure 1.8. Apoptosis-receptor-mediated and mitochondrial apoptosis cascades. Trimerization of the Fas receptor initiates recruitment of the death domain-containing adaptor protein FADD, which binds to procaspase- 8 promoting trans-catalytic cleavage of prodomain. Caspase- 8 initiates the caspase cascade by acting on downstream effector caspases 3 and 7. In mitochondria-mediated apoptosis cytochrome c, release is a key event in apoptosis and is stimulated by Bax and suppressed by Bcl-2. The released cytochrome $\mathrm{c}$ binds with Apaf-1 and in conjunction with dATP induces a conformational change in Apaf- 1 that permits oligomerization into a $\sim 700$-kDa complex, which is called the apoptosome complex and is capable of recruiting caspases- $9,-3$, and -7 .

large P20, and small P10 domains. The activated proteases cleave other proteins by recognizing an aspartic acid residue at the cleavage site and are consistent with an auto- or transcleavage processing mechanism for activation when recruited to activated death receptors.

Importantly, biochemical studies support the notion of a caspase hierarchy that consists of initators and effectors that are activated in a cascade fashion. Initiator caspases such as caspase- 8 and -9 are activated directly by apoptotic stimuli and function, in part, by activating effector caspases such as caspase-3, -6, and -7 by proteolytic cleavage. It is the effector caspases that result in highly specific cleavage of various cellular proteins and the biochemical and morphological degradation associated with apoptosis.

In contrast to death receptor-mediated apoptosis that functions through a well-defined pathway, mediators of stress-induced apoptosis such as growth factors, cytokines, and DNA damage activate diverse signaling pathways that converge on the mitochondrial membrane (51). Many proapoptotic agents have been shown to disrupt the mitochondrial membrane potential $\left(\Delta \Psi_{\mathrm{m}}\right)$, leading to an increase in membrane permeability and release of cytochrome $\mathrm{c}$ into the cytosol. Cytochrome $\mathrm{c}$ release is a common occurrence in apoptosis and is thought to be mediated by opening of the permeability transmembrane pore complex (PTPC), a large multiprotein complex that consists of at least 50 different proteins. The cytosolic cytochrome $\mathrm{c}$ interacts with apoptosis activating factor-1 (Apaf-1), dATP/ ATP, and procaspase-9 to form a complex known as the apoptosome. Cytochrome $\mathrm{c}$ and dATP/ATP stimulate Apaf-1 self-oligomerization and trans-catalytic activation of pro- 
caspase-9 to the active enzyme. Active caspase- 9 activates effector caspases- 3 and -7 and leads to the cellular protein degradation characteristic of apoptosis.

As release of cytochrome c can have dire consequences for viability of the cell, its release is tightly regulated. Indeed, a whole family of proteins, of which B-cell lymphoma-2 (Bcl-2) is the founding member, that share homology in regions called the Bcl-2 homology domains are dedicated to regulation of cytochrome c release from the mitochondria (52). Both positive regulators (Bax, Bak, Bik, and Bid) that promote apoptosis and negative regulators (Bcl-2 and Bcl- $\mathrm{x}_{\mathrm{L}}$ ), which suppress apoptosis, act by regulating permeability of the mitochondrial membrane to cytochrome c. Bcl-2 family members have been found in both the cytosol and associated with membranes. Bax is normally found in the cytosol, but subcellular localization changes during apoptosis. Bax has been shown to insert into the mitochondrial membrane where, because of its structure that is similar to other pore-forming proteins, it is thought to promote release of cytochrome c. Bcl-2 functions by inhibiting insertion of Bax into the mitochondrial membrane. Hence, a key factor that determines whether a cell will undergo apoptosis is the ratio of proapoptotic to antiapoptotic Bcl-2 family proteins.

Because apoptosis serves to eliminate cells with a high neoplastic potential, cancer cells have evolved to evade apoptosis primarily through two mechanisms. In the first of these, Bcl-2, which suppresses apoptosis, is overexpressed. The Bcl-2 oncogene was first identified as a break point in chromosomal translocations that frequently occurred in B-cellderived human tumors. Characterization of the rearrangements revealed that the Bcl-2 gene is overexpressed by virtue of being placed adjacent to the powerful IgH promoter. Cloning of the Bcl-2 gene and overexpression in cells of B-cell lineage reduced the sensitivity of these cells to apoptosis and allowed them to survive under conditions that ordinarily caused normal cells to die.

The second mechanism that provides cancer cells with resistance to apoptosis is the suppression of the Fas receptor. As with other receptors, mutations can occur in either the ligand binding domain or in the intracellular domain interfering with activation of the death signaling pathway. More recently a novel mechanism for suppressing Fas-receptor activation has been identified in which cancer cells synthesize decoy receptors to which ligands can bind but are unable to induce apoptosis (53).

\subsection{Increased Genetic Instability}

A hallmark of tumor cells is genetic instability that is manifested at the chromosomal level as either aneuploidy (the gain or loss of one or more specific chromosomes) or polyloidy (the accumulation of an entire extra set of chromosomes). Acquisition of extra chromosomes is one mechanism by which extra copies of a growth promoting gene can be acquired by cancer cells, providing them with a selective growth advantage. Structural abnormalities are also common in advanced tumors that lead to various types of chromosomal rearrangements. Translocations and random insertion of genetic material into one chromosome from another can place genes that are not normally located adjacent to one another in close proximity usually leading to abnormal gene expression. Some of these rearrangements are routinely observed in some cancers such as in Burkitt's lymphoma where rearrangements involving chromosome 8 and 14 lead to abnormal expression of the c-myc protooncogene as a consequence of being placed adjacent to the immunoglobulin heavy chain promoter.

In chronic myelogenous leukemia (CML), an abnormal chromosome known as the Philadelphia chromosome results from a translocation involving chromosomes 9 and 22. The genes for two unrelated proteins, c-Abl and $\mathrm{Bcr}$, a tyrosine kinase, and a GTPase activating protein (GAP), are spliced together, forming a chimeric protein that results in a powerful and constitutively active kinase that drives proliferation of the cells in which it is expressed.

Other forms of genetic instability include gene amplification. Under normal conditions, all DNA within the cell is replicated uniformly and only once per cell cycle. However, in cancer cells some regions of a chromosome can undergo multiple rounds of replication such that multiple copies of a growth-promoting 
gene(s) is obtained. These can result in chromosomes with regions of DNA that stain uniformly during karyotype analysis of a tumor cell or in the production of extrachromosomal DNA-containing bodies known as double minute chromosomes. A typical example of this type of amplification targets the N-myc gene, which is amplified in $\sim 30 \%$ of advanced neuroblastomas (54).

More subtle changes at the sequence level affecting growth-controlling genes is also common in human tumors. Mutations can occur as a consequence of either defects in DNA repair or decreased fidelity during DNA replication. The components of these pathways are critical for maintenance of genome integrity and inherited mutations in the genes of DNA repair proteins and proteins that repair misreplicated DNA explains some inherited cancerprone syndromes (55).

\subsection{Angiogenesis}

Without the production of new blood vessels, tumor growth is limited to a volume of a few cubic millimeters by the distance that oxygen and other nutrients can diffuse through tissues. As tumor size increases, intratumoral $\mathrm{O}_{2}$ levels fall and the center of the mass becomes hypoxic, leading to up-regulation of the hypoxia inducible factor (HIF1). HIF1 is a heterodimeric transcription factor composed of a constitutively expressed HIF-1 beta subunit and an $\mathrm{O}_{2}$ regulatable HIF-1 alpha subunit (56). Under normoxic conditions, levels of HIF1 are kept low through the actions of the VHL tumor suppressor protein, which functions as a ubiquitin ligase that promotes degradation through a proteosome mediated pathway (57). An important transcriptional target of HIF1 is the VEGF growth factor, which in conjunction with other cytokines, induces neovascularization of tumors and allows them to grow beyond the size limitation imposed by oxygen diffusion. This increased production of proangiogenic factors and reduction of anti-angiogenic factors is known as the "angiogenic switch" and is a significant milestone in tumorigenesis that leads to the development of more lethal tumors.

Angiogenesis is the sprouting of capillaries from preexisting vessels during embryonic development and is almost absent in adult tis- sues with the exception of transient angiogenesis during the female reproductive cycle and wound healing, and the soluble factor that plays a critical role in promoting angiogenesis is vascular endothelial growth factor (VEGF) (58). VEGF was first implicated in angiogenesis when it was identified as a factor secreted by tumor cells, which caused normal blood vessels to become hyperpermeable (59). The following evidence supports a role for VEGF in tumor angiogenesis.

1. VEGF is present in almost every type of human tumor. It is especially high in concentration around tumor blood vessels and in hypoxic regions of the tumor.

2. VEGF receptors are found in blood vessels within or near tumors.

3. Monoclonal neutralizing antibodies for VEGF can suppress the growth of VEGFexpressing solid tumors in mice. These lack any effect in cell culture where angiogenesis is not needed.

Ferrara and Henzel (60) identified VEGF as a growth factor capable of inducing proliferation of endothelial cells but not fibroblasts or epithelial cells. Inhibition of one of the identified VEGF receptors, FLK1, inhibits the growth of a variety of solid tumors (61). Similarly, the injection of an antibody to VEGF strongly suppresses the growth of solid tumors of the subcutaneously implanted human fibrosarcoma cell line HT-1080 (62).

There are several forms of VEGF that seem to have different functions in angiogenesis. These isoforms are VEGF, VEGF-B, VEFG-C, and VEGF-D. VEGF-B is found in a variety of normal organs, particularly the heart and skeletal muscle. It can form heterodimers with VEGF and can affect the availability of VEGF for receptor binding (63). VEGF-D seems to be regulated by c-fos and is strongly expressed in the fetal lung (64). However, in the adult it is mainly expressed in skeletal muscle, heart, lung, and intestine. VEGF-D is also able to stimulate endothelial cell proliferation (65).

VEGF-C is about $30 \%$ homologous to VEGF. Unlike both VEGF and VEGF-B, VEGF-C does not bind to heparin. It is able to 
increase vascular permeability and stimulate the migration and proliferation of endothelial cells, although at a significantly higher concentration than VEGF. VEGF-C is expressed during embryonal development where lymphatics sprout from venous vessels (66). It is also present in adult tissues and may play a role in lymphatic endothelial differentiation. Flt-4, the receptor for VEGF-C, is expressed in angioblasts, veins, and lymphatics during embryogenesis, but it is mostly restricted to the lymphatic endothelium in adult tissues. Because of these expression patterns, VEGF-C and Flt-4 may be involved in lymphangiogenesis. This is the process of lymphatic generation. Lymphatic vasculature is very important because of its involvement in lymphatic drainage, immune function, inflammation, and tumor metastasis.

Other cytokines and growth factors also play an important role in promoting angiogenesis. Some of these act directly on endothelial cells, whereas others stimulate adjacent inflammatory cells. Some can cause migration but not division of endothelial cells such as angiotropin, macrophage-derived factor, and $\mathrm{TNF} \alpha$, or stimulate proliferation such as EGF, acidic and basic fibroblast growth factors (aFGF, bFGF), transforming growth factor $\beta$ (TGF $\beta$ ), and VEGF (67). Tumors secrete these factors, which stimulate endothelial migration, proliferation, proteolytic activity, and capillary morphogenesis (68).

Several angiogenic factors have been identified that can be secreted from tumors. Many of these are growth factors that are described as heparin-binding growth factors. Specifically, these include VEGF, FGFs, TGF- $\beta$, and the hepatocyte growth factor (HGF). The binding of these factors to heparin sulphate proteoglycans (HSPG) may be a mechanism for bringing the growth factors to the cell surface and presenting them to their appropriate receptors in the proper conformation. This facilitates the interaction between the growth factors and receptors. Studies have shown that tumor growth is adversely affected by agents that block angiogenesis (69) but is stimulated by factors that enhance angiogenesis (70).

Angiogenesis may be useful as a prognostic indicator. Tumor sections can be stained im- munohistochemically for angiogenic determinants, such as VEGF, to determine the density of vasculature within the tumor, and there is a strong correlation between high vessel density and poor prognosis (71). This correlation implies a relationship between angiogenesis and metastasis.

\section{CANCER-RELATED GENES}

\subsection{Oncogenes}

Oncogenes are derived from normal host genes, also called protooncogenes, that become dysregulated as a consequence of mutation. Oncogenes contribute to the transformation process by driving cell proliferation or reducing sensitivity to cell death. Historically, oncogenes were identified in four major ways: chromosomal translocation, gene amplification, RNA tumor viruses, and gene transfer experiments. Gene transfer experiments consist of transfecting DNA isolated from tumor cells into normal rodent cells (usually NIH3T3 cells) and observing any morphological changes. These morphological changes became the hallmarks for cell transformation, the process of becoming tumorigenic. As previously discussed, the characteristics of transformed cells are as follows: (1) the ability to form foci instead of a monolayer in tissue culture; (2) the ability to grow without adherence to a matrix, or "anchorage-independent growth"; and (3) the ability to form tumors when injected into immunologically compromised animals.

There are seven classes of oncogenes, classified by their location in the cell and their biochemical activity (Table 1.3). All of these oncogenes have different properties that can lead to cancer. The classes of oncogenes are growth factors, growth factor receptors, membrane-associated guanine nucleotide-binding proteins, serine-threonine protein kinases, cytoplasmic tyrosine kinases, nuclear proteins, and cytoplasmic proteins that affect cell survival.

4.1.1 Growth Factors and Growth Factor Receptors. Cell growth and proliferation are subject to regulation by external signals that are typically transmitted to the cell in the 
Table 1.3 Oncogenes

\begin{tabular}{|c|c|c|}
\hline Oncogenes & Protein Function & Neoplasm(s) \\
\hline \multicolumn{3}{|l|}{ Growth Factors } \\
\hline sis & Platelet-derived growth factor & fibrosarcoma \\
\hline int-2 & Fibroblast growth factor & breast \\
\hline trk & Nerve growth factor & neuroblastoma \\
\hline \multicolumn{3}{|c|}{ Growth Factor Receptors } \\
\hline erb-B1 & Epidermal growth factor receptor & $\begin{array}{l}\text { squamous cell } \\
\text { carcinoma }\end{array}$ \\
\hline erb-B2/HER2/neu & Heregulin & breast carcinoma \\
\hline $\mathrm{fms}$ & Hematopoietic colony stimulating factor & sarcoma \\
\hline ros & Insulin receptor & astrocytoma \\
\hline \multicolumn{3}{|l|}{ Tyrosine kinases } \\
\hline bcr-abl & Tyrosine kinase & $\begin{array}{l}\text { chronic myelogenous } \\
\text { leukemia }\end{array}$ \\
\hline src & Tyrosine kinase & colon \\
\hline lck & Tyrosine kinase & colon \\
\hline \multicolumn{3}{|c|}{ Serine-Threonine protein kinases } \\
\hline raf & Serine-threonine kinase & sarcoma \\
\hline $\operatorname{mos}$ & Serine-threonine kinase & sarcoma \\
\hline \multicolumn{3}{|c|}{ Guanine nucleotide binding proteins } \\
\hline H-ras & GTPase & $\begin{array}{l}\text { melanoma; lung, } \\
\text { pancreas }\end{array}$ \\
\hline K-ras & GTPase & $\begin{array}{l}\text { leukemias; colon, } \\
\text { lung, pancreas }\end{array}$ \\
\hline N-ras & GTPase & $\begin{array}{l}\text { carcinoma of the } \\
\text { genitourinary } \\
\text { tract and thyroid; } \\
\text { melanoma }\end{array}$ \\
\hline \multicolumn{3}{|l|}{ Cytoplasmic proteins } \\
\hline bcl-2 & Anti-apoptotic protein & $\begin{array}{l}\text { non-Hodgkin's B-cell } \\
\text { lymphoma }\end{array}$ \\
\hline \multicolumn{3}{|l|}{ Nuclear proteins } \\
\hline myc & Transcription factor & Burkitt's lymphoma \\
\hline jun & Transcription factor (AP-1) & osteosarcoma \\
\hline fos & Transcription factor (AP-1) & sarcoma \\
\hline
\end{tabular}

form of growth factors that bind to and activate specific growth factor receptors. Predictably, one class of oncogenes consists of growth factors that can stimulate tumor cell growth. In normal cells and tissues, growth factors are produced by one cell type that then act on another cell type. This is termed paracrine stimulation. However, many cancer cells secrete their own growth factors as well as express the cognate receptors that are stimulated by those factors. Because of this autocrine stimulation, cancer cells are less dependent on external sources of growth factors for proliferation and their growth is unregulated. Examples of oncogenic growth factors include v-sis, which is the viral homolog of the platelet-derived growth factor (PDGF) gene. PDGF stimulates the proliferation of cells derived from connective tissue such as fibroblasts, smooth muscle cells, and glial cells. Thus, tumors caused by excess stimulation by v-sis include fibrosarcomas and gliomas.

The receptors that interact with growth factors are also another large family of oncogenes. Growth factor receptors are composed of three domains: an extracellular domain that contains the ligand binding domain that interacts with the appropriate growth factor, a hydrophobic transmembrane domain, and a cytoplasmic domain that typically contains a kinase domain that can phosphorylate tyrosine residues in other proteins. Hence, these receptors are frequently referred to as receptor tyrosine kinases (RTK). It is this kinase 


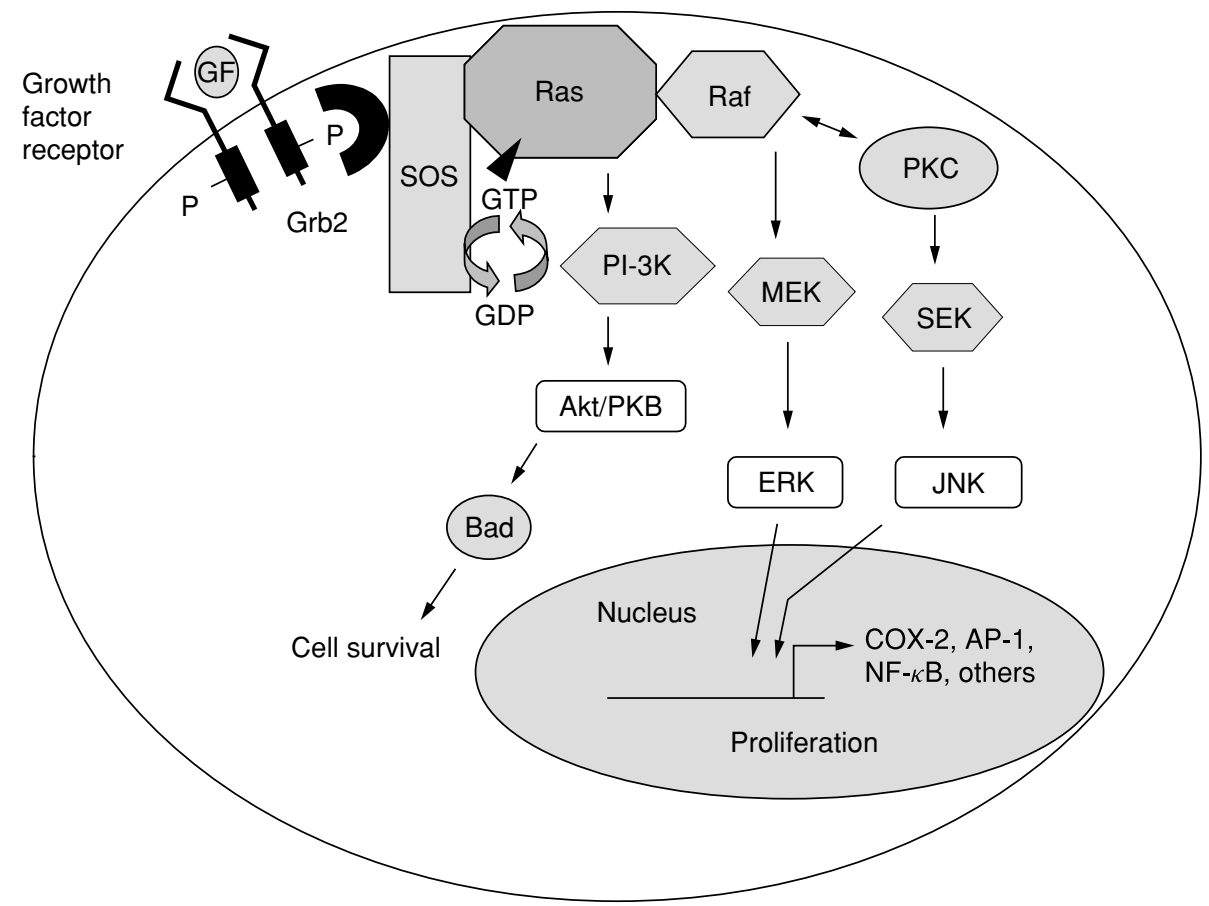

Figure 1.9. Ras signaling pathway. Growth factor (GF) binds to its receptor and initiates dimerization and autophosphorylation. Grb2 interacts with SOS, which activates ras by promoting the GTPbound form. Ras recruits Raf to the plasma membrane and initiates the Raf/MAPK signaling cascade. Protein kinase $\mathrm{C}$ also stimulates this pathway as well as another cascade of stress-activated kinases (SEK/JNK). Both of these signaling pathways promote cell proliferation by stimulating the transcription of genes like cyclooxygenase-2, activator protein-1, and nuclear factor- $\kappa \mathrm{B}$. Ras also signals phosphoinositol-3-kinase and Akt/protein kinase B for cell survival.

activity that is essential to the intracellular signaling that is stimulated by an activated receptor and in all oncogenic receptors mutations that lead to constitutive intracellular signaling promote unregulated cellular proliferation. RTKs can become oncogenically activated by mutations in each of the protein domains. Genetic mutations that result in the production of an epidermal growth factor receptor (EGFR) lacking the extracellular ligand binding domain leads to constitutive signaling. This oncogenic EGFR is known as erb-B1 (Fig. 1.9).

Normally, EGF binds to the extracellular portion of the EGFR and causes dimerization of the intracellular part of the receptor and association with adaptor proteins, Son of Sevenless (SOS), and growth factor receptor binding protein 2 (Grb 2). These proteins interact through src-homology (SH) do- mains SH2 and SH3, respectively. Through an unknown mechanism, the SOS-Grb 2 complex activates the oncogene ras. Ras induces an intracellular cascade of kinases to promote proliferation. These signaling cascades become constitutive when the extracellular portion of the EGFR becomes truncated, as in the case of erb-B1. Oncogenic activation of a related RTK, erb-B2, occurs as a consequence of a single point mutation that falls within the transmembrane region of this receptor (72). This mutated receptor is frequently found in breast cancers. Finally, mutations in the cytoplasmic kinase domain can also cause constitutive activity leading to constitutive signaling.

4.1.2 G Proteins. In many cases, signaling that is initiated by growth factors activating their receptors passes next to membrane asso- 
ciated guanine nucleotide-binding proteins, which when activated by mutation, constitute another class of oncogenes. The prototypical member of this family of oncogenes is the ras oncogene. There are three ras genes in this family of oncogenes, which include H-ras, Kras, and N-ras. These genes differ in their expression patterns in different tissues. All have been found to have point mutations in human cancers including liver, colon, skin, pancreatic, and lung cancers, which lead to constitutive signaling of genes involved in proliferation, cell survival, and remodeling of the actin cytoskeleton. Ras is a small molecular weight protein that is post-translationally modified by attachment of a farnasyl fatty acid moiety to the C-terminus. Because this post-translational modification is essential for activity of the ras oncogenes, this process has become a target for drug development aimed at interfering with ras activity (73).

Ras binds both guanosine $5^{\prime}$-triphosphate (GTP) and guanosine $5^{\prime}$-diphosphate (GDP) reversibly but is only in the activated state and capable of signaling when bound to GTP. The activated, GTP-bound form of ras signals a variety of mitogen-induced and stress-induced pathways, leading to transcription of genes necessary for cell growth and proliferation (74). Mitogens such as growth factors can activate ras through the epidermal growth factor receptor, and stress factors affecting ras include ultraviolet light, heat, and genotoxins. Guanine nucleotide exchange factors (GEFs) foster ras activation by promoting the exchange of GDP for GTP. In contrast, GTPase activating proteins (GAPs) suppress ras activity by promoting GTP hydrolysis by ras, resulting in the GDP-bound inactive form of ras (75). Importantly, because GAPs function to suppress cell proliferation, they can be thought of as tumor suppressors. Indeed, the neurofibromatosis gene, NF-1, is a GAP that acts as a tumor suppressor gene and can be inherited in a mutated and nonfunctional form giving rise to the Von Recklinghausen neurofibromatosis or neurofibromatosis type 1 cancer syndrome (76).

4.1.3 Serine/Threonine Kinases. Once activated, ras then transmits the growth signal to a third class of signaling molecules that is comprised of the serine/thereonine kinases. The best studied of these serine-threonine protein kinases is the raf oncogene, which is activated when it is recruited to the plasma membrane by ras (77). Raf then initiates a cascade of mitogen-induced protein kinases (MAPKs), which culminate in the nucleus with the activation of genes containing Elk-1 transcription factor binding sites. Raf can also directly activate protein kinase $\mathrm{C}$, which signals another set of kinases that phosphorylate the c-jun transcription factor.

Another ras effector gene is phosphoinositol 3-kinase (PI-3K), which initiates a signaling pathway for cell survival (78). PI-3K phosphorylates phosphatidalinositol $(3,4,5)$ triphosphate (PtdIns-3,4,5-P3), an important intracellular second messenger, thus aiding in the transmission of signals for proliferation to the nucleus. PI-3K consists of a catalytic subunit, $\mathrm{p} 110$, and a regulatory subunit, $\mathrm{p} 85$, and there are five isoforms of each subunit. PI-3K phosphorylates protein kinase B (Akt/PKB) on serine and threonine residues, which in turn modulate cellular processes like glycolysis and translation initiation and elongation. Akt/PKB also phosphorylates Bad, a pro-apoptotic protein. When Bad is phosphorylated, it is sequestered by the 14-3-3 protein, rendering it incapable of binding to the anti-apoptotic protein, bcl-2, and thus, results in apoptosis. Akt's phosphorylation of Bad serves to inhibit apoptosis and promote cell survival. This has deleterious effects for the organism because tumor cells are not permitted to undergo apoptosis and will survive and divide.

PI-3K has been linked to the development of colon cancer by a study showing that genetic inactivation of the p110gamma catalytic subunit of PI-3K leads to the development of invasive colorectal adenocarcinomas in mice (79). This pathway is not completely separate from the Raf/MAPK pathway, because Akt has been found to inhibit Raf activity. In fact, none of the aforementioned ras-mediated pathways operate completely independently; there are multiple examples of crosstalk between these signaling pathways.

4.1.4 Nonreceptor Tyrosine Kinases. In addition to growth factor receptors, other nonreceptor kinases target protein tyrosines for 
phosphorylation and can become activated as oncogenes. Indeed, one of the first oncogenes to be discovered, src, is the best characterized member of a family of proteins that have oncogenic potential. The src family of proteins are post-translationally modified by attachment of a myristate moiety to the $N$-terminus, which enables association with the plasma membrane. The members of the src family of proteins exhibit $75 \%$ homology at the amino acid level with the greatest degree of similarity found in three regions that have been labeled src homology domains 1, 2, and 3 (e.g., SH1, $\mathrm{SH} 2$, and SH3). The SH1 domain encompases the domain that contains kinase activity. The SH2 and SH3 domains are located adjacent to and $\mathrm{N}$-terminal to the kinase domain and function to promote protein/protein interactions. The SH2 domain binds with phosphorylated tyorsines, whereas the SH3 domain has affinity for the proline rich regions of proteins. Importantly, SH2 and SH3 domains are found in a large number of other proteins that are involved in intracellular signaling and that have oncogenic potential, and the structure of these domains are strongly conserved. Because $\mathrm{SH} 2$ and $\mathrm{SH} 3$ domains serve to potentiate signal transduction, they have also become targets for drug discovery programs aimed at disrupting the constitutive signaling generated by oncogenic activity (80).

A second oncogenic protein tyrosine kinase of considerable clinical importance is the Bcr$\mathrm{Abl}$ oncogene. The Bcr-Abl protein is a chimeric fusion protein formed by a reciprocal translocation involving chromosomes 9 and 22 . This chromosomal rearrangement is diagnostic for the hematopoietic malignancy, chronic myelogenous leukemia (CML), and the rearranged chromosome is known as the Philadelphia chromosome (81). The c-Abl gene maps to chromosome 9 and is a tyrosine kinase, whereas the BCR gene is now known to be GTPase-activating protein (GAP), which when fused to Abl results in an unregulated tyrosine kinase that functions to promote cellular proliferation (82). The bcr-abl protein interacts with SH2 domains on Grb 2 and relocates to the cytoskeleton and initiates ras signaling, a primary mode of tumorigenic potential. Bcr-abl reduces growth factor dependence, alters adhesion properties, and en- hances viability of CML cells. Consequently, the kinase activity of Bcr-Abl is a primary factor in stimulating the proliferation of $\mathrm{CML}$ cells, and therefore, has become the target for drug therapies aimed at combating this cancer. Indeed, the drug STI571 has been spectacularly successful in the clinic at causing remission of this disease (83).

4.1.5 Transcription Factors as Oncogenes. Another class of oncogenes are those that encode nuclear proteins, or transcription factors. Two examples of this class of oncogenes are AP-1 and c-myc. Activator protein-1 (AP-1) consists of Fos family members (c-fos, fos B, Fra 1, and Fra 2) and Jun family members (c-jun, jun B, and jun D), which can dimerize through a lucine rich protein/protein interaction domain known as the leucine zipper (84). Fos-jun heterodimers are the most active, junjun homodimers are weakly active, and fos-fos homodimers form only in extremely rare circumstances. These dimers bind to AP-1 DNA binding sites, which are also called the tumor promoter TPA-responsive element (TRE) or glucocorticoid response element (GRE). AP-1 can be activated by ionizing and ultraviolet irradiation, DNA damage, cytokines, and oxidative and cellular stresses (85).

AP-1 has several functions in the cell, including the promotion of cell proliferation and metastasis. AP-1 is a nuclear target for growth factor-induced signaling such as the aforementioned EGFR-mediated kinase cascade. AP-1-regulated genes include genes necessary for metastasis, and invasion like the MMPs matrilysin and stromelysin, as well as collagenase two proteins that aid in cell migration through connective tissue.

Deregulation of c-myc often occurs either by gene rearrangement or amplification in human cancers. Here again the hematologic cancers are instructive. In Burkitt's lymphoma, a frequent reciprocal translocation between chromosomes 8 and 14 leads to juxtapositioning of the myc gene adjacent to the Ig heavy chain promoter/enhancer complex, causing uncontrolled expression and production of the myc protein (86). Translocations between chromosomes 2 and 8 and between 8 and 22 also occur and involve other immunoglobulin 
producing gene complexes. In all cases the overproduction of myc results in uncontrolled cell proliferation.

Myc overexpression also occurs in solid tumors, but is usually the result of gene amplification (87). The oncogenic potential of c-myc has been studied most widely as it pertains to the development of colon cancer. Both c-myc RNA and protein are overexpressed at the early and late stages of colorectal tumorigenesis. The cause for this overexpression is still unknown, but a strong possibility may be that it is regulated by the APC pathway. The APC tumor suppressor gene is mutated in approximately $90 \%$ of colorectal tumors, both sporadic and inherited forms. APC will be discussed in detail in the "tumor suppressor" section of this chapter.

He et al. (88) found that when APC expression was induced in stably transfected $\mathrm{APC}^{-/-}$ colon cancer cells (using an inducible metallothionine promoter linked to the APC gene), they observed a time-dependent decrease in the RNA and protein levels of c-myc. This suggested that c-myc may be regulated by APC through the $\beta$-catenin/T-cell factor-4 (Tcf-4) transcription complex. They also showed that constitutive expression of mutant $\beta$-catenin (mutated so that it is insensitive to APC) in embryonic kidney cells resulted in a significant increase of c-myc expression. Analysis of the c-myc gene revealed two possible Tcf- 4 transcription factor binding sites. Mobility shift assays demonstrated that Tcf- 4 binds to both of the potential binding sites, leading to c-myc gene expression. Expression of dominant-negative Tcf-4 in HCT116 (mutant $\beta$-catenin) or SW480 (mutant APC) reduced endogenous levels of c-myc (88).

The c-myc protein binds to DNA through its basic, helix-loop-helix/leucine zipper domain. Many target genes of c-myc have been identified that are involved in cell growth and proliferation. Some of these genes include ODC, cell cycle genes cyclins A, E, and D1, as well as cdc2, cdc25, eukaryotic initiation factor $4 \mathrm{E}$ (eIF4E), heat shock protein 70 (hsp70), and dihydrofolate reductase. Overexpression of c-myc may therefore affect the transcription of these genes, thus promoting hyperproliferation and tumorigenesis.
C-myc is also found to be amplified in promyelocytic leukemia and small cell lung cancer. The c-myc protein requires dimerization with Max to initiate transcription, and Max homodimers serve as an antagonist of transcription. The formation of Mad-Max dimers also suppresses transcription. It is also interesting to note that the full oncogenic potential of c-myc relies on cooperation with other oncogenes like ras.

4.1.6 Cytoplasmic Proteins. Bcl-2 is an example of a cytoplasmic oncogene that has antiapoptotic potential. Increased production of bcl-2 protein is seen in a variety of tumor types and is associated with poor prognosis in carcinomas of the colon and prostate. The function of bcl-2 is explained in detail in the "apoptosis" section of this chapter.

\subsection{Tumor Suppressor Genes}

In contrast to oncogenes, tumor suppressor genes can directly or indirectly inhibit cell growth. Those that directly inhibit cell growth or promote cell death are known as "gatekeepers" and their activity is rate limiting for tumor cell proliferation. Hence, both copies of gatekeeper tumor suppressors must be functionally eliminated for tumors to develop. This characteristic requirement is a hallmark of tumor suppressor genes. Mutations that inactivate one allele of a gatekeeper gene can be inherited through the germline, which in conjunction with somatic mutation of the remaining allele, leads to cancer predisposition syndromes. For example, mutations of the APC gene lead to colon tumors. Somatic mutations that inactivate both gatekeeper alleles occur in sporadic tumors.

Those tumor suppressor genes that do not directly suppress proliferation, but function to promote genetic stability are known as "caretakers." Caretakers function in DNA repair pathways and elimination of caretakers results in increased mutation rates. Because numerous mutations are required for the full development of a tumor, elimination of caretaker tumor suppressors can greatly accelerate tumor progression. As with gatekeepers, mutations can be inherited through the germline and can give rise to cancer predisposition syndromes. An example of a caretaker gene is 
Table 1.4 Tumor Suppressor Genes

\begin{tabular}{lll}
\hline TS Gene & \multicolumn{1}{c}{ Protein Function } & \multicolumn{1}{c}{ Neoplasm(s) } \\
\hline APC & cell adhesion & colon \\
BRCA 1 & transcription factor & breast and ovary \\
bRCA 2 & DNA repair & melanoma \\
CDK4 & cyclin D kinase & HNPCC ${ }^{a}$ \\
hMLH1 & DNA mismatch repair & HNPCC \\
hMSH2 & DNA mismatch repair & HNPCC \\
hPMS1 & DNA mismatch repair & HNPCC \\
hPMS2 & DNA mismatch repair & thyroid \\
MEN1 ${ }^{b}$ & Ret receptor & neuroblastoma \\
NF1 & GTPase & colon, lung, breast \\
p53 & transcription factor & retinoblastoma \\
Rb & cell cycle checkpoint & childhood kidney \\
WT-1 & transcription factor & \\
\hline \multicolumn{2}{c}{${ }^{a}$ Hereditary non-polyposis colon cancer. } & \\
${ }^{b}$ Multiple endocrine neoplasia. &
\end{tabular}

MSH2, which functions in the mismatch DNA repair system, and inherited mutations in this gene gives rise to the hereditary nonpolyposis colorectal cancer (HNPCC) syndrome (Table 1.4).

4.2.1 Retinoblastoma. Retinoblastoma $(\mathrm{Rb})$ is a childhood disease. There are both hereditary and nonhereditary forms of the disease. Approximately $60 \%$ of patients develop the nonhereditary form and present with unilateral tumor development (one eye is affected). About $40 \%$ of $\mathrm{Rb}$ patients have a germline mutation that predisposes them to the disease. Of these patients, $80 \%$ of the cases are bilateral, $15 \%$ are unilateral, and about $5 \%$ are asymptomatic carriers of the mutation. It is an autosomal dominant trait and is caused by mutations in the Rb gene on chromosome 13. Abnormalities of the $\mathrm{Rb}$ gene have also been seen in breast, lung, and bladder cancers.

Retinoblastoma arises when both of the $\mathrm{Rb}$ alleles are inactivated. In the inherited form, one parental chromosome carries a defect (most often a deletion) at the Rb locus. A second somatic mutation must occur in retinal cells to cause the loss of the other (normal) $\mathrm{Rb}$ allele. In sporadic cases, both of the parental chromosomes are normal and both Rb alleles are lost as a result of individual somatic mutations. Approximately one-half of all retinoblastoma cases show a deletion at the $\mathrm{Rb}$ locus. The locus is very large, $>150 \mathrm{~kb}$, and there- fore may be more susceptible to mutations because it is such a large target.

$\mathrm{Rb}$ was the first human tumor suppressor gene identified, and the loss of RB protein function leads to malignancy. The RB protein is localized in the nucleus where it is either phosphorylated or unphosphorylated (Fig. 1.10). When unphosphorylated, RB binds to the E2F transcription factor and prevents transcriptional activation of E2F target genes. This normally occurs during the $\mathrm{M}$ and early G1 phases of the cell cycle. During late G1, S, and G2 phases, RB is phosphorylated. When phosphorylated, RB can no longer bind to $\mathrm{E} 2 \mathrm{~F}$. This release from inhibition allows E2F to activate transcription of S-phase genes and the cell cycle progresses. When loss of RB function occurs because of various mutations in the $\mathrm{Rb}$ gene, the cell cycle becomes deregulated, and uncontrolled cell division results. This is because RB can no longer bind to and inhibit E2F. Therefore, the transcription factor can constitutively activate its target genes. This ultimately leads to tumor development (89).

4.2.2 p53. The p53 tumor suppressor is activated in response to a wide variety of cellular stresses including DNA damage, ribonucleotide depletion, redox modulation, hypoxia, changes in cell adhesion, and the stresses created by activated oncogenes. The p53 protein functions as a transcription factor that, when 
M-phase and early $G_{1} \quad$ Late $G_{1}, S$, and $G_{2}$ phases

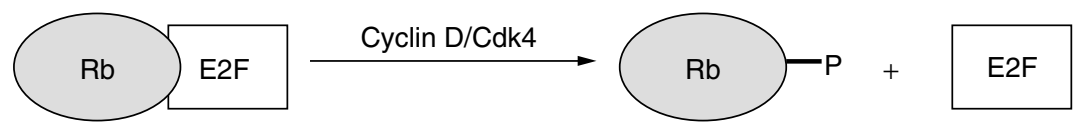

$\mathrm{Rb}$ sequesters and inhibits the function of E2F

Phosphorylated $\mathrm{Rb}$ releases E2F

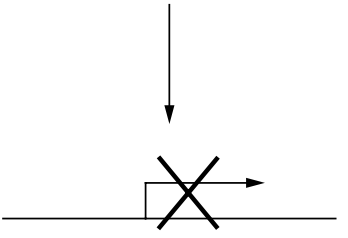

Transcription of E2F target genes is inhibited which is then free to bind to its target genes

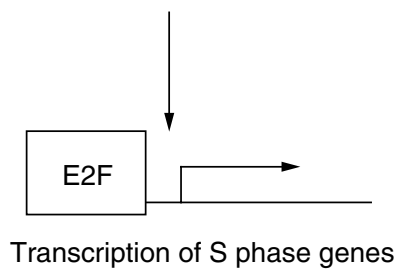

$\downarrow$

Cell cycle progression

Figure 1.10. Cell cycle control by the retinoblastoma $(\mathrm{Rb})$ tumor suppressor protein. Unphosphorylated $\mathrm{Rb}$ negatively regulates progression into the $\mathrm{S}$ phase of the cell cycle by binding to the E2F transcription factor. In this complex, E2F is prevented from activating transcription of its target genes. During late G1, Rb is phosphorylated by the cyclin D/Cdk4 complex and can no longer sequester the E2F transcription factor. E2F then binds to its target S-phase genes, promoting their transcription and allowing the cell cycle to progress.

activated, stimulates the expression of a variety of effectors that bring about growth arrest, promote DNA repair, and stimulate cell death by apoptosis. Collectively these activities act to maintain genomic stability. Elimination of p53 function leads to increased rates of mutation and resistance to apoptosis. Thus, p53 sits at the crux of several biochemical pathways that are disrupted during tumorigenesis. Consequently, mutations in p53 are the most frequent genetic change encountered in human cancers.

p53 activity can be eliminated by at least three mechanisms. The most common event that leads to a nonfunctioning protein is mutation of the p53 gene, which occurs in about $50 \%$ of all sporadic human tumors. As with other tumor suppressors, mutations can occur in somatic tissues or can be inherited through the germline. Inherited p53 mutations give rise to the Li-Fraumeni syndrome in which affected individuals develop bone or soft-tissue sarcomas at an early age. In addition, nonmutational inactivation of $\mathrm{p} 53$ can occur in the presence of viral transforming antigens. For example, the simian virus 40 (SV40) large T antigen binds with p53 and forms an inactive complex, whereas the papilloma virus E6 protein eliminates $\mathrm{p} 53$ by causing premature degradation of the protein through the $26 \mathrm{~S}$ proteosome. Clearly, the interaction between these transforming antigens and p53 is critical because viral antigens that are incapable of doing so lose their transforming ability. The third mechanism by which p53 activity can be eliminated is by cytoplasmic sequestration. p53 that is unable to enter the nucleus cannot induce the expression of downstream effector genes that are necessary for mounting the cellular response to genotoxic stress.

Activation of $\mathrm{p} 53$ by ionizing radiation (IR) and other DNA damaging agents involves a complex set of interdependent post-translational modifications that control protein/ protein associations, protein turnover, and subcellular localization. Under normal conditions, levels of p53 are kept minimal by ubiquitination and proteosome-mediated degradation that contributes to the short half-life (3-20 $\mathrm{min})$ of the protein. A key player in 
maintenance of low p53 levels is mdm2. Mdm2 performs this function by interacting with $\mathrm{p} 53$ at its $\mathrm{N}$-terminus and targets p53 for proteosome-mediated degradation. Exposure to IR results in a series of, as yet incompletely understood, phosphorylation events in p53's $N$ terminus, which inhibits Mdm2 binding and results in increased intracellular p53 levels. $\mathrm{Mdm} 2$ and p53 function in a feedback loop where activated p53 stimulates the expression of $\mathrm{Mdm} 2$, which in turn reduces the duration of up-regulated p53 activity. Overexpression of $\mathrm{Mdm} 2$ suppresses $\mathrm{p} 53$ by preventing its accumulation in response to DNA damage. Consequently, Mdm2 can function as an oncogene that acts in much the same way as the papilloma virus E6 protein. In fact, $\mathrm{Mdm} 2$ is overexpressed in some tumors such as osteosarcomas.

The p53 protein can be divided into three structural domains that are essential for tumor suppressor function. The $\mathrm{N}$-terminus consists of a transactivation domain that interacts with various basal transcription factors and cellular and viral proteins that modify its function. The central domain contains the sequence specific DNA binding activity. Most mutations in the p53 gene fall within this domain that disrupts the structure of this region and eliminates DNA binding activity. The importance of DNA binding is emphasized by the fact that mutations accumulate preferentially in several amino acids that are involved in directly contacting DNA. The Cterminus has been assigned several activities including non-specific DNA binding activity, acting as a binding site for other p53 molecules, and formation of p53 tetramers, and functioning as a pseudosubstrate domain that occludes the central DNA binding domain.

Because of the frequency with which p53 is mutated in human tumors, much attention has been directed at developing methods that compensate for the loss of wild-type function or can reactivate wild-type p53 activity in mutant proteins. For example, strategies aimed at manipulating the conformation of mutant proteins have led to the discovery that peptides that bind the $\mathrm{C}$-terminus can reactivate wild-type function in some mutant proteins. Strategies that take advantage of the vast knowledge of virus biology and p53 function have lead to the construction of viral vectors that can introduce a wild-type p53 into tumor cells. One clever approach takes advantage of the fact that adenoviruses with a defective E1B 55K protein cannot replicate in normal human cells. For adenoviruses to replicate in cells, they must suppress p53 activity, which functions to limit the uncontrolled DNA replication that is required for production of virus genomes. However, adenoviruses with a defective E1B 55K gene can replicate in tumor cells because they lack a functional p53. Thus, these viruses kill tumor cells specifically and leave normal cells untouched (90).

4.2.3 Adenomatous Polyposis Coli. The tumor suppressor gene, APC, is mutated in almost $90 \%$ of human colon cancers and $30 \%$ of melanoma skin cancers. The inherited loss of APC tumor suppressor function results in familial adenomatous polyposis (FAP). FAP patients develop hundreds to thousands of colon polyps by their second or third decade of life. By age 40, one or two of these polyps usually develops into a malignant carcinoma, and thus, many of these patients choose to have a colectomy to prevent carcinoma formation. Mutations in APC occur in the majority of sporadic colon cancers too.

APC mutation is an early event in colon carcinogenesis, and is therefore, considered to be the initiating event. Loss of this tumor suppressor gene results in constitutive activity of the oncogene, c-myc, through an intricate collection of protein-protein interactions. Briefly, APC interacts with other cellular proteins, including the oncogene $\beta$-catenin (Fig. 1.11). Axin, an inhibitor of Wnt signaling, forms a complex with glycogen synthase kinase $3 \beta$ $($ GSK3 $\beta), \beta$-catenin, and APC and stimulates the phosphorylation of $\beta$-catenin by GSK3 $\beta$, thus causing down-regulation of gene expression mediated by $\beta$-catenin/Tcf complexes (91). Dissociation of the axin, GSK3 $\beta$, $\beta$-catenin, and APC complex by Wnt family members leads to stabilization of $\beta$-catenin and activation of Tcf-mediated transcription. Deletion of APC alleles, or mutations causing truncations in APC that influence its interaction with $\beta$-catenin, also leads to stabilization of $\beta$-catenin and activation of Tcf/lymphoid enhancing factor (Lef)-dependent gene expression. At 
least one member of the Tcf/Lef family of transcriptional activators has been identified in human colon mucosal tissues. This member is termed hTcf-4. Several target genes for Tcf/ Lef have been identified, including the c-myc oncogene. Overexpression of wild-type APC cDNA in human colon tumor-derived HT29 cells, which lack a normal APC allele, causes down-regulation of c-myc transcription. Upregulation of $\beta$-catenin in cells expressing normal APC alleles causes increased c-myc expression. Thus, wild-type APC serves to suppress c-myc expression. Either normal regulation by Wnt signaling, or mutation/deletion of APC, activates c-myc expression. In many colon cancers, the APC gene is not necessarily mutated, but the mutation in the pathway is found in $\beta$-catenin, which yields the same constitutive signaling from the pathway.

APC regulates the rates of proliferation and apoptosis by several different mechanisms. Wild-type APC is important for cytoskeletal integrity, cellular adhesion, and Wnt signaling. APC plays a role in the G1/S transition of the cell cycle by modulating expression levels of c-myc and cyclin D1. Wildtype, full length APC is also important in maintaining intestinal cell migration up the crypt and inducing apoptosis.

4.2.4 Phosphatase and Tensin Homologue. The phosphatase and tensin homologue (PTEN) or mutated in multiple advanced cancers (MMAC) tumor suppressor gene was first identified in the most aggressive form of brain cancer, glioblastoma multiform. PTEN also is mutated in a significant fraction of endometrial carcinomas, prostate carcinomas, and melanomas. PTEN's primary functions as a tumor suppressor gene are the induction of cell cycle arrest and apoptosis (92). PTEN is a dual-specificity phosphatase, meaning that it can dephosphorylate proteins on serine, threonine, and tyrosine residues. It specifically dephosphorylates PtdIns-3,4,5-P3, antagonizing the function of PI-3K. PTEN, therefore, acts as a negative regulator of Akt activation. Because Akt can suppress apoptosis by the phosphorylation of the pro-apoptotic protein Bad, PTEN can induce apoptosis of mutated or stressed cells to prevent tumor formation.
In addition to modulating apoptosis, PTEN plays a role in angiogenesis. PTEN suppresses the PI-3K-mediated induction of blood vessel growth factors like VEGF. EGF and ras act to induce genes regulated by the hypoxia-induced factor (HIF-1), which is blocked by PTEN activity. PTEN also inhibits cell migration and formation of focal adhesions when overexpressed in glioblastoma cell lines, suggesting that it helps to inhibit metastasis as well (93).

PTEN also inhibits signaling from the insulin growth factor receptor (IGF-R). Insulin receptor substrates-1/2 (IRS-1/2) are docking proteins that are recruited by the insulin receptor and in turn, recruit PI-3K for signal transduction. The tumor suppressor function of PTEN helps to prevent aberrant signaling when insulin binds to its cell surface receptor.

4.2.5 Transforming Growth Factor- $\beta$. Transforming growth factor- $\beta$ (TGF- $\beta$ ) is growth stimulatory in endothelial cells but growth inhibitory for epithelial cells, rendering it a tumor suppressor gene in epithelialderived cancers. The TGF- $\beta$ family of growth factors binds to two unique receptors, TGF- $\beta$ type I and type II. Tumor cells lose their response to the growth factor and mutations in the receptors also contribute to carcinogenesis. Ligand binding to the TGF- $\beta$ receptors causes intracellular signaling of other tumor suppressor genes, the Smad proteins. Smads help to initiate TGF- $\beta$-mediated gene transcription.

TGF- $\beta 1$ normally inhibits growth of human colonic cells, but in the process of becoming tumorigenic, these cells obtain a decreased response to the growth inhibitory actions of TGF- $\beta$. TGF- $\beta 1$ also serves as an inhibitor of immune surveillance (94). TGF- $\beta 1$ indirectly suppresses the function of the immune system by inhibiting the production of TNF- $\alpha$ and by inhibiting the expression of class II major histocompatibility complex (MHC) molecules. TGF- $\beta 1$ also promotes tumor progression by modulating processes necessary for metastasis such as degradation of the extracellular matrix, tumor cell invasion and VEGF-mediated angiogenesis.

The TGF- $\beta$ receptor type II (T $\beta$ RII) is mutated in association with microsatellite instability in most colorectal carcinomas (95). As 

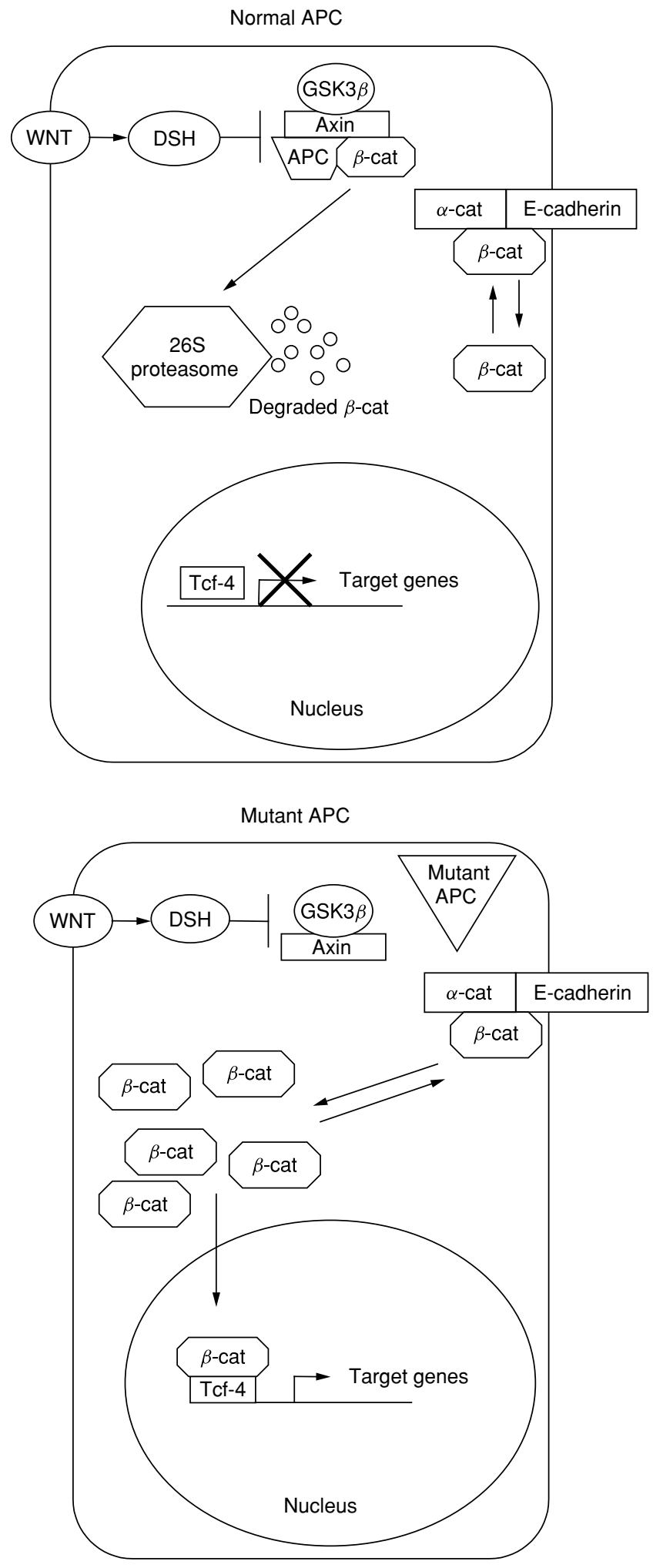

Figure 1.11. The APC signaling pathway. In a normal cell, APC forms a complex with axin, GSK- $3 \beta$, and $\beta$-catenin. This promotes proteosomal degradation of $\beta$-catenin and prevents transcription of $\beta$-catenin/Tcf 4 target genes. When APC is mutated, the multi-protein complex cannot form and $\beta$-catenin is not degraded. Instead, $\beta$-catenin is translocated to the nucleus where it binds with Tcf4 to activate transcription of various target genes. Some of the known target genes, like c-myc and cyclin D1, play important roles in cell proliferation. 
many as $25 \%$ of colon cancers have missense mutations in the kinase domain of this receptor. A missense mutation in the kinase domain of the T $\beta R I$ has also been identified in metastatic breast cancer. It was also found that the expression of the TGF- $\beta 2$ receptor is suppressed in metastatic oral squamous cell carcinomas compared with the primary tumor.

4.2.6 Heritable Cancer Syndromes. There are several known inheritable DNA repair-deficiency diseases. Four of these are autosomal recessive diseases and include Xeroderma pigmentosum (XP), ataxia telangiectasia (AT), Fanconi's anemia (FA), and Bloom's syndrome (BS). XP patients are very sensitive to UV light and have increased predisposition to skin cancer (approximately 1000-fold) (96). AT patients exhibit a high incidence of lymphomas, and the incidence of lymphoma development is also increased for both FA and BS patients.

HNPCC arises due to a defect in mismatch repair (MMR). The incidence of HNPCC is often quoted as $1-10 \%$ of all colorectal cancers (97). It is an autosomal dominant disease and results in early onset of colorectal adenocarcinoma. Many of these tumors demonstrate microsatellite instability and are termed replication error positive (RER+). Endometrial and ovarian cancers are the second and third most common cancers in families with the HNPCC gene defect.

The most common mutations in HNPCC are in the mismatch repair genes, MSH2 and MLH1 (>80\%) (98). The mismatch repair system normally corrects errors of $1-5$ base pairs made during replication. Therefore, defects in this system result in many errors and create microsatellite instability. A suggested model for HNPCC development starts with a mutation in the MMR genes followed by another mutation in a gene such as APC. These two events lead to cellular hyperproliferation. Next, a mutation occurs leading to the inactivation of the wild-type allele of the MMR gene. Because of this MMR defect, mutations in other genes involved in tumor progression, such as deleted in colon cancer (DCC), p53, and K-ras, occur.

A variety of genes are responsible for the different inherited forms of GI cancers. For example, individuals with FAP, bearing germline mutations/deletions in the APC tumor suppressor gene, account for only a small fraction of colon cancers in the United States $(<1 \%)$. However, the majority of sporadic colon adenomas have also been found to contain single allele alterations in APC and exhibit altered signaling of $\beta$-catenin, a protein negatively regulated by APC. Altered $\beta$-catenin signaling is inferred from immunohistochemical studies demonstrating that $\beta$-catenin is translocated to the nucleus in the majority of epithelial cells in adenomas, whereas $\beta$-catenin is generally seen associated with the cell membrane in normal colonic epithelia. These data suggest that the process of adenoma development selects for alterations in APC.

\section{INTERVENTIONS}

\subsection{Prevention Strategies}

Numerous investigators are taking advantage of our current knowledge of the mechanisms of carcinogenesis in human epithelial tissues to develop strategies for disrupting this process and thereby preventing cancer. As discussed earlier in this chapter, carcinogenesis proceeds by a multistep process, in which normal epithelial tissues acquire aberrant growth properties. These neoplastic cells progress to become invasive cancer. Historically, cancer therapy has addressed only the last phase of this process. Prevention strategies are now focusing on pre-invasive, yet neoplastic lesions.

Prevention strategies generally influence one or more of five processes in carcinogenesis (99). One strategy has been to inhibit carcinogen-induced initiation events, which lead to DNA damage. An important caveat to this strategy is that the intervention must be present at the time of carcinogen exposure to be effective. Once irreversible DNA damage has occurred, this type of strategy is ineffective in preventing cancer development.

Another strategy has been to inhibit initiated cell proliferation associated with the promotion stage of carcinogenesis. An advantage to this type of strategy is that interventions affecting promotion are effective after initiating events have occurred. Because humans are exposed to carcinogenic agents (e.g., chem- 
icals in tobacco smoke, automobile exhaust) throughout their lifetimes, cancer preventive agents that work after initiating events have occurred are desirable. Two strategies of decreasing cell proliferation are induction of apoptosis, or cell death, and differentiation, which may or may not be associated with apoptosis. Induction of either differentiation or apoptosis will stabilize or decrease, respectively, overall cell number in a tissue.

A final strategy for preventing cancer is to inhibit development of the invasive phenotype in benign, or non-invasive, precancers that occur during the process of epithelial carcinogenesis.

Investigators are beginning to address the possibility that the efficacy of cancer prevention strategies may depend on both genetic and environmental risk factors affecting specific individuals. Mutations/deletion of the APC tumor suppressor gene, discussed earlier, causes intestinal tumor formation in both rodents and humans. Increasing levels of dietary fat increases intestinal tumor number in rodent models (100). However, mice with a defective APC gene develop tumors even on lowfat diets. Thus, dietary modifications may reduce carcinogenesis in individuals without, but may be ineffective in individuals with, certain genetic risk factors for specific cancers. Recently, several large randomized studies conducted in the United States have failed to detect any protective effect of dietary fiber increase or dietary fat decrease on colon polyp recurrence (101).

\subsection{Targets}

Targets for cancer prevention strategies can be either biochemical species produced by the action of a physical or chemical carcinogen or an enzyme/protein aberrantly expressed as a consequence of a genetic or environmental risk factor (the latter would include exposure to environmental carcinogens). In developing mechanism-based prevention or treatment strategies based on specific "targets," it is crucial to establish that the "target" is present in the target tissue (or cells influencing target tissue behaviors), causatively involved in the disease process in question and modulated by the intervention.
5.2.1 Biochemical Targets. One example of a biochemical target produced by carcinogens is reactive oxygen species (ROS). Ionizing radiation is a complete carcinogen and produces much of its DNA damage through ROS (102). Several strategies for preventing ROS-induced cell damage have been developed. The aminothiol, amifostine, inhibits radiation-induced DNA damage to a large degree by scavenging free radicals produced by ionizing radiation. Amifostine and its derivatives suppress ionizing radiation-induced transformation and carcinogenesis. Antioxidants, including protein and non-protein sulfhydrals and certain vitamins, are effective modulators of ROS produced by physical and chemical carcinogens (103). Antioxidants are effective in inhibiting carcinogenesis in some experimental models, but their roles in human cancer prevention remains unclear. At least some agents with antioxidant activity may increase carcinogenesis in some tissues. Heavy smokers receiving combinations of beta-carotene and vitamin A had excess lung cancer incidence and mortality, compared with control groups not receiving this intervention (104).

Other examples of biochemical targets are the dihydroxy bile acids, which are tumor promoters of colon cancer (105). Both genetic and dietary factors are known to influence intestinal luminal levels of these steroid-like molecules, whose levels are associated with colon cancer risk. Calcium reduces intestinal luminal bile acid levels by several possible mechanisms, and dietary calcium supplementation is associated with a small $(\sim 25 \%)$, but statistically significant, reduction in colon polyp recurrence (106). This result requires cautious evaluation, however, as similar levels of calcium supplementation have been associated with increased risk of prostate cancer (107). This example and the result of the beta-carotene study mentioned above underscore the tissue-specific differences in carcinogenesis and the difficulties of applying common dietary components (e.g., calcium, antioxidants) in cancer prevention strategies in humans.

5.2.2 Cyclooxygenase-2 and Cancer. Cyclooxygenase (COX) enzymes catalyze prostaglandins from arachidonic acid. Prostaglandins play a role in biological processes 


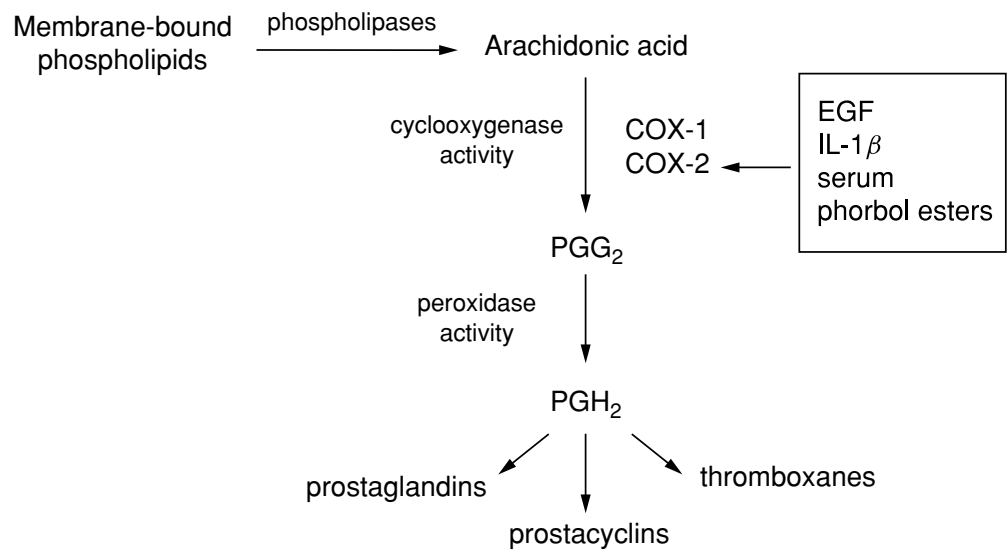

Figure 1.12. Cyclooxygenases catalyze prostaglandins from arachidonic acid. COX-2 is inducible by a variety of stimuli including growth factors, cytokines, and tumor promoters. PGH2 forms three classes of eicosanoids: prostaglandins, prostacyclins, and thromboxanes. Adapted from C. S. Williams and R. N. DuBois, Am. J. Physiol., 270, G393 (1996).

including blood clotting, ovulation, bone metabolism, nerve growth and development, and immune responses (108). There are two COX isoforms, COX-1 and COX-2. COX-1 is constitutively expressed in most cell types and is necessary for homeostasis of colonic epithelium and platelet aggregation. COX-2, on the other hand, is inducible by a variety of stimuli including growth factors, stress conditions, and cytokines (Fig. 1.12).

Several studies have implicated COX-2 in carcinogenesis. COX-2 protein levels, and therefore, prostaglandin production, are upregulated in many tumor types, including pancreatic, gastric, breast, skin, and colon cancers. Several lines of evidence suggest that overexpression of COX-2 plays an important role in colonic polyp formation and cancer progression. COX-2 modulates metastatic potential by inducing MMPs, which can be directly inhibited by COX-2 inhibitors. In addition, cells overexpressing COX-2 secrete increased levels of angiogenic factors like VEGF and bFGF. COX-2 not only aids in invasion but also inhibits apoptosis by up-regulating Bcl-2.

COX-2 has come under intensive study as a target for colon cancer prevention. Multiple studies have illustrated that COX-2 selective inhibitors suppress tumorigenesis in multiple intestinal neoplasia (Min) mice. COX-2 inhibitors also inhibit tumor cell growth in immunocompromised mice (109). The same phe- nomena has been illustrated in human chemoprevention trials. Recent studies have linked prolonged use of nonsteroidal anti-inflammatory drugs (NSAIDs) to decreased colon cancer risk and mortality. NSAIDs inhibit the cyclooxygenase enzymes, and new COX-2 selective agents are gaining popularity in the treatment of inflammation. NSAIDs that inhibit both COX-1 and COX-2 have been associated with reduced cancer risk in several large epidemiology studies. Whether inhibition of COX-1 and/or COX-2 is the optimal strategy for reducing risks of certain cancers is unknown.

Because COX-2 is induced in certain neoplastic tissues, the molecular regulation of its expression is being studied in a variety of experimental models. Human and rodent cell lines expressing various levels of COX-2 are being studied for genetic modifications that lead to the dysregulation of COX-2. COX-2 regulation occurs both transcriptionally and translationally, and this regulation differs depending on the species studied and the mutational status of the cell lines.

Signaling pathways leading to modulation of COX-2 expression are also being investigated. Both oncogenes and tumor suppressor genes have been shown to modulate COX-2 in cell model systems. The activation of the $\mathrm{H}$-ras and K-ras oncogenes leads to induction of COX-2 expression in colon cancer cells. This 
induction is mediated by the stabilization of COX-2 mRNA. Wild-type, full-length APC suppresses COX-2 expression, suggesting that normal activity of this tumor suppressor gene may prevent cancer by inhibiting expression of cancer-promoting genes like COX-2. APC down-regulates COX-2 protein without affecting COX-2 mRNA levels. Thus, both ras and APC regulate COX-2 expression by post-transcriptional mechanisms. TGF- $\beta 1$ is another tumor suppressor gene that influences expression of COX-2. TGF- $\beta 1$-mediated transformation of rodent intestinal epithelial cells causes a significant induction of COX-2 protein expression. TGF- $\beta 1$ synergistically enhances ras-induced COX-2 expression by stabilizing COX-2 mRNA. COX-2 expression is also influenced by the PI-3K pathway. Pharmacological inhibition of PI-3K or downstream PKB/Akt, as well as dominant-negative forms of Akt dramatically reduce COX-2 protein levels.

5.2.3 Other Targets. Technologies such as DNA microarrays are identifying genes that are aberrantly up-regulated in human intraepithelial neoplasia (IEN). As discussed earlier, ODC, the first enzyme in polyamine synthesis, is up-regulated in a variety of IEN as a consequence of specific genetic alterations. Difluoromethylornithine (DFMO), an enzyme activated irreversible inhibitor of ODC, is a potent suppressor of several experimental models of epithelial carcinogenesis and is being evaluated in human cancer prevention trials (110). Pathways signaling cell behaviors are also activated in specific cancers. A number of agents, including NSAIDs and components of green and black teas, have been shown to inhibit certain signaling pathways in cell-type and tissue-specific manners.

\subsection{Therapy}

5.3.1 Importance of Studying Gene Expression. Cancer, among other diseases, is caused by the deregulation of gene expression. Some genes are overexpressed, producing abundant supplies of their gene products, whereas other crucial genes are suppressed or even deleted. The expression levels of genes associated with cancer influence processes such as cell proliferation, apoptosis, and invasion. Genes in- volved in growth, for example, are often overexpressed in tumor tissues compared with normal adjacent tissue from the same organ. It is imperative to elucidate which genes are overexpressed or down-regulated in tumors because these genes represent critical therapeutic targets.

Researchers today generally concentrate on a few particular genes and study their regulation, expression, and downstream signaling using conventional molecular biology tools. With the onslaught of new genome data, and the development of the GeneChip, scientists are now able to study the expression levels of numerous genes simultaneously. The ability to analyze global profiles of gene expression in normal tissue compared with tumor tissue can help reveal how gene expression affects the overall process of carcinogenesis.

5.3.2 cDNA Microarray Technology. cDNA microarray technology is based on the simple concept of DNA base pairing. cDNA from tumor samples hybridize with the complementary DNA sequences on the chip. The DNA sequences are the target genes that will be studied for expression levels in particular tissues. These sequences, or probes, can be in the form of known oligos, DNA encoding the full-length gene, open reading frames (ORFs), or sometimes even the entire genome of an organism like Saccharomyces cerevisiae. Genes can be chosen by their proximity to each other on a chromosome or their similar functions. cDNA probes are then spotted onto a glass slide or computer chip (GeneChip), using a variety of different robotic techniques. A typical microarray slide will contain approximately 5000 genes.

cDNA microarray is particularly useful to the field of cancer biology because it allows scientists to study changes in gene expression caused when a normal tissue becomes neoplastic. In addition, normal tissue can be compared with preneoplastic lesions as well as metastatic cancer, to fully examine the entire tumorigenic process. The mRNA is extracted from cell lines or tissue and is reverse transcribed into the more stable form of cDNA. The cDNA is then labeled with reporters containing two colored dyes, rhodamine red, Cy3, 

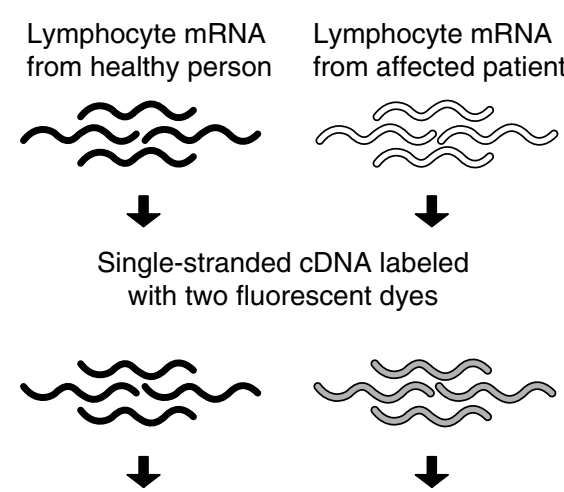

Add equal amounts to microarray of cDNAs from human lymphocytes

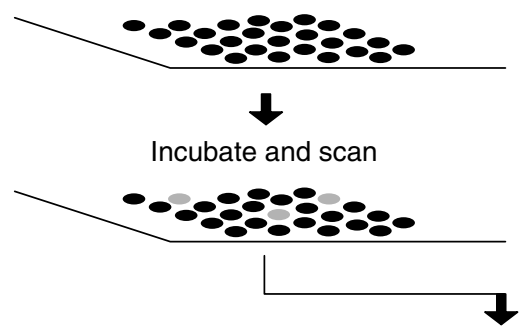

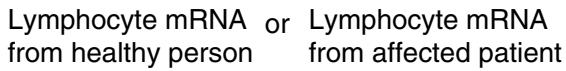

from healthy person from affected patient

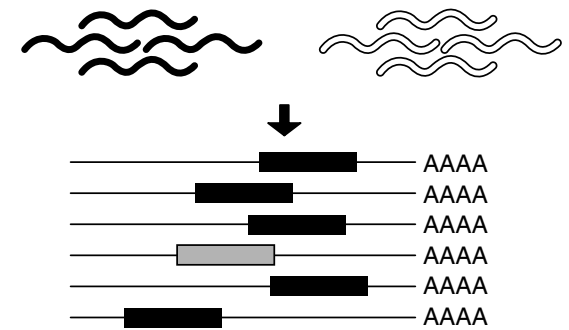

Isolate 9 base pair "tag" from a defined region of the cDNAs

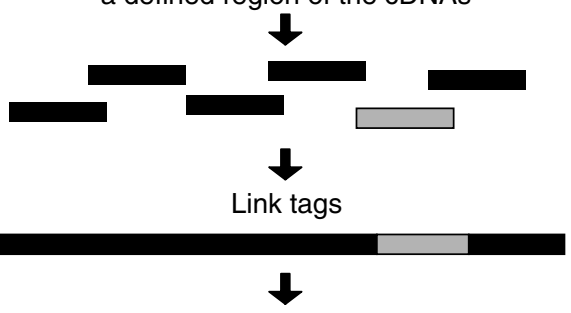

Sequence and count number of each tag
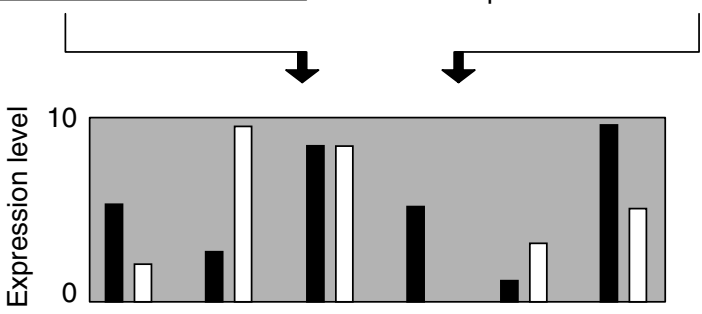

Genes (Healthy, black: Sick, white)

Figure 1.13. Comparison of cDNA microarray and SAGE technologies. At left is a diagram of the microarray assay for gene expression; the SAGE technique is illustrated at right. Here, the procedures assess how gene expression differs in lymphocytes from a healthy person and those from a person fighting off an infection. Reprinted with permission from K. Sutliff, Science, 270, 368 (1995). American Association for the Advancement of Science.

and fluorescien green, Cy5. The cDNA is then hybridized to the DNA on the microarray slide. The slides are exposed to a laser beam, causing the dyes to give off their respective emissions and the relative expression levels of that gene are read and processed.

A similar technique to cDNA microarray that allows for multigene expression analysis is serial analysis of gene expression (SAGE) (Fig. 1.13). SAGE is based on the principle that a $9-10$ nucleotide sequence contains sufficient information to identify a gene. These short nucleotide sequences are amplified by polymerase chain reaction (PCR) and then
30-50 of these SAGE "tags" are linked together as a single DNA molecule. These long DNA molecules are sequenced and the number of times that a single "tag" appears correlates to that gene's expression level. Proof of concept for this technique was illustrated in a study of gene expression in pancreatic cells. The most abundant "tags" found were those that encoded highly expressed pancreatic enzymes like trypsinogen 2. cDNA microarray methodology has also been validated by studies showing that expression data for tumor cell lines grown in tissue culture conditions can be classified according to their tissue of origin. 


\subsubsection{Discoveries from cDNA Microarray} Data. The contribution of microarray technology is influential in both the basic understanding of cancer pathology as well as in drug discovery and development. These studies reveal genes that may prove to be important diagnostic or prognostic markers of disease. They also can be used to predict adverse reactions to chemotherapies if mRNA from drugtreated cells is hybridized to panels of genes related to liver toxicity or the immune response.

Microarray technology also corroborates many in vitro cell studies that are criticized for ignoring the important role of other cell types in the tumor microenvironment. This technology can aid in distinguishing between cell type-specific or tumor-specific gene expression. For example, SAGE analysis of colon tumors and colon cancer cell lines showed $72 \%$ of the transcripts expressed at reduced levels in colon tumors were also expressed at reduced levels in the cell lines. One interesting finding from this study was that two commonly mutated oncogenes, c-fos and c-erbB3, were found to be expressed at higher levels in normal colonic epithelium than in colonic tumors; this contradicts reports that these oncogenes are up-regulated in transformed cells compared with normal cells. Again, microarray analysis is helping to merge cell biology studies with whole tumor biology.

Activation of the c-myc oncogene is a common genetic alteration occurring in many cancers. A cDNA microarray study found that cmyc activation leads to down-regulation of genes encoding extracellular matrix proteins, and thus, may play a role in regulating cell adhesion and structure. C-myc has also been associated with cell proliferation, which was illustrated by up-regulation of the genes eIF-5A and ODC. Another study of colon tumors revealed that only $1.8 \%$ of the 6000 transcripts studied were differentially expressed in normal tissues and tumors (111). Studies such as these suggest the critical importance of these differentially regulated genes in the cancer phenotype.

In addition to oncogene activation, the effects of tumor suppressor genes have been investigated through microarray technology. Over 30 novel transcripts were identified as regulated by p53 induction (112). Such a great number of genes simultaneously linked to p53 expression would not have been possible without SAGE technology. However, only $8 \%$ of these new genes were induced in normal cells compared with p53 knockout cells, suggesting that most of these p53-dependent genes are also dependent on other transcription factors. This is just one example of how microarray technology may be able to look at crosstalk in signaling pathways.

5.3.4 Limitations of Microarray Technologies. Although cDNA microarray and SAGE technologies are quickly identifying new genes involved in tumorigenesis, there are significant limitations to these strategies. First, the expression pattern of a gene only provides indirect information about its function; a new gene may be classified as necessary for a certain biological process, but its exact role in that process cannot be determined. Second, mRNA levels do not always correlate with protein levels, and even protein expression may not translate into a physiological effect. Third, the up-regulation or suppression of a gene may be either the cause or the effect of a disease state and microarray technology does not distinguish between the two possibilities.

Both cDNA microarray and SAGE analyses require verification of changes in gene expression by Northern blots. Modest changes in gene expression are often overlooked when data is reported in terms of fourfold or greater changes. Because the ability to detect differences in gene expression is dependent on the magnitude of variance, a small induction or suppression of a gene may be discarded as inconsequential when it may actually be critical for downstream signaling of other genes.

\subsection{Modifying Cell Adhesion}

5.4.1 MMP Inhibitors. Several MMP inhibitors are currently being developed for cancer treatment. If MMPs do play an integral role in malignant progression, then pharmacological inhibition of MMPs could inhibit tumor invasiveness. The inhibition of MMP function is currently the focus of most antimetastatic efforts. MMP inhibitors fall into three categories: (1) collagen peptidomimetics and non- 
peptidomimetics, (2) tetracycline derivatives, and (3) bisphosphonates. The peptidomimetic MMP inhibitors have a structure that mimics that of collagen at the site where the MMP binds to it. Batimastat, a peptidomimetic inhibitor, was the first MMP inhibitor to be evaluated in cancer patients and is not orally available. Matimastat is orally available and is currently in phase II and III clinical trials (113). When bound to the MMP, these inhibitors chelate the zinc atom in the enzyme's active site. There are several nonpeptidomimetic inhibitors that are also in various phases of clinical trials. These are more specific than their peptidic counterparts and have exhibited antitumor activity in preclinical studies (113).

Tetracycline derivatives inhibit both the activity of the MMPs and their production. They can inhibit MMP-1, -3 , and -13 (the collagenases) and MMP-2 and -9 (the gelatinases) by several different mechanisms. These mechanisms include (1) blocking MMP activity by chelation of zinc at the enzyme active site, (2) inhibiting the proteolytic activation of the proMMP, (3) decreasing the expression of the MMPs, and (4) preventing proteolytic and oxidative degradation of the MMPs.

The mechanism of action of the bisphosphonates has not been elucidated, but they have been used extensively for disorders in calcium homeostasis and recently in breast cancer and multiple myeloma patients to prevent bone metastases (114). Clodronate, a bisphosphonate, inhibited expression of MT1MMP RNA and protein in a fibrosarcoma cell line and effectively reduced the invasion of melanoma and fibrosarcoma cell lines through artificial basement membranes (115).

5.4.2 Anticoagulants. One theory surrounding the invasion process is that bloodclotting components may play a role in metastasis by either trapping the tumor cells in capillaries or by facilitating their adherence to capillary walls. Large numbers of tumor cells are released into the bloodstream during the metastatic process, and they must be able to survive the wide range of host defense mechanisms. Tumor cells have been shown to interact with platelets, lymphocytes, and leu- kocytes, and this may serve to promote metastasis. Studies have been done that inhibit tumor cell-platelet interactions, and these have resulted in a decreased probability of metastasis formation. It has also been shown that fibrin is always located in and around cancerous lesions, which may indicate that the cells use the fibrin structure as a support on which to attach themselves and grow. It may also serve as protection against host inflammatory cells so that the tumor is not destroyed.

Treating hepatic metastases of a human pancreatic cancer in a nude (lacking a thymus) mouse with prostacyclin, a potent inhibitor of platelet aggregation, led to a significant reduction in the mean surface area of the liver covered with tumor compared with the untreated control group (116). Many other groups have reported a reduction in metastatic potential with treatment of prostacyclin and prostacyclin-analogues, such as iloprost and cicaprost. There are currently over 50 different clinical trials in varying phases underway to determine the efficacy of these anticoagulant therapies. Most of these trials are in combination with other conventional anti-cancer regimens. So far, the experimental evidence indicates that anticoagulants or inhibitors of platelet aggregation are useful in the prevention of metastases.

5.4.3 Inhibitors of Angiogenesis. The growth and expansion of tumors and their metastases are dependent on angiogenesis, or new blood vessel formation. Angiogenesis is regulated by a complex of stimulators and inhibitors (Fig. 1.14). The balance between the positive and negative regulators of angiogenesis inside a tumor environment is important for the homeostasis of microvessels. Tumor cells can secrete proangiogenic paracrine factors, which stimulate endothelial cells to form new blood vessels. The use of angiogenesis inhibitors may be a potential mode of therapy and is still in early clinical trials. This type of therapy would be a way of controlling the disease rather than eliminating it. Whereas toxicity may not be a major problem, adverse effects may be expected in fertility and wound healing. 


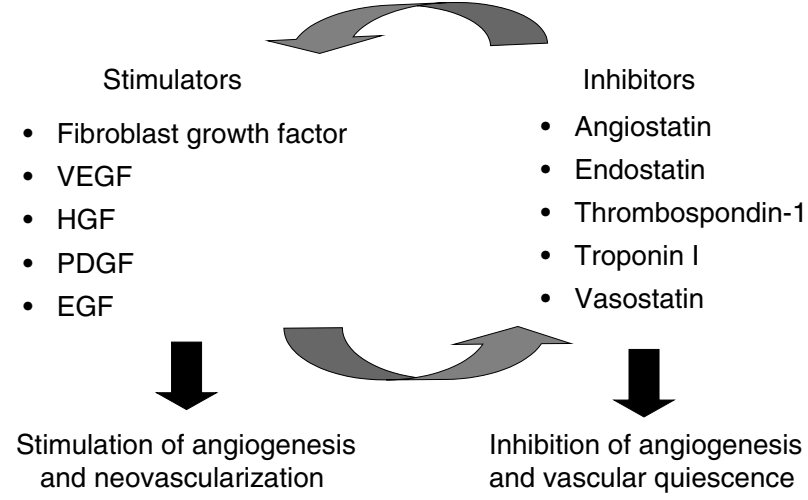

Figure 1.14. Stimulators and inhibitors of angiogenesis. Under physiological conditions, the balance of factors that affect angiogenesis is precisely regulated. However, under pathophysiological conditions, normal angiogenesis is disturbed because of the continued production of stimulators.

\subsection{Prospects for Gene Therapy of Cancer}

Gene therapy is the transfer of genetic material into cells for therapeutic purpose. Gene transfer technology has become available after extensive study of molecular mechanisms of many diseases and improvement of techniques for manipulating genetic materials in the laboratory. Concepts for genetic therapy of cancer were developed based on knowledge that neoplasia is a molecular disorder resulting from loss of expression of recessive tumor suppressor genes and activation of dominant oncogenes.

Cancer gene therapy is aimed at correcting genetic mutations found in malignant cells or delivering biologically active material against cancer cells. One approach used in gene therapy of cancer is gene replacement/correction to restore the function of a defective homologous gene or to down-regulate oncogenic expression in somatic cells. Another approach is immune modulation by introduction of therapeutic genes, such as cytokines, into the target cells to treat cancer by stimulating an immune response against the tumor. Molecular therapy by activating prodrugs (e.g., ganciclovir, 5 -fluorocytosine) within tumor cells and suicide gene therapy approaches have already been successful in early clinical trials. The high performance of these approaches fully depends on the efficacy and specificity of therapeutic gene expressing and delivery systems.

5.5.1 Gene Delivery Systems. The exogenous genetic material (the transgene) is usually introduced into tumor cells by a vector. A vector, or plasmid, is a circular DNA sequence that is designed to replicate inserted foreign DNA for the purpose of producing more protein product. Plasmids designed for gene therapy applications usually contain the gene of interest and regulatory elements that enhance the gene's expression. The ideal vector for gene therapy is one that would be safe, have high transfection efficiency, and be easy to manipulate and produce in large quantities. It would be efficient at delivering genetic material and selectively transducing cells within a tumor mass. The vector would be immunogenic for the recipient and would express the gene in a regulated fashion and at high levels as long as required.

There are two main approaches for the insertion of gene expressing systems into cells. In the ex vivo technique, cells affected by the disease are transfected with a therapeutic gene in vitro for the expression of exogenous genetic material. After viral propagation, replication is rendered incompetent and these cells can be transplanted into the recipient. In the in vivo technique, vectors are inserted directly into target tissue by systemic injections of the gene expressing system.

The simplest delivery system is a plasmid by itself, or so-called naked DNA. Direct injections of DNA have been successfully used to transfect tissues with low levels of nuclease activity in muscle tissue (117), liver (118), and experimental melanoma (119). Systemic injection of naked DNA is, in general, much less efficient because serum nucleases degrade plasmid DNA in the blood within minutes (120). 
$\underline{\text { Integrating vectors }}$

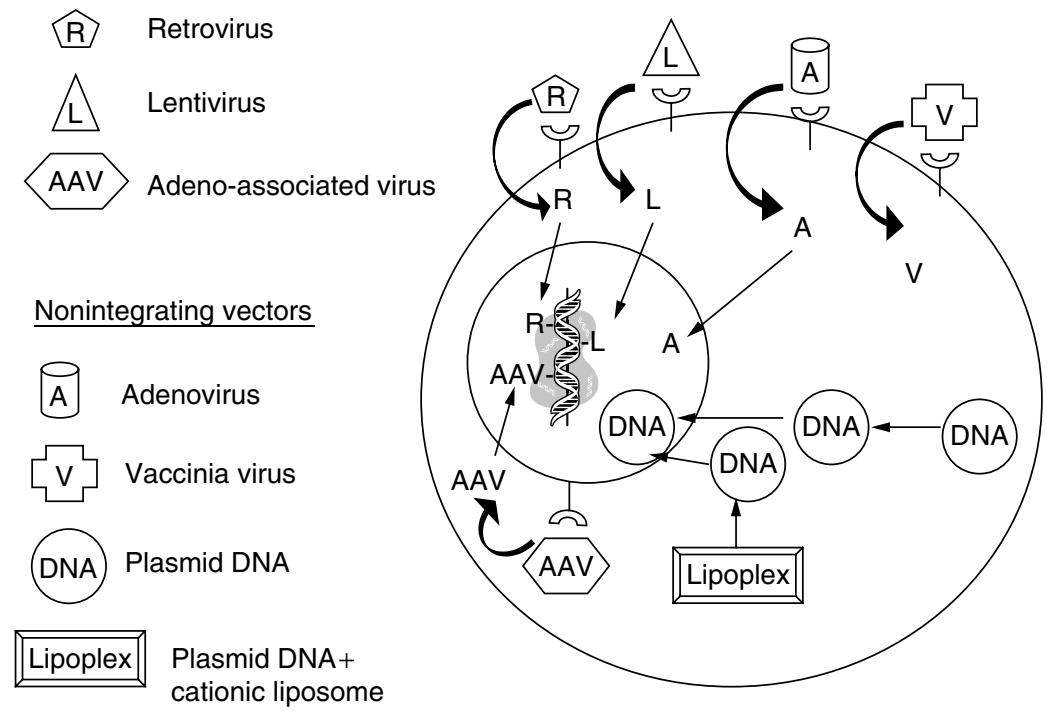

Figure 1.15. Virus particles bind to specific receptors on the surface of target cells. These vectors are internalized and their genome enters the cells. In the case of retroviruses, the single-stranded RNA genome is converted into double-stranded DNA by the reverse transcriptase enzyme encoded by the virus. The double-stranded DNA is taken up by the nucleus and integrated within the host genome as a provirus. The integration is random for retroviruses. Lentiviruses have a similar life cycle. Adenovirus binds to specific receptors on the surface of susceptible cells and are then absorbed and internalized by receptor-mediated endocytosis. The viral genome enters the cytoplasm of the cell and the double-stranded DNA genome is taken up by the nucleus. Vaccinia virus replicates in the cytoplasm of cells. DNA delivered by lipoplex and other nonviral systems enters cells through electrostatic interactions (endocytosis, phagocytosis, pinocytosis, and direct fusion with cell membrane). DNA is released before entry into the nucleus, where it stays as an episome.

To protect DNA on systemic application, it is usually complexed with viruses or with cationic lipids, polymers, or peptides. The resulting complex protects the DNA from the attack of nucleases and potentially improves transfection efficiency and specificity on multiple levels through interaction of DNA complexes with the various biological barriers.

The choice of viral or non-viral (synthetic) delivery strategy depends on localization and type of affected tissue, as well as on therapeutic approach. Viral vectors use the ability of viruses to overcome the cellular barriers and introduce genetic material either through the integration of the vector into the host genome (retroviruses, lentiviruses, adeno-associated viruses) or by episomal delivery (adenoviruses) followed by stable gene expression (Fig. 1.15).
5.5.1.1 Viral Vectors. Retroviral vectors have been used for ex vivo gene delivery and are the most useful vectors for stably integrating foreign DNA into target cells. Retroviruses are enveloped viruses that contain 7 - to 12 -kb RNA genomes. After the virus enters the cells through specific cell surface receptors, its genome is reverse transcribed into doublestranded DNA and subsequently integrated into the host chromosome in the form of a provirus. The provirus replicates along with the host chromosome and is transmitted to all of the host cell progeny. Because the retrovirus genome is relatively small and well characterized, it was possible to engineer a vector encoding only the transgene without replication competent viruses (RCV) or virus structural genes. 
The most widely used retrovirus vectors are based on murine leukemia viruses (MLV). The lack of specificity of these vectors is a major obstacle for appropriate and controlled expression of foreign genes. Retroviruses are not efficient for direct in vivo injection because of inactivation by the host immune system (121). To circumvent this, cis-acting viral sequences, such as long terminal repeats (LTRs), transfer RNA (tRNA) primer binding sites, and polypurine tracts, have been used for developing packaging systems of retrovirus vectors. Many recombinant retrovirus vectors are designed to express two genes, one of which is often a selectable marker. New strategies for expression, such as splicing, transcription from heterologous promoters, and translation directed by an internal ribosome entry signal (IRES), have been used for expression of the second gene. Attempts have also been made to achieve efficient gene delivery by targeting retroviral integration through modifying protein sequences in the viral envelope (122). These modifications include various targeting ligands, particularly ligands for the human EGFR, erythropoetin receptor, and single chain antibody fragments against the lowdensity lipoprotein (LDL) receptor.

Examples of lentiviruses are the human immunodeficiency virus (HIV-1), the equine infectious anemia virus, and the feline immunodeficiency virus (123). Although lentiviruses also have an RNA genome, their advantage compared with other retroviruses is the ability to infect and stably integrate into nondividing cells. To create a safe gene transfer vector based on the HIV-1 genome, the genome was altered and mutated to produce replication-defective particles. Several studies, both in vitro and in vivo, have shown successful gene transfer, including transduction of non-dividing hematopoetic cells at high efficiencies (up to 90\%) and stable gene expression in several target tissues of interest such as liver ( 8 weeks) and muscle and brain ( 6 months) with no detectable immune response (124). At the same time, the safety concern still remains for in vivo applications of this vector.

Vaccinia virus is a member of the Poxviridae family, which possesses a complex DNA genome encoding more than 200 proteins. The advantages of using vaccinia viruses for gene transfer include their ability to accommodate large or multiple gene inserts, to infect cells during different stages of the cell cycle, and their unique feature to replicate in the cytoplasm. Recombinant vaccinia vectors can be constructed using homologous recombination after transfection of vaccinia virus-infected cells with plasmid DNA constructs. This vector has been used in clinical trials to deliver genes encoding tumor antigens such as melanoma antigen (MAGE-1), carcinoembryonic antigen (CEA), prostate-specific antigen (PSA), interleukins (e.g., IL-1 $\beta$, IL-12), and costimulatory molecule B7 (125).

In recent years, there has been a great interest in the use of adenoviral vectors for cancer gene therapy. The main reasons for this are the ease in construction of adenoviruses in the laboratory and their ability to grow to high titers, infect a variety of cell types, and produce the heterologous protein of interest in dividing and non-dividing cells. Adenoviruses are also characterized by efficient receptormediated endocytosis, mediated by its fiber protein, and on infection of cancer cells, they exhibit high levels of transgene expression (126). They often are used to transfer genes of large sizes because of their high packaging capacity (up to $36 \mathrm{~kb}$ ). Adenoviral vectors do not integrate into the host chromosomes, and therefore, they are degraded by the host. This results in a short-term expression of the transduced gene, which, nevertheless, could be sufficient to achieve the cancer gene therapy efficacy. Adenoviruses are widely used for direct in vivo injections. Adenoviruses are DNA-containing, non-enveloped viruses.

The two most commonly used adenoviruses for recombinant vectors are Ad2 and Ad5, mainly because their genomes have been best characterized and because these viruses have never been shown to induce tumors. Adenoviruses, like other viral vectors, lack cell and tissue specificity. To improve targeted gene delivery, attempts have been made to couple ligands or antibodies to the adenovirus capsid proteins (127). Specificity of the transgene expression also can be introduced by using tissue specific antigens, such as CEA for the treatment of pancreatic and colon cancers, mucin (MUC-1) promoters for breast cancer cells, al- 
Table 1.5 Cell-Type Specific Promoters for Targeted Gene Expression

\begin{tabular}{|c|c|c|}
\hline Promoter & Target Cell/Tissue & Therapeutic Gene \\
\hline PEPCK promoter & Hepatocytes & $\begin{array}{l}\text { Neomycin phosphotransferase } \\
\text { Growth hormone }\end{array}$ \\
\hline AFP promoter & Hepatocellular carcinoma & HSV-tk, VZV-tk \\
\hline MMTV-LTR & Mammary carcinoma & $\mathrm{TNF} \alpha$ \\
\hline WAP promoter & Mammary carcinoma & Recombinant protein $\mathrm{C}$ \\
\hline$\beta$-casein & Mammary carcinoma & In development \\
\hline CEA promoter & Colon and lung carcinoma & HSV-tk, CD \\
\hline SLPI promoter & Carcinomas & HSV-tk, CD \\
\hline Tyrosinase promoter & Melanomas & HSV-tk, IL-2 \\
\hline c-erbB2 promoter & $\begin{array}{l}\text { Breast, pancreatic, gastric } \\
\text { carcinomas }\end{array}$ & CD, HSV-tk \\
\hline Myc-max-responsive element & Lung & HSV-tk \\
\hline \multicolumn{3}{|c|}{ Therapy-Inducible Tissues } \\
\hline Egr-1 promoter & Irradiated tumors & $\mathrm{TNF} \alpha$ \\
\hline Grp78 promoter & Anoxic, acidic tumor tissue & Neomycin phosphotransferase \\
\hline MDR1 promoter & Chemotherapy-treated tumors & $\mathrm{TNF} \alpha$ \\
\hline HSP70 & Hyperthermy-treated tumors & IL-2 \\
\hline
\end{tabular}

pha-fetoprotein promoters for hepatocellular carcinoma, and the tyrosinase promoter for melanoma (126). In vivo administration of adenoviral vector has been extensively used in preclinical and clinical cancer therapy (128).

There are many regulatory elements controlling cell type-specific gene expression and inducible sequences within promoters that have been used in construction of viral vectors for cancer therapy. Vector systems that include cell type-specific promoters or elements responding to regulatory signals represent a way for a safe, selective, and controlled expression of therapeutic genes that could increase efficacy and stability of gene expression (Table 1.5).

Vectors based on adenoassociated viruses (AAV) also have been successfully used to transfer genes. AAV is a small, singlestranded DNA virus that requires a helper virus for infection, usually an adenovirus or herpesvirus. AAV vectors can be used for the delivery of antisense genes, "suicide" gene therapy, and recently, for the delivery of antiangiogenic factors. Recent studies in the area of vector design have been focused on conditional expression that can be induced by antibiotics (129), heat shock (130), or other small molecules (131).
5.5.1.2 Non-Viral Gene Delivery Systems. Non-viral gene delivery systems are based on non-covalent bonds between cationic carrier molecules (e.g., lipids or polymers) and the negatively charged plasmid DNA. Complexes of DNA with three main groups of materials, i.e., cationic lipids (lipoplex) such as CTAB and DMRI, polymers (polyplex) such as polyL-lysine and polyathylenimine, or peptides have been evaluated as synthetic gene delivery systems (132). The formation of these complexes, which is generally based on electrostatic interactions with the plasmid DNA, is difficult to control as they depend on both the stoichiometry of DNA and complexing agent and on kinetic parameters (e.g., speed of mixing and volumes). It has been shown that DNA is efficiently condensed and protected from nucleases at higher lipid:DNA ratios, proving that the positive charges of the complexes are important for the interaction with cells in vitro and in vivo. Although the resulting particles are stable, they have a high tendency to interact non-specifically with biological surfaces and molecules.

Lipoplexes are actively used in clinical trials for in vivo and ex vivo delivery of genes encoding cytokines, immunostimulatory molecules, and adenoviral genes (133). In vivo, 
these interactions may compromise the tissuespecific delivery of the complexes, creating uneven biodistribution and transgene expression in the body, particularly, in lungs. To overcome this problem, the complexes can be injected either into the vasculature or directly into the affected organ (134).

The combinatorial gene delivery approach uses the whole virus, either replication deficient or inactivated, or only essential viral components, together with the non-viral system. Systems, based on adenovirus ("adenofection"), or viral proteins that are required to trigger efficient endosomal escape, and polyplex and lipoplex non-viral systems have shown improvement in transfection efficiency and resistance to endosomal degradation (135).

\subsection{Gene Therapy Approaches}

5.6.1 Immunomodulation. This approach employs the patient's physiological immune response cascade to amplify therapeutic effects (136). Most patients with cancer lack an effective immune response to their tumors. This could be caused by defects in antigen presentation, stimulation, or differentiation of activated T cells into functional effector cells. Antitumor immunity response requires participation of different immune cells, including helper effector T-cells (Th), cytotoxic T-lymphocytes (CTLs), and natural killer (NK) cells. Activation of $\mathrm{CD} 4^{+}$and $\mathrm{CD} 8^{+} \mathrm{T}$-cells requires at least two major signals. The first signal is triggered by binding of complexes of T-cell receptor (TCR) and specific antigenic peptide with MHC-class II or I molecules, respectively. The second signal for $\mathrm{CD} 4^{+} \mathrm{T}$-cells is provided by engagement of CD28 on the T-cell surface by members of the B7 family of costimulatory molecules on the surface of professional antigen-presenting cells. The nature of second signal for $\mathrm{CD}^{+} \mathrm{T}$-cells has not been completely understood but requires the presence of helper $\mathrm{CD} 4^{+}$T-cells. Following activation and clonal expansion, activated $\mathrm{CD} 4^{+} \mathrm{T}$-cells differentiate into helper effector cells of either the Th1 or Th 2 phenotype. Th 1 cells produce cytokines, such as IL-2, interferon- $\gamma$, and $\mathrm{TNF}$, that stimulate monocytes and NK cells and promote the differentiation of activated $\mathrm{CD}^{+}$T-cells into CTLs.

The growing understanding of the biological basis of antigen-specific cellular recognition and experimental studies of an antitumor effect mediated through the cellular immune system helped to develop various immunomodulation strategies. Modulation of immune response can be achieved through stimulation and modification of immune effector cells, enabling them to recognize and reject cells that carry a tumor antigen. Additionally, tumor cells can be genetically modified to increase immunogenicity and trigger an immune response.

Cytokine levels are relatively low in cancer patients. To correct for this deficiency, cytokines can be introduced as recombinant molecules, and this is advantageous in controlling their blood concentration and biological activity. Because cytokines are relatively unstable in vivo, cancer patients have to receive a large amount of the recombinant protein to maintain the required blood concentration for biological activity. Administration of the protein is often toxic to the patients. Another therapeutic approach is the introduction of genes encoding various cytokines, costimulatory molecules, allogenic antigens, and tumor-associated antigens into tumors (137). Previous preclinical studies have shown that cytokines that facilitate Th1 cell-mediated immune reactions but not Th2 cell-mediated reactions, when produced in tumors, are effective for antitumor responses. In addition, cytokines or costimulatory molecules delivered to tumor cells may enhance the transfer of tumor antigens to antigen-presenting cells. The most potent known antigen-presenting cells for actively stimulating specific cellular immune responses are dendritic cells. Ex vivo gene delivery to cultured dendritic cells or direct in vivo gene delivery to antigen-presenting cells can be more efficient in stimulating cellular antitumor immunity (138).

Several technical problems of expressing sufficient amounts of immunostimulatory proteins in appropriate target cells remain unsolved, but the potential of immune modulation gene therapy is high. Immunotherapy trials also contribute to the present knowledge of 
Figure 1.16. Mechanisms of thymidine kinase (TK) ganciclovir (GCV)-induced apoptosis. TK phosphorylates the nontoxic prodrug GCV to GCV-triphosphate (GCVPPP), which causes chain termination and single-strand breaks on incorporation into DNA. TK/GCV induces p53 accumulation, which can cause translocation of preformed death receptor CD95 from the Golgi apparatus to the cell surface without inducing $d e$ novo synthesis of CD95. The signaling complex then is formed by CD95, the adapter molecule Fas-associated death domain (FADD) protein, and the initiator caspase-8, which leads to cleavage of caspases causing apoptosis. TK/GCV also leads to mitochondria damage, including loss of mitochondrial membrane potential and the release of cytochrome $\mathrm{c}$ inducing caspase activation and nuclear fragmentation.

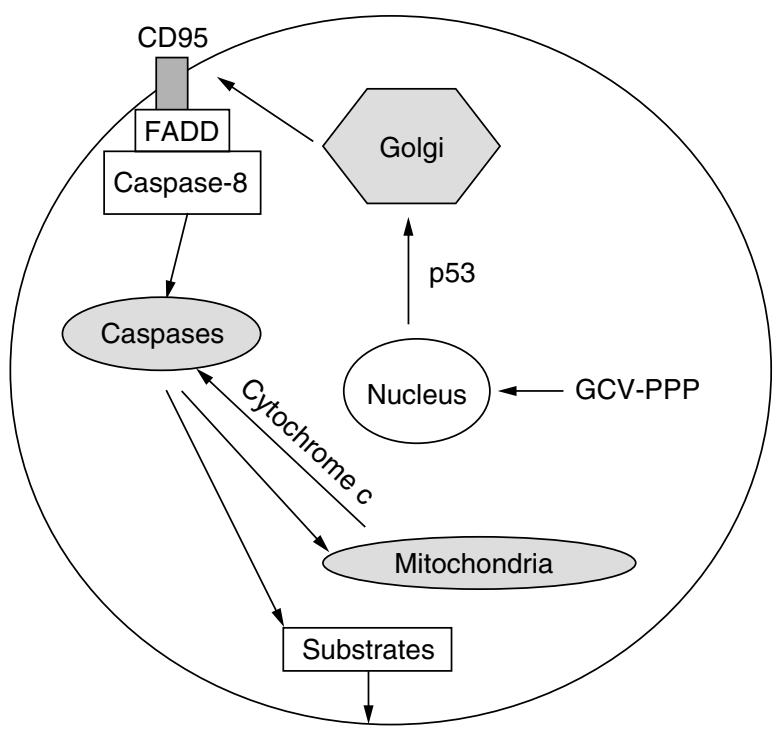

how antitumor responses can be effectively produced in cancer patients.

5.6.2 Suicidal Gene Approach. Elimination of cancer cells can be accomplished by the introduction of vectors that specifically express death promoting genes in tumor cells. One method, called suicide gene therapy, involves the expression of a gene encoding an enzyme, normally not present in human cells, that converts a systemically delivered nontoxic prodrug into a toxic agent. The toxin should kill the cancer cells expressing the gene as well as the surrounding cells not expressing the gene (bystander effect).

The herpes simplex virus thymidine kinase type 1 (HSV-tk) gene was initially used for long-term replacement gene therapy because it is about 1000 -fold more efficient than mammalian thymidine kinase at phosphorylating the nontoxic prodrug ganciclovir (GCV) into its toxic metabolite ganciclovir triphosphate. The efficacy of HSV-tk transduction of tumors followed by ganciclovir therapy has been confirmed by systemic administration of ganciclovir after intratumoral injection of fibroblasts transduced with an HSV-tk retroviral vector in several preclinical models (139). The molecular mechanism of HSV-tk therapy is based on induction of apoptosis in target cells through accumulation of p53 protein (Fig. 1.16). Clinical trials of HSV-tk suicide gene therapy,

where ganciclovir was given after the retroviral or adenoviral introduction of HSV-tk gene, have been conducted in patients with brain tumors, melanoma, or mesothelioma (140-142) (Fig. 1.16).

Another suicide gene under active investigation for cancer therapy is the cytosine deaminase (CD) gene. CD converts the nontoxic fluoropyrimidine 5-fluorocytosine to 5-fluorouracil. Transduction of the CD renders tumor cells sensitive to 5-fluorocytosine in vitro and in vivo. The $\mathrm{CD} / 5$-fluorocytosine system has been used in a clinical trial, where adenovirus expressing the CD gene was injected intratumorally into hepatic metastases from colorectal cancer (143). As with HSV-tk gene transfer, evidence exists that cytosinedeaminase gene transfer into tumor cells promotes antitumor immune responses. The malignancies targeted with suicide gene therapy in the field of pediatric oncology are brain tumors, neuroblastoma, and acute lymphoblastic leukemia (144).

5.6.3 Targeting Loss of Tumor Suppressor Function and Oncogene Overexpression. Several tumor suppressor genes, including p53, $\mathrm{Rb}$, and $\mathrm{APC}$, have been identified by their association with hereditary cancers. Many sporadic tumors harbor inactivating or recessive mutations in one or more tumor suppressor genes. Gene transfer techniques can be ap- 
plied to introduce wild-type copies of tumor suppressor genes into malignant cells, thus potentially reversing the neoplastic phenotype. The p53 tumor suppressor gene has been of interest because p53 mutation occurs commonly in a variety of human cancers, including breast, lung, colon, prostate, bladder, and cervix. The use of adenoviral vectors to deliver the p53 transgene to human tumors is now under evaluation in several clinical trials (145). The overexpression of Fas ligand caused by adenovirus-mediated wild-type p53 gene transfer induces neutrophil infiltration into human colorectal tumors, which may play a critical role in the bystander effect of p53 gene therapy (146).

Besides the p53 gene, other tumor suppressor genes that regulate the cell cycle have been used in cancer gene therapy. Among them are Rb, BRCA1, PTEN, p16, E2F, and fragile histidine triad (FHIT) genes. Clinical trials with BRCA1 and Rb have been initiated (147).

Protooncogenes, in contrast to tumor suppressor genes, gain dominant mutation resulting in excessive expression of their protein products, which lead to development of the malignant phenotype. Three members of the Ras family of oncogenes (H-ras, K-ras, and Nras) are among the most commonly activated oncogenes in human cancers. Several strategies have been designed to combat K-ras mutations, including antisense nucleotide, ribozymes (148-150), and intracellular singlechain antibodies (151). cDNA encoding antisense RNA can be delivered using the viral vector system approach. In vivo gene therapy with K-ras, c-fos, and c-myc antisense nucleotides is currently being applied in clinical trials.

5.6.4 Angiogenesis Control. Gene therapy offers a new strategy for the delivery of angiogenesis inhibitors. By engineering and delivering vectors that carry the coding sequence for an antiangiogenic protein, it is possible to produce high levels of antiangiogenic factors in the tumor location or to systemically prevent the growth of distant metastasis. Several angiogenic inhibitors, such as angiostatin (152), endostatin (153), plasminogen activator inhibitor type 1 (154), and truncated VEGF receptor (155), have been tested using this ap- proach. These studies have demonstrated that retroviral and adenoviral vectors could be used to inhibit endothelial cell growth in vitro and angiogenesis in vivo. The inhibition of tumor-associated angiogenesis results in increased apoptotic tumor cell death, leading to inhibition of tumor growth.

5.6.5 Matrix Metalloproteinase. As mentioned earlier in the chapter, MMPs are capable of proteolytic degradation of stromal ECM, which is essential in cancer cell migration and invasion, as well as in tumor-induced angiogenesis. The activity of MMPs in vivo is inhibited by TIMPs, small secreted proteins with molecular weight of between 20 and $30 \mathrm{kDa}$. TIMPs inhibit MMPs by binding to both the latent and active forms of MMPs. The following properties of TIMPs such as secretion, diffusion (TIMP-1, -2 and -4), induction of apoptosis (TIMP-3), and inhibition of multiple MMPs make them very attractive tools for gene therapy application.

Inhibition of cancer cell invasion after overexpression of TIMPs using different gene delivery vectors has been shown in vitro in gastric cancer cells and mammary carcinoma cells $(156,157)$. Overexpression in vitro of TIMP-2, which was delivered by a recombinant adenovirus (AdTIMP-2), inhibited the invasion of both tumor and endothelial cells in three murine models without affecting cell proliferation (158). Its in vivo efficiency has been evaluated in the LLC murine lung cancer model, the colon cancer C51 model, as well as in MDAMB231 human breast cancer in athymic mice. Preinfection of tumor cells by AdTIMP-2 resulted in an inhibition of tumor establishment in more than $50 \%$ of mice in LLC and C51 models and in $100 \%$ of mice in the MDAMB231 model. A single local injection of AdTIMP-2 into preestablished tumors of these three tumor types reduced tumor growth rates by $60-80 \%$, and the tumor-associated angiogenesis index by $25-75 \%$. Lung metastasis of LLC tumors was inhibited by $>90 \%$. In addition, AdTIMP-2-treated mice showed a significantly prolonged survival in all the cancer models tested. These data demonstrate the potential of adenovirus-mediated TIMP-2 therapy in cancer treatment. 


\section{ACKNOWLEDGMENTS}

We would like to acknowledge the expert and dedicated assistance of Kim Nicolini without whom this chapter would never have been completed. Her perseverance and insistence that we keep pushing forward to the end are much appreciated.

\section{REFERENCES}

1. M. H. Myers and L. A. Ries, Can. Cancer J. Clin., 39, 21-32 (1989).

2. R. Peto, IARC Sci. Publ., 39, 27-28 (1982).

3. P. C. Nowell, Science, 194, 23-28 (1976).

4. D. Stehelin, H. E. Varmus, J. M. Bishop, and P. K. Vogt, Nature, 260, 170-173 (1976).

5. H. Land, L. F. Parada, and R. A. Weinberg, Nature, 304, 596-602 (1983).

6. E. R. Fearon and B. Vogelstein, Cell, 61, 759767 (1990).

7. H. Hennings, A. B. Glick, D. A. Greenhalgh, D. L. Morgan, J. E. Strickland, T. Tennenbaum, and S. H. Yuspa, Proc. Soc. Exp. Biol. Med., 202, 1-8 (1993).

8. M. A. Nelson, B. W. Futscher, T. Kinsella, J. Wymer, and G. T. Bowden, Proc. Natl. Acad. Sci. USA, 89, 6398-6402 (1992).

9. T. Minamoto, M. Mai, and Z. Ronai, Carcinogenesis, 20, 519-527 (1999).

10. I. Tannock and R. P. Hill, The Basic Science of Oncology, Pergamon Press, New York, 1987.

11. J. S. Bertram, Mol. Aspects Med., 21, 167-223 (2000).

12. E. C. Friedberg, G. C. Walker, and W. Siede, DNA Repair and Mutagenesis, American Society for Microbiology Press, Washington, DC, 1995.

13. M. L. Slattery, W. Samowitz, L. Ballard, D. Schaffer, M. Leppert, and J. D. Potter, Cancer Res., 61, 1000-1004 (2001).

14. M. Iwamoto, D. J. Ahnen, W. A. Franklin, and T. H. Maltzman, Carcinogenesis, 21, 1935-1940 (2000).

15. Y. Guo, R. B. Harris, D. Rosson, D. Boorman, and T. G. O'Brien, Cancer Res., 60, 6314-6317 (2000).

16. T. Bestor, A. Laudano, R. Mattaliano, and V. Ingram, J. Mol. Biol., 203, 971-983 (1988).

17. A. P. Bird and A. P. Wolffe, Cell, 99, 451-454 (1999).

18. W. Doerfler, Annu. Rev. Biochem., 52, 93-124 (1983).
19. T. Goto and M. Monk, Microbiol. Mol. Biol. Rev., 62, 362-378 (1998).

20. D. P. Barlow, Science, 270, 1610-1613 (1995).

21. S. B. Baylin, M. Esteller, M. R. Rountree, K. E. Bachman, K. Schuebel, and J. G. Herman, Hum. Mol. Genet., 10, 687-692 (2001).

22. R. Z. Chen, U. Pettersson, C. Beard, L. Jackson-Grusby, and R. Jaenisch, Nature, 395, 89-93 (1998).

23. M. O. Hiltunen, L. Alhonen, J. Koistinaho, S. Myohanen, M. Paakkonen, S. Marin, V. M. Kosma, and J. Janne, Int. J. Cancer, 70, 644648 (1997).

24. M. F. Kane, M. Loda, G. M. Gaida, J. Lipman, R. Mishra, H. Goldman, J. M. Jessup, and R. Kolodner, Cancer Res., 57, 808-811 (1997).

25. S. J. Nass, J. G. Herman, E. Gabrielson, P. W. Iversen, F. F. Parl, N. E. Davidson, and J. R. Graff, Cancer Res., 60, 4346-4348 (2000).

26. C. M. Bender, J. M. Zingg, and P. A. Jones, Pharm. Res., 15, 175-187 (1998).

27. L. E. Lantry, Z. Zhang, K. A. Crist, Y. Wang, G. J. Kelloff, R. A. Lubet, and M. You, Carcinogenesis, 20, 343-346 (1999).

28. R. W. Ruddon,. Cancer Biology, 3rd ed., Oxford University Press, New York, (1995).

29. J. C. Houck, V. K. Sharma, and L. Hayflick, Proc. Soc. Exp. Biol. Med., 137, 331-333 (1971).

30. D. J. Bearss, L. H. Hurley, and D. D. Von Hoff, Oncogene, 19, 6632-6641 (2000).

31. F. Ciardiello, Drugs, 60, 25-32 (2000).

32. I. Stamenkovic, Sem. Cancer Biol., 10, 415433 (2000).

33. H. Nagase, Biol. Chem., 378, 151-160 (1997).

34. A. Lochter and M. J. Bissell, Apmis., 107, 128 136 (1999).

35. B. Davidson, I. Goldberg, P. Liokumovich, J. Kopolovic, W. H. Gotlieb, L. Lerner-Geva, I. Reder, G. Ben-Baruch, and R. Reich, Int. J. Gynecol. Pathol., 17, 295-301 (1998).

36. J. D. Knox, C. Wolf, K. McDaniel, V. Clark, M. Loriot, G. T. Bowden, and R. B. Nagle, Mol. Carcinog., 15, 57-63 (1996).

37. R. G. Chirivi, A. Garofalo, M. J. Crimmin, L. J. Bawden, A. Stoppacciaro, P. D. Brown, and R. Giavazzi, Int. J. Cancer, 58, 460-464 (1994).

38. A. E. Aplin, A. Howe, S. K. Alahari, and R. L. Juliano, Pharmacol Rev., 50, 197-263 (1998).

39. Z. Dong, R. Kumar, X. Yang, and I. J. Fidler, Cell, 88, 801-810 (1997).

40. J. P. Witty, S. McDonnell, K. J. Newell, P. Cannon, M. Navre, R. J. Tressler, and L. M. Matrisian, Cancer Res., 54, 4805-4812 (1994). 
41. A. B. Pardee, Proc. Natl. Acad. Sci. USA, 71, 1286-1290 (1974).

42. C. Hutchison and D. M. Glover, Cell Cycle Control, IRL Press, Oxford, 1995.

43. B. T. Zafonte, J. Hulit, D. F. Amanatullah, C. Albanese, C. Wang, E. Rosen, A. Reutens, J. A. Sparano, M. P. Lisanti, and R. G. Pestell, Front Biosci., 5, D938-D961 (2000).

44. J. W. Harper, Cancer Surv., 29, 91-107 (1997).

45. W. S. el-Deiry, J. W. Harper, P. M. O'Connor, V. E. Velculescu, C. E. Canman, J. Jackman, J. A. Pietenpol, M. Burrell, D. E. Hill, and Y. Wang, Cancer Res., 54, 1169-1174 (1994).

46. L. Liu, N. J. Lassam, J. M. Slingerland, D. Bailey, D. Cole, R. Jenkins, and D. Hogg, Oncogene, 11, 405-412 (1995).

47. T. Weinert, Cancer Surv., 29, 109-132 (1997).

48. S. W. Lowe, H. E. Ruley, T. Jacks, and D. E. Housman, Cell, 74, 957-967 (1993).

49. S. N. Farrow, Biochem. Soc. Trans., 27, 812 814 (1999).

50. J. Wang and M. J. Lenardo, J. Cell Sci., 113, 753-757 (2000).

51. M. Loeffler and G. Kroemer, Exp. Cell Res., 256, 19-26 (2000).

52. A. Gross, J. M. McDonnell, and S. J. Korsmeyer, Genes Dev., 13, 1899-1911 (1999).

53. A. Ashkenazi and V. M. Dixit, Curr. Opin. Cell Biol., 11, 255-260 (1999).

54. R. C. Seeger, G. M. Brodeur, H. Sather, A. Dalton, S. E. Siegel, K. Y. Wong, and D. Hammond, N. Engl. J. Med., 313, 1111-1116 (1985).

55. E. C. Friedberg, Cancer J. Sci. Am., 5, 257-263 (1999).

56. G. L. Semenza, J. Appl. Physiol., 88, 14741480 (2000).

57. J. R. Gnarra, S. Zhou, M. J. Merrill, J. R. Wagner, A. Krumm, E. Papavassiliou, E. H. Oldfield, R. D. Klausner, and W. M. Linehan, Proc. Natl. Acad. Sci. USA, 93, 10589-10594 (1996).

58. I. J. Fidler, and L. M. Ellis, Cell, 79, 185-188 (1994).

59. D. R. Senger, S. J. Galli, A. M. Dvorak, C. A. Perruzzi, V. S. Harvey, and H. F. Dvorak, Science, 219, 983-985 (1983).

60. N. Ferrara, and W. J. Henzel, Biochem. Biophys. Res. Commun., 161, 851-858 (1989).

61. B. Millauer, M. P. Longhi, K. H. Plate, L. K. Shawver, W. Risau, A. Ullrich, and L. M. Strawn, Cancer Res., 56, 1615-1620 (1996).

62. M. Asano, A. Yukita, T. Matsumoto, S. Kondo, and H. Suzuki, Cancer Res., 55, 5296-5301 (1995).
63. B. Olofsson, K. Pajusola, A. Kaipainen, G. von Euler, V. Joukov, O. Saksela, A. Orpana, R. F. Pettersson, K. Alitalo and U. Eriksson, Proc Natl Acad Sci U S A, 93, 2576-81 (1996).

64. M. Orlandini, L. Marconcini, R. Ferruzzi and S. Oliviero., Proc. Natl. Acad. Sci. U S A, 93, 11675-80 (1996).

65. M. G. Achen, M. Jeltsch, E. Kukk, T. Makinen, A. Vitali, A. F. Wilks, K. Alitalo and S. A. Stacker, Proc. Natl. Acad. Sci. U S A, 95, 548-53 (1998).

66. E. Kukk, A. Lymboussaki, S. Taira, A. Kaipainen, M. Jeltsch, V. Joukov and K. Alitalo, Development, 122, 3829-37 (1996).

67. S. Tessler, P. Rockwell, D. Hicklin, T. Cohen, B. Z. Levi, L. Witte, I. R. Lemischka, and G. Neufeld, J. Biol. Chem., 269, 12456-12461 (1994).

68. W. Risau, Prog. Growth Factor Res., 2, 71-79 (1990).

69. K. J. Kim, B. Li, J. Winer, M. Armanini, N. Gillett, H. S. Phillips, and N. Ferrara, Nature, 362, 841-844 (1993).

70. N. Ueki, M. Nakazato, T. Ohkawa, T. Ikeda, Y. Amuro, T. Hada, and K. Higashino, Biochim. Biophys. Acta., 1137, 189-196 (1992).

71. N. Weidner, J. P. Semple, W. R. Welch, and J. Folkman, N. Engl. J. Med., 324, 1-8 (1991).

72. C. I. Bargmann, M. C. Hung, and R. A. Weinberg, Cell, 45, 649-657 (1986).

73. M. Crul, G. J. de Klerk, J. H. Beijnen, and J. H. Schellens, Anticancer Drugs, 12, 163-184 (2001).

74. A. B. Vojtek and C. J. Der, J. Biol. Chem., 273, 19925-19928 (1998).

75. H. R. Bourne, D. A. Sanders, and F. McCormick, Nature, 349, 117-127 (1991).

76. M. R. Wallace, D. A. Marchuk, L. B. Andersen, R. Letcher, H. M. Odeh, A. M. Saulino, J. W. Fountain, A. Brereton, J. Nicholson, and A. L. Mitchell, Science, 249, 181-186 (1990).

77. D. Stokoe, S. G. Macdonald, K. Cadwallader, M. Symons, and J. F. Hancock, Science, 264, 1463-1467 (1994).

78. P. Rodriguez-Viciana, P. H. Warne, R. Dhand, B. Vanhaesebroeck, I. Gout, M. J. Fry, M. D. Waterfield, and J. Downward, Nature, 370, 527-532 (1994).

79. T. Sasaki, J. Irie-Sasaki, Y. Horie, K. Bachmaier, J. E. Fata, M. Li, A. Suzuki, D. Bouchard, A. Ho, M. Redston, S. Gallinger, R. Khokha, T. W. Mak, P. T. Hawkins, L. Stephens, S. W. Scherer, M. Tsao, and J. M. Penninger, Nature, 406, 897-902 (2000). 
80. M. Vidal, V. Gigoux, and C. Garbay, Crit. Rev. Oncol. Hematol., 40, 175-186 (2001).

81. G. Q. Daley and Y. Ben-Neriah, Adv. Cancer Res., 57, 151-184 (1991).

82. D. Diekmann, S. Brill, M. D. Garrett, N. Totty, J. Hsuan, C. Monfries, C. Hall, L. Lim, and A. Hall, Nature, 351, 400-402 (1991).

83. M. J. Mauro, M. O’Dwyer, M. C. Heinrich, and B. J. Druker, J. Clin. Oncol., 20, 325-334 (2002).

84. T. Hai, and T. Curran, Proc. Natl. Acad. Sci. USA, 88, 3720-3724 (1991).

85. M. Karin, Z. Liu, and E. Zandi, Curr. Opin. Cell. Biol., 9, 240-246 (1997).

86. K. F. Mitchell, J. Battey, G. F. Hollis, C. Moulding, R. Taub, and P. Leder, J. Cell. Physiol., Suppl 3, 171-177 (1984).

87. P. J. Koskinen and K. Alitalo, Sem. Cancer Biol., 4, 3-12 (1993).

88. T. C. He, A. B. Sparks, C. Rago, H. Hermeking, L. Zawel, L. T. da Costa, P. J. Morin, B. Vogelstein, and K. W. Kinzler, Science, 281, 1509-1512 (1998).

89. L. Zheng and W. H. Lee, Exp. Cell Res., 264, 2-18 (2001).

90. J. R. Bischoff, D. H. Kirn, A. Williams, C. Heise, S. Horn, M. Muna, L. Ng, J. A. Nye, A. Sampson-Johannes, A. Fattaey, and F. McCormick, Science, 274, 373-376 (1996).

91. S. Ikeda, S. Kishida, H. Yamamoto, H. Murai, S. Koyama, and A. Kikuchi, EMBO J., 17, 1371-1384 (1998).

92. L. Simpson and R. Parsons, Exp. Cell Res., 264, 29-41 (2001).

93. M. Tamura, J. Gu, K. Matsumoto, S. Aota, R. Parsons, and K. M. Yamada, Science, 280, 1614-1617 (1998).

94. G. Torre-Amione, R. D. Beauchamp, H. Koeppen, B. H. Park, H. Schreiber, H. L. Moses, and D. A. Rowley, Proc. Natl. Acad. Sci. USA, 87, 1486-1490 (1990).

95. S. Markowitz, J. Wang, L. Myeroff, R. Parsons, L. Sun, J. Lutterbaugh, R. S. Fan, E. Zborowska, K. W. Kinzler, and B. Vogelstein, Science, 268, 1336-1338 (1995).

96. J. E. Cleaver, J. Dermatol. Sci., 23, 1-11 (2000).

97. H. T. Lynch, T. C. Smyrk, P. Watson, S. J. Lanspa, J. F. Lynch, P. M. Lynch, R. J. Cavalieri, and C. R. Boland, Gastroenterology, 104, 1535-1549 (1993).

98. P. Peltomaki and H. F. Vasen, Gastroenterology, 113, 1146-1158 (1997).
99. P. Greenwald, Sci. Am., 275, 96-99 (1996).

100. H. S. Wasan, M. Novelli, J. Bee, and W. F. Bodmer, Proc. Natl. Acad. Sci. USA, 94, 33083313 (1997).

101. D. S. Alberts, M. E. Martinez, D. J. Roe, J. M. Guillen-Rodriguez, J. R. Marshall, J. B. van Leeuwen, M. E. Reid, C. Ritenbaugh, P. A. Vargas, A. B. Bhattacharyya, D. L. Earnest, and R. E. Sampliner, N. Engl. J. Med., 342, 11561162 (2000).

102. S. A. Leadon, Sem. Radiat. Oncol., 6, 295-305 (1996).

103. M. Abdulla, and P. Gruber, Biofactors, 12, 45-51 (2000).

104. G. S. Omenn, G. E. Goodman, M. D. Thornquist, J. Balmes, M. R. Cullen, A. Glass, J. P. Keogh, F. L. Meyskens Jr., B. Valanis, J. H. Williams Jr., S. Barnhart, M. G. Cherniack, C. A. Brodkin, and S. Hammar, J. Natl. Cancer Inst., 88, 1550-1559 (1996).

105. B. Reddy, A. Engle, S. Katsifis, B. Simi, H. P. Bartram, P. Perrino, and C. Mahan, Cancer Res., 49, 4629-4635 (1989).

106. J. A. Baron, M. Beach, J. S. Mandel, R. U. van Stolk, R. W. Haile, R. S. Sandler, R. Rothstein, R. W. Summers, D. C. Snover, G. J. Beck, J. H. Bond, and E. R. Greenberg, N. Engl. J. Med., 340, 101-107 (1999).

107. E. Giovannucci, E. B. Rimm, A. Wolk, A. Ascherio, M. J. Stampfer, G. A. Colditz, and W. C. Willett, Cancer Res., 58, 442-447 (1998).

108. R. N. Dubois, S. B. Abramson, L. Crofford, R. A. Gupta, L. S. Simon, L. B. Van De Putte, and P. E. Lipsky, Faseb J., 12, 1063-1073 (1998).

109. A. T. Koki, K. M. Leahy, and J. L. Masferrer, Expert Opin. Investig. Drugs, 8, 1623-1638 (1999).

110. F. L. Meyskens Jr. and E. W. Gerner, Clin. Cancer Res., 5, 945-951 (1999).

111. D. A. Notterman, U. Alon, A. J. Sierk, and A. J. Levine, Cancer Res., 61, 3124-3130 (2001).

112. J. Yu, L. Zhang, P. M. Hwang, C. Rago, K. W. Kinzler, and B. Vogelstein, Proc. Natl. Acad. Sci. USA, 96, 14517-14522 (1999).

113. M. Hidalgo and S. G. Eckhardt, J. Natl. Cancer Inst., 93, 178-193 (2001).

114. P. D. Delmas, N. Engl. J. Med., 335, $1836-$ 1837 (1996).

115. O. Teronen, P. Heikkila, Y. T. Konttinen, M. Laitinen, T. Salo, R. Hanemaaijer, A. Teronen, P. Maisi, and T. Sorsa, Ann. NY Acad. Sci., 878, 453-465 (1999). 
116. M. A. Schwalke, G. N. Tzanakakis, and M. P. Vezeridis, J. Surg. Res., 49, 164-167 (1990).

117. M. E. Barry, D. Pinto-Gonzalez, F. M. Orson, G. J. McKenzie, G. R. Petry, and M. A. Barry, Hum. Gene Therap., 10, 2461-2480 (1999).

118. M. A. Hickman, R. W. Malone, K. LehmannBruinsma, T. R. Sih, D. Knoell, F. C. Szoka, R. Walzem, D. M. Carlson, and J. S. Powell, Hum. Gene Therap., 5, 1477-1483 (1994).

119. J. P. Yang, and L. Huang, Gene Therap., 3, 542-548 (1996).

120. R. Niven, R. Pearlman, T. Wedeking, J. Mackeigan, P. Noker, L. Simpson-Herren, and J. G. Smith, J. Pharm. Sci., 87, 1292-1299 (1998).

121. R. M. Bartholomew, A. F. Esser, and H. J. Muller-Eberhard, J. Exp. Med., 147, 844-853 (1978).

122. F. Bushman, Science, 267, 1443-1444 (1995).

123. S. V. Joang, E. B. Stephens, and O. Narayan in B. N. Fields, D. M. Knipe and P. M. Howley, Eds., Virology, Lippincott-Raven, Philadelphia, PA, 1996, 1997-1996.

124. U. Blomer, L. Naldini, T. Kafri, D. Trono, I. M. Verma, and F. H. Gage, J. Virol., 71, 66416649 (1997).

125. J. C. Cusack Jr. and K. K. Tanabe, Surg. Oncol. Clin. North Am., 7, 421-469 (1998).

126. P. Seth, Gene Therapy for the Treatment of Cancer, Vol. 44-77, Cambridge University Press, Cambridge, 1998.

127. V. N. Krasnykh, G. V. Mikheeva, J. T. Douglas, and D. T. Curiel, J. Virol., 70, 6839-6846 (1996).

128. J. A. Roth and R. J. Cristiano, J. Natl. Cancer Inst., 89, 21-39 (1997).

129. A. Iida, S. T. Chen, T. Friedmann, and J. K. Yee, J. Virol., 70, 6054-6059 (1996).

130. E. W. Gerner, E. M. Hersh, M. Pennington, T. C. Tsang, D. Harris, F. Vasanwala, and J. Brailey, Int. J. Hyperthermia, 16, 171-181 (2000).

131. T. Clackson, Curr. Opin. Chem. Biol., 1, 210218 (1997).

132. P. L. Felgner and G. M. Ringold, Nature, 337, 387-388 (1989).

133. N. S. Templeton, D. D. Lasic, P. M. Frederik, H. H. Strey, D. D. Roberts, and G. N. Pavlakis, Nature Biotechnol., 15, 647-652 (1997).

134. A. Kikuchi, Y. Aoki, S. Sugaya, T. Serikawa, K. Takakuwa, K. Tanaka, N. Suzuki, and H.
Kikuchi, Hum. Gene Therap., 10, 947-955 (1999).

135. C. Meunier-Durmort, R. Picart, T. Ragot, M. Perricaudet, B. Hainque, and C. Forest, Biochim. Biophys. Acta, 1330, 8-16 (1997).

136. T. Tuting, W. J. Storkus, and M. T. Lotze, J. Mol. Med., 75, 478-491 (1997).

137. M. Lindauer, T. Stanislawski, A. Haussler, E. Antunes, A. Cellary, C. Huber, and M. Theobald, J. Mol. Med., 76, 32-47 (1998).

138. J. Banchereau, F. Briere, C. Caux, J. Davoust, S. Lebecque, Y. J. Liu, B. Pulendran, and K. Palucka, Annu. Rev. Immunol., 18, 767-811 (2000).

139. B. M. Davis, O. N. Koc, K. Lee, and S. L. Gerson, Curr. Opin. Oncol., 8, 499-508 (1996).

140. Z. Ram, Isr. Med. Assoc. J., 1, 188-193 (1999).

141. D. Klatzmann, P. Cherin, G. Bensimon, O. Boyer, A. Coutellier, F. Charlotte, C. Boccaccio, J. L. Salzmann, and S. Herson, Hum. Gene Therap., 9, 2585-2594 (1998).

142. D. H. Sterman, K. Molnar-Kimber, T. Iyengar, M. Chang, M. Lanuti, K. M. Amin, B. K. Pierce, E. Kang, J. Treat, A. Recio, L. Litzky, J. M. Wilson, L. R. Kaiser, and S. M. Albelda, Cancer Gene Therap., 7, 1511-1518 (2000).

143. R. G. Crystal, E. Hirschowitz, M. Lieberman, J. Daly, E. Kazam, C. Henschke, D. Yankelevitz, N. Kemeny, R. Silverstein, A. Ohwada, T. Russi, A. Mastrangeli, A. Sanders, J. Cooke, and B. G. Harvey, Hum. Gene Therap., 8, 9851001 (1997).

144. C. Beltinger, W. Uckert, and K. M. Debatin, J. Mol. Med., 78, 598-612 (2001).

145. J. Nemunaitis, S. G. Swisher, T. Timmons, D. Connors, M. Mack, L. Doerksen, D. Weill, J. Wait, D. D. Lawrence, B. L. Kemp, F. Fossella, B. S. Glisson, W. K. Hong, F. R. Khuri, J. M. Kurie, J. J. Lee, J. S. Lee, D. M. Nguyen, J. C. Nesbitt, R. Perez-Soler, K. M. Pisters, J. B. Putnam, W. R. Richli, D. M. Shin, and G. L. Walsh, J. Clin. Oncol., 18, 609-622 (2000).

146. T. Waku, T. Fujiwara, J. Shao, T. Itoshima, T. Murakami, M. Kataoka, S. Gomi, J. A. Roth, and N. Tanaka, J. Immunol., 165, 5884-5890 (2000).

147. D. L. Tait, P. S. Obermiller, A. R. Hatmaker, S. Redlin-Frazier, and J. T. Holt, Clin. Cancer Res., 5, 1708-1714 (1999).

148. K. R. Birikh, P. A. Heaton, and F. Eckstein, Eur. J. Biochem., 245, 1-16 (1997).

149. Y. A. Zhang, J. Nemunaitis, and A. W. Tong, Mol. Biotechnol., 15, 39-49 (2000). 
150. H. J. Andreyev, P. J. Ross, D. Cunningham, and P. A. Clarke, Gut, 48, 230-237 (2001).

151. W. A. Marasco, Gene Therap., 4, 11-15 (1997).

152. F. Griscelli, H. Li, A. Bennaceur-Griscelli, J. Soria, P. Opolon, C. Soria, M. Perricaudet, P. Yeh, and H. Lu, Proc. Natl. Acad. Sci. USA, 95, 6367-6372 (1998).

153. P. Blezinger, J. Wang, M. Gondo, A. Quezada, D. Mehrens, M. French, A. Singhal, S. Sullivan, A. Rolland, R. Ralston, and W. Min, Nature Biotechnol., 17, 343-348 (1999).

154. D. Ma, R. D. Gerard, X. Y. Li, H. Alizadeh, and J. Y. Niederkorn, Blood, 90, 2738-2746 (1997).
155. H. L. Kong, D. Hecht, W. Song, I. Kovesdi, N. R. Hackett, A. Yayon, and R. G. Crystal, Hum. Gene Therap., 9, 823-833 (1998).

156. M. Watanabe, Y. Takahashi, T. Ohta, M. Mai, T. Sasaki, and M. Seiki, Cancer, 77, 1676-1680 (1996).

157. D. F. Alonso, G. Skilton, M. S. De Lorenzo, A. M. Scursoni, H. Yoshiji, and D. E. Gomez, Oncol. Rep., 5, 1083-1087 (1998).

158. H. Li, F. Lindenmeyer, C. Grenet, P. Opolon, S. Menashi, C. Soria, P. Yeh, M. Perricaudet, and H. Lu, Hum. Gene Therap., 12, 515-526 (2001). 